\title{
Die Architektur der Metatarsalien des Menschen ${ }^{11}$.
}

\author{
Von \\ Generaloberarzt a. D. Dr. A. Kirchner, \\ Göttingen.
}

Mit 18 Figuren im Text.

Eingegangen am 19. Juli 1907.

Die Architektur der Metatarsalien des Menschen war bis vor kurzem noch wenig erforscht, obwohl das Metatarsale I der erste Knochen war, bei welchem Culman vor 40 Jahren, als H. Meyer ${ }^{2}$ ) seinen ersten Vortrag iber Knochenarchitekturen vor der Züricherischen naturforschenden Gesellschaft hielt, darauf hinwies, daß die auf dem Sagittalschnitt sich kennzeichnenden, im Köpfchen sich kreuzenden Längszüge Druck- und Zugkurven darstellen.

Bourgery ${ }^{3}$, dessen ausgezeichnete Abbildungen (von $\mathrm{J}_{\mathrm{ACOB}}$ ) von Schnitten der großen Röhrenknochen und der größeren Tarsalien vielfach die charakteristische Struktur richtig wiedergeben, so besonders beim Calcaneus, sind an den Metatarsalien keine durch ihren Verlauf und ihre Anordnung besonders bemerkenswerten Züge aufgefallen. Allerdings bildet BourgerY nur Sagittalschnitte der Metatarsalien $a b$.

RasunowskY ${ }^{4}$ ) gibt in seinen Untersuchungen über den Bälkchenverlauf in den Knochen des Fußes, welche er namentlich mit Rïck-

1) Diese detaillierte Schilderung und Beurteilung der typischen Struktur der Metatarsalien soll als Unterlage für die nachfolgende Behandlung der Plattund Klumpfußarchitektur dienen.

Roux.

2) H. Mryer, Die Architektur der Spongiosa. Arch. f. Anat. u. Phys. 1867.

3) J. M. Bourgery, Traité complet de l'anatomie de l'homme. T. I. Ostéologie. Paris 1832.

4) W. Rasumowskx, Beitrag zur Architektonik des Fußskeletes. Internat. Monatsschr. f. Anat. u. Phys. 1889. S. 197. 
sicht auf die Feststellung einer Gewölbekonstruktion in diesen Knochen vornabm, die Abbildung eines Frontalschnittes dureh die Basen der Metatarsalien mit genauerer Zeichnung des Bälkchenverlanfes. Nach Rasumowsky bilden hier die Knochenfasern, wie in den Keilbeinen und dem Cnboideum, einen querliegenden Gewölbebogen, welcher der Fubrückenfläcbe parallel die Bạsen sämtlicher Metatarsalknochen durchsetzt. In dem lateralen Teile dieses Bogens, und namentlich innerhalb der Basen des 4 . und 5. Metatarsalknochens, spalten sich einige Fasern von der allgemeinen, der Fußrückenflïche parallelen Richtung ab und steigen bogenförmig zur Fulssohle hinab. "Außer dem eben beschriebenen Systeme von Fasern bemerken wir hier noch Vertikalfasern, welche zı denen des ersteren Systems senkrecht stehen und gegen die Fußsohle hin einen bogenförmigen Verlauf annehmen. In dem 4. und 5. Metatarsalknochen ist die rechtwinkelige Kreuzung der oberen Bogen mit den unteren scharf ansgesprochen. " Die Vertikalfasern betrachtet und beurteilt Rasumowskx nur in Beziehang zu den plantarwärts von den Intermetatarsalgelenken gelegenen Zwischenknochenbändern und sieht sie als Zugbalken an, die eine Fortsetzung dieser Bänder darstellen und zu den Druckbalken eine senkrechte Lage annehmen.

Weitere Untersuchungen und Darstellungen der Arehitektur der Metatarsalien sind mir nicht bekannt.

Die Architektur der Metatarsalien verdient eingehend studiert zu werden, da wir in ibr einen getrenen Ausdruck der verschiedenartigen Beanspruchung des Fußes finden.

Besonders interessant ist die Architektur der einzelnen Metatarsalien, wie sie sich unter dem Einfluß der wechselnden Belastung beim Gehakt ausgebildet hat. Die unter diesem Einfluß beim Metatarsale V entstandene Architektur, deren Elemente sich bis zum Mctatarsale II wiederfinden, habe ich in einer friineren Arbeit ${ }^{1}$ ) beschrieben und ebenda erörtert, wie wir aus dieser Architektur mit zwingender Notwendigkeit folgern mïssen, daß die Fußsohle beim Gehen zuerst auf ihren fibularen Rand aufgesetzt wird, also in Supination steht, dann auf dem M. V und den sich ansehließenden Metatarsalien bis zum M. II in Pronation dreht. Ebenda habe ich hervorgeboben, daß die Folge dieser regelmäßigen verhältnismäßig starken Beanspruchung des M. V beim Gehen die Entwicklung einer starken

1) A. Krrchner, Wie wird beim Gehen die Fußsohle aufgesetzt? Arch. f. Anat. u. Phys., phys. Abt. 1906. 
Compacta, namentlich plantarwärts, ist, einer Compacta, die an Stärke diejenige sämtlicher andern Metatarsalien iubertrifft.

In vollständig andrer Weise als die Metatarsalia V-II wird das Metatarsale I beim Gehakt beansprucht. Auf diesem Metatarsale erfolgt die Abwicklung des Fußes, es hat hierbei die ganze Körperlast zu tragen und weist, abgesehen von einer beträchtlichen Volumsvermehrung im Vergleich zu den übrigen Metatarsalien, eine für jene Funktion besonders geeignete Struktur auf. Nur das M. II wird bei der Abwicklung des Fußes als Seitenstutze des M. I in geringem Grade mitbeansprueht, und diese Funktion wird in der Architektur des M. II zum Ausdruck kommen. Dagegen wird das M. III bei der Abwicklung des Fußes in keiner Weise beansprucht, anch nicht im Beginn der Abwicklungsperiode. H. v. Meyers ${ }^{1}$ ) Annabme, die er noch im Jahre 1886 vertrat, daß beim Erheben des Fußes im Beginn der Abwicklung »während der Annahme der Streckstellung" die Unterstitzung stets durch die dritte Zehe gegeben sei, ist nicht richtig. Nach den Untersuchungen 0 . Fischers ${ }^{2}$ ) hat beim Gehen der Gesamtschwerpunkt in der Periode des Aufstehens des Fußes mit ganzer Sohle seine größte Entfernnng von der durch die Gangrichtung gehenden mittleren Vertikalebene, aber auch im Augenblick der größten Entfernung fällt die Schwerlinie sehr nahe dem tibialen Fußrande in den FuB hinein. Mit Beginn der Abwicklungsperiode nähert sich der Gesamtschwerpunkt rasch der durch die Gangrichtung gehenden mittleren Vertikalebene, mit Beginn dieser Periode muß also das Metatarsale I, abgesehen von der geringen Beteiligung des Metatarsale II als Hilfsstiitze, ansschließlich belastet werden. Ist diese physiologische Feststellung zutreffend, so werden wir auch im Metatarsale III keine Struktur finden, die es fuir die Funktion als Stuitze bei der Abwicklung des Fußes geeignet macht.

Außer beim Aufsetzen der Fußsohle beim Gehen werden die Metatarsalia IV-II beim Stehen beansprucht. Nach BEELY ${ }^{3}$ stiitzt sich beim gewöhnlichen Stehen auf beiden Füßen der Körper außer auf die Tuberositas calcanei auf die Köpfehen der Metatarsalia II

1) H. v. Merer, Statik und Mechanik des menschlichen Fußes. Jena 1886.

2) O. Fischer, Der Gang des Menschen. II. Teil: Die Bewegungen des Gesamtschwerpunktes und die äußeren Kräfte, u. IV. Teil: Über die Bewegung des Fußes und die auf denselben einwirkenden Kräfte. Abh. d. math.-phys. Kl. d. K. Sächs. Ges. d. Wiss. Bd. 25, 1 u. 26, 7. Leipzig 1899 u. 1901.

3) F. Bexly, Zur Mechanik des Stehens. Über die Bedeutung des Fußgewölbes beim Stehen. Arch. f. klin. Chir. Bd 27 (1882). 
und III, beim Stehen auf einem Fuß außerdem auf die Tuberositas metatars. V. Beim Stehen auf den Zehen werden auch die Köpfehen der fibularen Metatarsalien belastet, besonders stark beim niederen Zehenstande ${ }^{1}$ ). Hin und wieder vorïbergehend kommt eine derartige Beanspruchung bei allen Menschen vor, häufiges oder gar vorwiegendes Stehen auf den Zehen (Hocken) ist verhältnismäßig selten. Wird das Metatarsale IV und V in der Tat in dieser Weise stark beansprucht, so wird das auch die Arehitektur beeinflussen.

Es würde das Studium der Architektur der Metatarsalien sehr fördern, wenn wir bei jedem Präparat wüßten, in welcher Weise die Knochen vorwiegend beansprucht worden sind. Leider besitzen wir diese Kenntnis bei den anatomischen Präparaten in der Regel nicht.

Ich habe schon für das Metatarsale I darauf hingewiesen, daß mit der erhöhten Beanspruchung eine Volumsvermehrung verbunden ist. Diese kann also als Folge jener angesehen werden. Es ist nicht von der Hand zu weisen, daß auch bei den tubrigen Metatarsalien die Art und der Grad der Beanspruchung von Einfluß anf den Umfang, »die Stärke " der einzelnen sein kann, und daß, da jedes dieser Metatarsalien bei jeder Beanspruchungsart individuell verschieden stark beansprucht werden kann, das gegenseitige Stärkeverhältnis ein verschiedenes sein kann. In dieser Minsicht sind die Feststellungea von Interesse, welche Pficzner 2) iber dieses Verhältnis gemacht hat. Er sagt, daß das Metatarsale II fast immer stärker als III, IV häufig stärker als III, und V sehr häufig stärker als IV sei. Als abweichendstes Extrem von der urspruinglichsten Reihenfolge beim Säugetier: III, IV, II, V, I bezeichnet PfrTzans beim Menschen die Reihenfolge I, V, II, IV, III oder gar I, V, IV, II, III. Letztere möchte Pficzner als diejenige hinstellen, auf die der derzeitige Entwicklungsgang hinzuarbeiten scheint. Inwieweit diese Annahme berechtigt ist, wird die weitere Untersuchung ergeben.

Für das Studium der Architektur der Metatarsalien ist es von großer Wichtigkeit, geeignete Präparate zu haben. Am besten eignen sich Präparate von jüngeren Individuen mit reichlich erhaltener Spongiosa. Fig. 1 gibt ein derartiges Präparat, vom fibularen zum tibialen Fußrande durchschnitten, links plantare, rechts dorsale Hälfte,

1) P. Grützner, Über den Mechanismus des Zehenstandes. Arch. f. d. ges. Physiol. Bd. 73 (1898).

2) W. Pfitzner, Ein Fall von beiderseitiger Doppelbildung der 5. Zehe. Nebst Bemerkungen über die angeblichen Rïckbildungserscheinungen an der skleinen Zehe« des Menschen. Morpholog. Arb. Bd. 5. H. 2. 1896. 


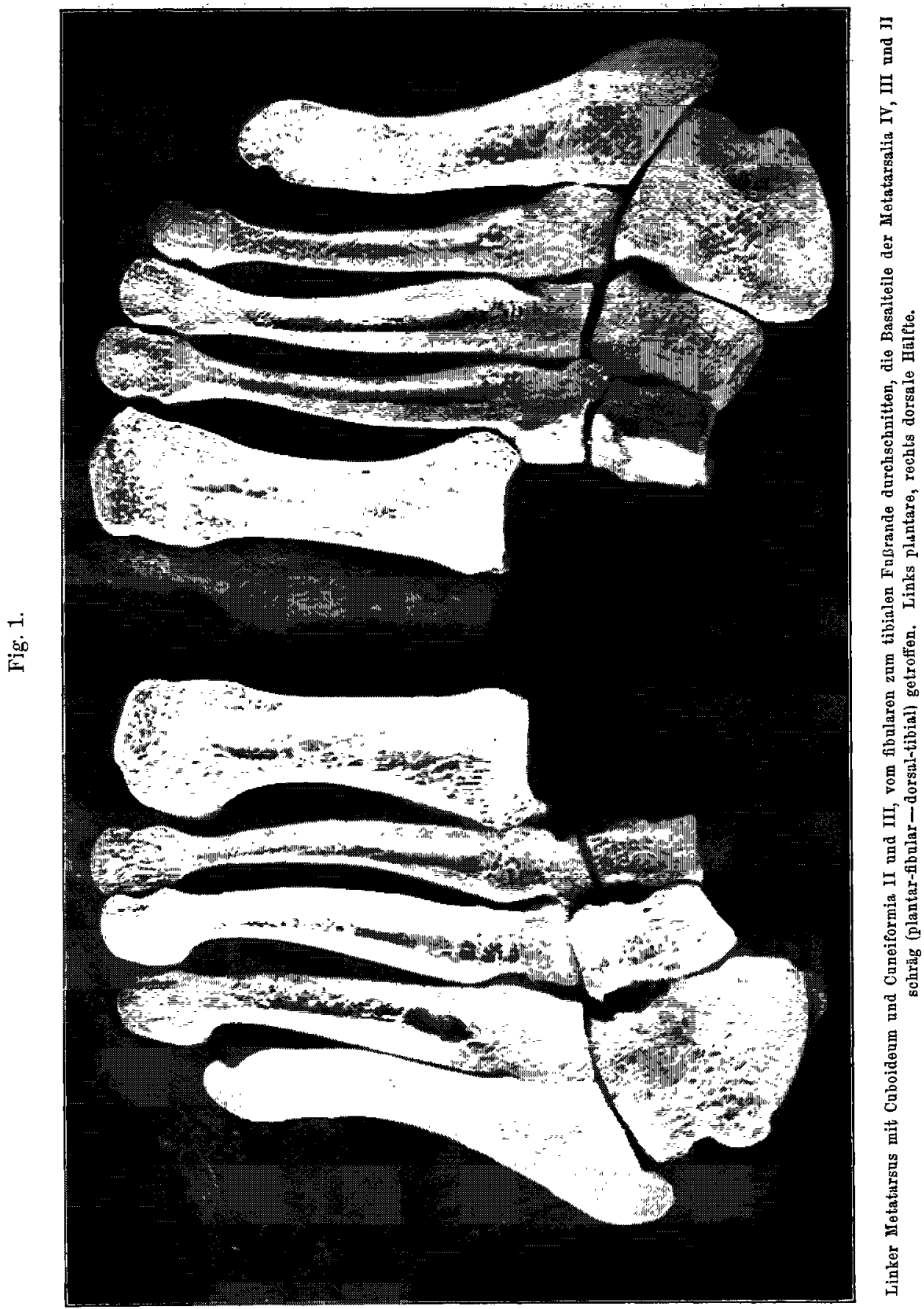


wieder. Dieses Präparat läßt das gegenseitige Mengeverbältnis der. Spongiosa und das Dickenverhältnis der Compacta der einzelnen Metatarsalien gut erkennen. Wir sehen die sehr reichliche Entwicklung der Spongiosa in den Metatarsalia I und V und dabei den erheblichen Unterschied in der Stärke der Compacta zwischen I und $\mathrm{V}$, ferner daß $\mathrm{V}$ die drei mittleren nicht nur durch seine sehr reichliche und dichte Spongiosa, sondern auch durch die Stärke seiner Compacta übertrifft. Gleich hervorheben möchte ich auch die in diesem Präparat sich besonders gut kennzeichnende Lage der Markhöhle. Dieselbe liegt in den M. V-II in der proximalen, im M. I in der distalen Schafthälfte.

Bei der nachfolgenden Beschreibung der Architektur der einzelnen Metatarsalien werde ich mit dem M. $V$ beginnen und die anschließenden bis zum M. I folgen lassen, in der Reihenfolge, wie sie beim Gehen bei dem Aufsetzen der FuBsolule den Boden beriihren. Es ist diese Reihenfolge iu der Beschreibung durchans erforderlich, da Elemente der Struktur des M. V, welche durch seine besonders starke Beanspruchung beim Aufsetzen der Fußsoble besonders charakteristisch ausgebildet ist, in den M. IV, III und II sich wiederfinden und ohne Kenntuis der Struktur des M. V nicht verständlich sind. Das ausschließlich für die Abricklung beanspruchte M. I bildet mit seiner Sonderstruktur den Schluß.

\section{Metatarsale V.}

Es empfiehlt sich zunächst, die Struktur des Knochenabschnitts proximal der Markhöhle zu erörtern, welchem die Tuberositas angehört, mit der beim Aufsetzen der ganzen Fußsolle beim Gehen der fibulare FuBrand nïchst dem Calcaneus zuerst den Boden beriilurt. Es ist dies nur ein kurzer Knochenabschnitt, durchschnittlich das proximale Viertel der Knochenlänge, aber entsprechend seiner Dicke und Breite der bemerkenswerteste, während umgekehrt beim M. I der distale Knochenabschnitt, welcher bei diesem sich auf den Boden stitzt, sich durch seine Struktur auszeichnet.

Der Funktion entsprechend hat die Architcktor der proximalen') Spongiosa des M. V große Ähnlichkeit mit der des Calcaneus, die Tuberositas $\mathrm{m}$. $\mathrm{V}$ ist ein Tuber calcanei im Kleinen. Ebenso wie beim Calcaneus stellt sich die charakteristische

$1)=$ proximal der Markhöhle, distalen Spongiosa = distal der Markhöhle. 
Struktur der proximalen Spongiosa des M. V auf dem Sagittalschnitt ) dar. Dieselbe ist schon in Fig. 1 deutlich zu erkennen, noch deutlicher auf dem Röntgenbild Fig. 2 der in Fig. 1 dargestellten beiden Hälften des M. V. Entsprechend dem Drucktrajectoriensystem, welches aus dem Tuber calcanei heraus leicht dorsalwïrts geschwungen

Fig. 2.

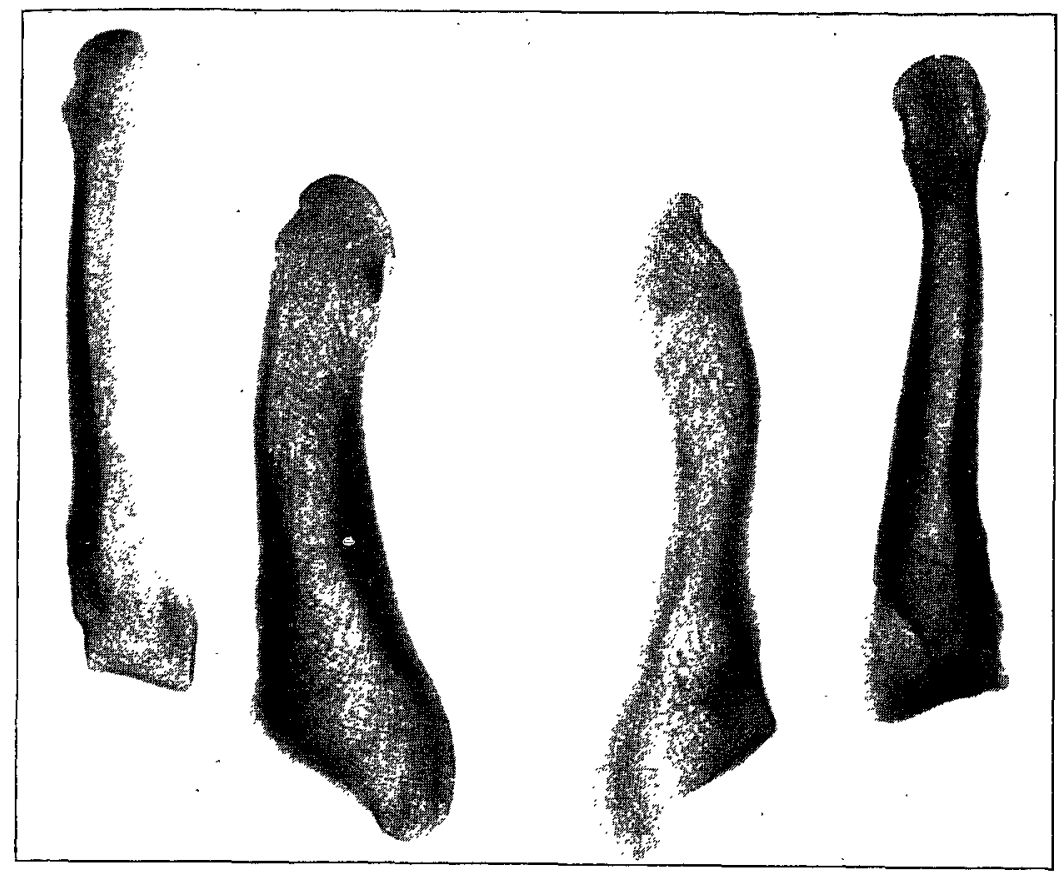

Róntgenbilder der beiden Hälften eines linken sagittal (in Supinationsstellung) durchschnittenen Ietatarsale $\mathrm{V}$ und IV, links laterale, rechts mediale Hälften.

gegen die Gelenkfläche mit dem Talus zieht und den Druck auf diesen iiberträgt, haben wir in der proximalen Spongiosa des M. V ein Tra-

1) Das M. V in der Stellung gedacht, wie es beim Gehen auf den Fußboden anftrifft, bei welcher die Fußriickenflïche annähernd in der Sagittalebene steht. Der' Schnitt verläuft also etwa von der Mitte der Fläche, auf welcher sich die Gelenkflïche des M. V mit dem M. IV befindet, nach dem gegenüberliegenden, in der angegebenen Stellung plantaren Rande. Der Einheitlichkeit der Darstellung wegen bezeichne ich die ganze der Gelenkfläche mit dem M. IV entsprechende Fläche des M. V als dorsale, wie den gegenüberliegenden Rand als plantaren. Für die breiten Flächen des M. V bleibt dann nur die Bezeichnung: laterale und mediale (fibulare und tibiale) zu wählen. Diese Seitenbezeichnung entspricht der bei HenLe, Handb. d. Knochenlehre. 1871. S. 308. 
jectoriensystem, welches aus der Tuberositas herans, in seinen Zuigen rechtwinkelig zum plantaręn Rande stehend, leicht geschwungen, nách distal konkar, gegen die Gelenkfläche mit dem M. IV zieht und auf diese den Drack überträgt. Gekrenzt wird dieses System, besonders in seiner plantaren Hälfte, wie jenes des Calcaneus in seiner hinteren und plantaren Hälfte, von einem rechtwinkelig stehenden, vorwiegend in der Längsrichtung des $M . V$ verlaufenden, dessen Züge von dem proximalen Ende der Tuberositas und den Gelenkflächen her distalwärts auf das proximale Ende der plantaren Schaftcompacta zu konvergieren. Wie beim Calcaneus können diese Züge zum Teil als Fortsetzung einer Sehne angesehen werden, wie dort der Achillessehne, so hier der Sehne des M. peroneus brevis und, soweit sie

Fig. 3.
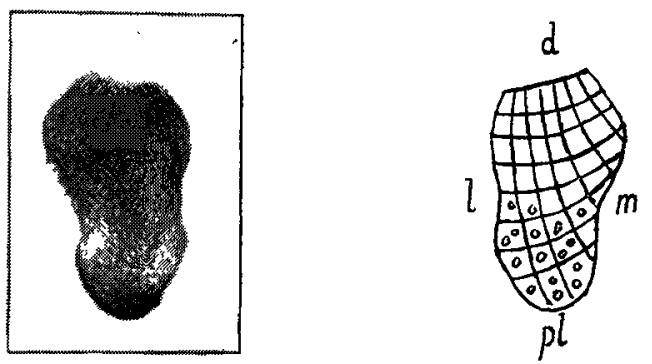

Röntgenbild der ersten proximalen, $0,5 \mathrm{~cm}$ dicken Scheibe eines durch Frontalschnitte zerlegten linken Metatarsale $V$ and schematische Darstellung der Zūge auf der distalen Seite dieser Scheibe, dem ersten Schnitt. $d$ dorsal (Durchschnitt der Gelenkfláche mit dem M. IV), $p l$ plantar, $l$ lateral, $m$ medial. Bei dem Röntgenbilde ist links medial, rechts lateral.

vorhanden ist, der Tuberositas $\mathrm{m}$. V-Portion des M. abductor dig. V. Ebenso wie beim Calcaneus der nach der Talusgelenkfläche zu gelegene Teil der Spongiosa hat in der proximalen Spongiosa des M. V der nach der Gelenkfläche mit dem M. IV zu gelegene Abschnitt häufig ausgesprochen die tubulöse Form, während sich im Tuberositasabsehnitt melrr Bälkchen und Plättchen finden.

Sehr ausgesprochen findet man diese von plantar nach dorsal ziehenden Trajectorien auch auf dem Frontalschnitt ${ }^{1}$ ) (Fig. 3). Auf diesem verlaufen sie leicht nach lateral geschwungen (lateral-konvex), kommen aber nicht nur aus der Tuberositas, sondern auch von der

i) Genau genommen verläuft der Schnitt parallel mit der Gelenkfläche.des M. V mit dem Cuboideum. Da das Röntgenbild Fig. 3 namentlich die Züge des sekundären Systems nicht deutlich genug wiedergibt, habe ich eine schematische Darstellung der Ziige beigefiugt. 
medialen Knochenfläche her, gegen die Gelenkfläche mit dem M. IV konvergierend, zu welcher sie rechtwinkelig stehen. Gekreuzt wird dieses Drucksystem von einem zu ihm rechtwinkelig stehenden System, dessen Züge nahe der Gelenkfläche mit dem M. IV zu dieser annähernd parallel, doch deutlich nach ihr konkav verlaufen, weiter plantarwärts in der Richtung von dorsal-medial nach plantar-lateral. In der Tuberositas findet sich auf dem Frontalschnitt dichte Rundmaschenspongiosa, in welche hinein sich die Züge des Drucksystems verlieren.

Die vom proximalen Ende der plantaren Schaftcompacta proximal verlaufenden Züge sind am dichtesten in der Tuberositas, spärlicher ziehen sie auf die Gelenkflächen zu und verlieren sich anf diesem Zuge großenteils in dem Drucksystem (s. Fig. 2). Sie treten aber gewissermaßen wieder zutage in dem sehr dichten feinen Stäbchensystem, welches unmittelbar auf der tarsalen Gelenkfläche senkrecht steht und oft ein sehr zierliches Aussehen hat. Anch dieses feine System ist öfters ausgesprochen tubulös.

Im Zusammenhange mit den nach proximal von der plantaren Compacta verlanfenden Ziugen stehen Spongiosazüge, die von ihr, ebenfalls geschwungen, nach der Markhöhle zu konkav, nach distal divergierend auf die dorsale Knochenwand und in das Köpfchen hinein verlaufen. Sie sind als die Fortsetzung der ersteren anzusehen und bilden mit ihnen zusammen ein Trajectoriensystem. Betrachten wir diese von der plantaren Compacta nach proximal und distal abgehenden Züge auf dem Röntgenbild (Fig. 2) und vergleichen die. beiderseits von der Markhöhle nach der dorsalen Knochenwand und die weiterhin auf die Knochenenden zu verlaufenden Züge miteinander, so ist eine gewisse Symmetrie unverkennbar. Und diese betrifft nicht nur die Spongiosazüge, sondern auch die Compacta, die, im Bereich der Markhöhle annähernd gleich dick, sich von da aus nach den Knochenenden hin fast gleichmäßig verjüngt. Vergleichen wir mit diesen symmetrisch verlaufenden Spongiosazügen und der Compacta, von der sie ausgehen, das Schema, welches Roux ${ }^{1}$ ) für eine Biegungskonstruktion gegeben hat (Fig. 4), so uiberzengen wir uns, daß wir in diesen Zuigen zusammen mit ibrer Compacta ebenfalls das eine Trajectoriensystem einer Biegungskonstruktion

1) W. Rovx, Gesammelte Abhandlungen iiber Entwicklungsmechanik der Organismen. Leipzig 189ẽ. Bd. I. S. 684. 
vor uns haben. Dio der Markhöhle zunächst gelegenen stark gebogen nach der dorsalen Knochenwand verlaufenden Spongiosazuige entsprechen dem der Symmetriecbene zunächst auf die konvexe Seite auftreffenden Trajectorium $d$ bei loox, die weiter entfernt ron der Markhöhle auf die dorsale Knochenwand und die nach dem Köpfehen und der Tuberositas zu verlaufenden gestreckteren Spongiosaziige den Trajectorien $c$ und $b$ bei Roux. Naturgemäß bedingt der beim M. V weit flachere Bogen, der außerdem nicht genau einem Kreisbogen entspricht, dessen Rundung vielmelır in der Gegend der Markhöhle abgeflacht ist, immerhin einen wesentlich untersehiedlichen Verlauf der der Symmetrieebene zunächst gelegenen Trajectoricn beim

Fig. 4.

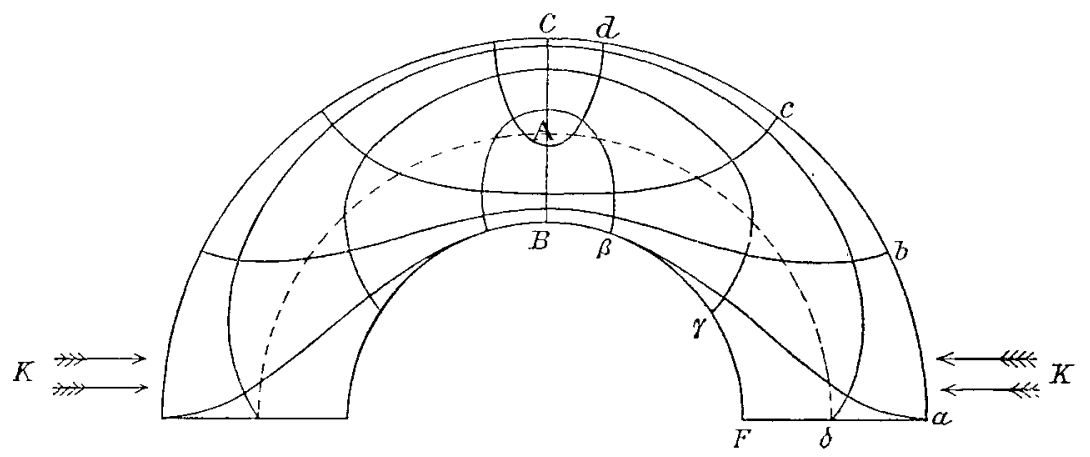

Sohema einer Biegungskonstrulition nach Rocx. $B C^{t}$ Symmetrieebenc, $h, h^{-}$Kräfte.

M. V und im Schema. Die Enden dieser Trajectorien bleiben beim M. V, da wo sie auf die konvexe Seite auftreffen, weiter voneinander entfernt als im Schema. Sie fassen beim M. V dic Markhöhle zwischen sich. Entsprechend den Trajectorien in Rouxs Schema drängen sich die Spongiosazüge nach der Symmetrieebene lin gegen die Oberflïche zusammen und bilden die sehr dichte Compacta, die, im Bereich der Markhöhle gleich dick, sich nach beiden Knochenenden hin infolge des symmetrischen Abgangs der Spongiosazüge annähernd gleichmüßig verjüngt. Das centralste, am stärksten gekrümmte Trajectorium beim M. V nimmt nicht an der Bildung der Compacta teil, sondern bildet, wie dies auch aus dem Röntgenbild ersichtlich, einen fortlaufenden Spongiosazug, der, an der konvexen (dorsalen) Knochenseite beginnend, hart central der plantaren Compacta vorbei wieder zur konvexen (dorsalen) Knochenseite hinläuft. Mit seinem mittleren 
Teil, einer der plantaren Compacta in ibrer dicksten Stelle anliegenden Platte, bildet er die plantare Markhöhlenwand ${ }^{1}$.

Wie das Röntgenbild Fig. 2 zeigt, sind die von der plantaren Compacta ausgehenden Spongiosazuige distal und proximal an verschiedenen Stellen verschieden stark ausgesprochen. Die der Markhöhle zunächst gelegenen stark gekrümmten sind distal stärker als proximal. Thre Schwäche im proximalen Abschnitt rübrt wohl daher, daß hier das Drucktrajectoriensystem, dessen Züge ron plantar nach dorsal verlaufen, so anßerordentlich stark, mit so sehr dichten Zügen entwickelt ist. Umgekehrt sind die von der Markhöhle entfernteren gestreckter verlanfenden Züge proximal besonders stark entwickelt und weit zahlreicher als distal, wohl infolge der Notwendigkeit stärkerer, zum Drucksystem rechtwinkelig verlanfender Zuige nahe der Oberfläche der Tuberositas, um jenes gegen den Druck beim Aufsetzen des Fußes widerstandsfäliger zu machen.

Verfolgen wir die von der plantaren Compacta nach den Krochenenden zu verlaufenden Spongiosaziige bis an den plantaren Knochenrand heran, so sehen wir, daß dieser Rand den ihm zunächst gelegenen Spongiosazügen annähernd gleich gerichtet ist und selbst gewissermaßen das letzte Trajectorinm in dem System bildet ${ }^{2}$ ).

Diese von der plantaren Compacta ausgehenden Spongiosaziuge stellen zusammen mit der Compacta ein Zugtrajectoriensystem dar, nicht wie in Rouxs Schema die Trajectorien auf der konkaven Balkenseite ein Drucktrajectoriensystem. Dies ergibt sich aus der andersartigen Beanspruchung. Wie Rouxs Figur zeigt, werden bei seinem Balken die Enden durch die auf sie wirkenden Kräfte zusammengebogen, beim M. V infolge der Belastung bzw. des Gegendrucks des Bodens die Enden auseinander gebogen. Infolgedessen wird die plantare (konkave) Knochenseite auf Zug beansprucht. Für den Trajectorienverlauf macht dies keinen Unterschied; der Ort des stärksten Widerstandes ist hier die Markhöhlengegend, wo sich die Trajectorien nach der Oberfläche hin zusammendrängen.

Wie verhält sich nun zu diesem Zugtrajectoriensystem der Biegungskonstruktion das sekundäre, das Drucktrajectoriensystem auf der konvexen Knochenseite? Da lehrt ein Blick auf das Röntgenbild, daß die von der dorsalen Compacta nach proximal und

1) Dies ist dentlich auf Fig. 1 zu erkennen, auf welcher viele Züge des beschriebenen Trajectoriensystems, ebenso wie des zu ihm rechtwinkelig stehenden ziemlich genau zu verfolgen sind, namentlich mit Hilfe der Lupe.

2) Roux, a. a. 0. S. 690 . 
distal abgehenden Spongiosazüge nicht in gleicher Weise symmetrisch verlaufen wie die von der plantaren Compacta, und daß dies nicht so sein kann, ist die einfache Folge der durch die Funktion bedingten Gestalt des proximalen Endes des M. V. Dieses Ende dient der Übertragung des Druckes rom Boden auf das M. IV und muB sich, um diese in zweckmäßiger Weise zu ermöglichen, proximalwärts verbreitern. Die dorsale Knochenwand verläuft daher im proximalen Abschnitt des M. V nicht einmal annähernd parallel zu dem plantaren Rande, sondern divergiert von ihm stark, so daß das proximale Knochenende doppelt so breit ist wie der Knochen in der Markhöhlengegend, und trifft auf die tarsale Gelenkfläche unter einem Winkel anf. In diesem proximalen Knochenende ist, wie vorher beschrieben, ein sehr dichtes Drucktrajectoriensystem ausgebildet, dessen Züge wesentlich die Richtung von plantar nach dorsal haben, weniger von proximal nach distal. Dagegen verlaufen die von der dorsalen Compacta nach distal abgehenden Züge ausgesprochen in der Längsrichtung des Knochens in das Köpfchen hinein, wie namentlich das Röntgenbild Fig. 2 rechts zeigt. Der centralste dieser Züge stößt mit dem der Markhöhle zunächst gelegenen des proximalen Drucksystems unter annähernd demselben Winkel zusammen, wie die Gelenkfläche für das M. IV mit der tarsalen Gelenkfläche. Es ist dies auf dem Röntgenbild links zu erkennen. Die Stelle, wo diese Ziige zusammenstoßen, die also in der Höhe des proximalen Markhöhlenendes liegt (s. auch Fig. 1), ist der Ort der größten Stärke der dorsalen Compacta. Diese nimmt von hier aus langsam aber ständig bis zum Köpfchen hin ab, während sie nach proximal, wie das am Präparat dentlicher zu sehen ist, sich rasch verjüngt und aufhört, bevor sie die tarsale Gelenkfläche erreicht. Eine symmetrische $A b$ nahme der dorsalen Compacta von ihrer dicksten Stelle aus nach distal and proximal ist also nicht vorhanden und ebensowenig möglich, wie der symmetrische Abgang der Drucktrajectorien.

Während man so auf der dorsalen (konvexen) Knochenseite von einem einheitlichen, in sich symmetrischen sekundären (Druck-) Trajectoriensystem nicht sprechen kann, verlaufen doch die von der dorsalen Compacta, proximal nach dem plantaren Knochenrande und distal in das Köpfehen hinein ziehenden Spongiosazüge rechtwinkelig zu den Zugtrajectorien. Ansgezeichnet dentlich tritt dies auf dem Röntgenbilde in der Tuberositas hervor, wo die Züge des Drucksystems zum Teil bis an den plantaren Knocbenrand heran zu verfolgen sind und auf diesen rechtwinkelig anftreffen. Der plantare 
Knochenrand ist also an seinem proximalen Ende mit Bezug auf seine Beanspruchung auf Biegung durchaus funktionell gestaltet.

In der distalen Knochenhälfte treten die Beziehungen des Drucksystems zum Zugsystem auf dem Röntgenbilde weniger scharf hervor, sie sind indes nahe der Markhöhle immerhin deutlich. Da die dor. sale Knochenwand dem plantaren Rande hier annähernd parallel läuft, so hat das ganze distale Knochenende eine mit Bezug auf die Biegungsbeanspruchung annähernd funktionelle Gestalt. Es treffen daher die von plantar her kommenden Zugtrajectorien auf die Druckseite, also die dorsale Knochenwand, wenigstens nahe der Markhöhle annähernd rechtwinkelig auf. Sie werden in der Nähe der letzteren deutlich erkennbar (auch in Fig. 1) von den Drucktrajectorien rechtwinkelig gekreuzt. Letztere sind besonders auf dem Röntgenbilde rechts bis zu der plantaren Gelenkfläche des Köpfchens zu verfolgen und treffen auf diese rechtwinkelig auf. Sie entsprechen in ihrem Verlauf dem der Trajectorien $\gamma$ und $\delta$ in Rouxs Schema.

In der proximalen Knochenhälfte können die von der plantaren Compacta her kommenden Trajectorien auf die dorsale Knochenwand infolge ihres von dem plantaren Rande divergenten Verlaufs nicht rechtwinkelig auftreffen, dagegen ist der rechtwinkelige Verlauf dieser Trajectorien auf die proximale Rundung der Tuberositas und den nächst angrenzenden Abschnitt der tarsalen Gelenkfläche zu deutlich.

Die von der plantaren Compacta ansgehenden Spongiosazüge treten zwar anf dem Röntgenbilde besonders scharf hervor und bilden mit dieser Compacta zusammen bei Beanspruchung des ganzen Knochens auf Biegung beim Aufsetzen der Fußsohle auf den Boden das Haupt- (Zugtrajectorien-) System, während für diese Beanspruchung: sämtliche von der dorsalen Compacta ausgehenden Trajectorien das sekundäre System darstellen. Ich habe indes schon oben das Drucksystem in der proximalen Spongiosa des M. V in Parallele gesetzt zu dem Drucksystem im Calcaneus, und ebenso wie dieses stellt jenes bei der ausschlieBlichen ${ }^{1}$ Beanspruchnng des proximalen Knochenabschnitts des M. V auf Druck wie beim einbeinigen Stehen ein primäres und dann die von der plantaren Compacta ausgehenden Züge, welche jenes System rechtwinkelig kreuzen, das sekundäre System dar. Es kreuzen sich also in der proximalen Spongiosa zwe Trajectoriensysteme, welche bei wechselnderBeanspruchung

1) Nur im Gegensatz zu der vorher erwähnten Biegungsbeanspruchung gedacht, bei welcher gegen die Tuberositas $m$. $V$ auch Druck vom Boden her stattfindet. 
einmal als primäres, das andreMal als sekund ̈̈res fungieren. Das Drucksystem in der proximalen Spongiosa charakterisiert sich übrigens als primäres System noch besonders durch seine sehr dicht stehenden Züge und seine gleichmäßige Entwicklung in ganzer Ausdehnung des Knochenabschnitts proximal der Markhöhle.

Eine derartige, wenn auch nur annähernde, Symmetrie in dem Verlauf der Trajectorien des Zugsystems wie in dem Präparat der Fig. 1 und 2 findet sich für gewöhnlich nicht beim M. V. Stets liaßt sich allerdings eine beträchtliche gleichmäßige Dicke der plantaren Compacta im Bereich der Markhöhle feststellen, aber von hier ans erstreckt sich die Compacta in der Regel erheblich länger nach distal als nach proximal. Im übrigen entspricht der Verlauf der sowoll von der plantaren als von der dorsalen Compacta abgehenden Spongiosazüge stets dem eben geschilderten, so daß auf dem Sagittalschnitt eine Biegungskonstruktion wohl stets unverkennbar ist, wenn auch nicht mit der Regelmäßigkeit auf der Zugseite wie in jenem Präparat. Die dorsale Compacta ist in der Regel weniger dick als in diesem Präparat, hat im allgemeinen höchstens $2 / 3$ der Dicke der plantaren und erstreckt sich in dieser Stärke vom proximalen Markhöhlenende bis gegen die Mitte der Knochenlänge hin, sich dann langsam bis zum Köpfehen hin verjüngend. Die auffallende Dicke der dorsalen Compacta in der Gegend des proximalen Markhöhlenendes bei dem Präparat der Fig. 1 und 2, eine Dicke, welche der größten Dicke der plantaren Compacta gleich kommt, rïhrt wohl daher, daß dieses Präparat von einem stark gewölbten Fuß stammt, bei welchem der laterale Fußrand stärker als gewöhnlich belastet wird.

Der RegelmäBigkeit, mit welcher der Fuß beim Gehen immer in derselben Weise aufgesetzt und somit das M. V beim Niedersetzen des lateralen FuBrandes immer in derselben Ebene auf Biegung beansprucht wird, entspricht es, daß auf Frontalschnitten die Compacta im Schaft sich an zwei einander gegenüberliegenden Stellen in besonderer Stärke findet. Es sind das der plantare Rand und die dorsale $W$ and, letztere besonders nahe dem scharfen lateral-dorsalen Rande.

Ich habe zum Zwecke der Feststellung der Dicke der Compacta auf den verschiedenen Seiten des Schaftes ein $5,5 \mathrm{~cm}$ langes ${ }^{1)}$

1) Auf der dorsalen Seite gemessen, ebenso die folgenden Entfernungsangaben der Schnitte von der tarsalen Gelenkfläche. 
rechtes M. V durch Frontalschnitte ${ }^{1}$ in zehn annäliernd gleich dicke Scheiben zerlegt. Die Compacta erscheint, von proximal beginnend, in bemerkenswerter Stärke zuerst auf dem z weiten Schnitt in der dorsal-lateralen Ecke, $1 \mathrm{~cm}$ von der tarsalen Gelenkfläche entfernt. Die Compacta ist hier $1 \mathrm{~mm}$ dick. Es entspricht diese Stelle dem distalen Ende der Gelenkfläche für das M. IV. Auf der lateralen und medialen Seite und in der dorsal-medialen Ecke ist auf dem zweiten Schnitt die Compacta nur 0,1-0,3 mm dick. - Auf dem dritten Schnitt (Fig. 5a), der noch annähernd dreieckig wie der vorhergehende ist, $1,5 \mathrm{~cm}$ Entfernung, ist die Compacta in der dorsal-lateralen und plantaren Ecke annähernd gleich dick, $2 \mathrm{~mm}$, in der Mitte der lateralen Seite 0,6 , im oberen Drittel der medialen Seite $0,8 \mathrm{~mm}$

Fig. 5.
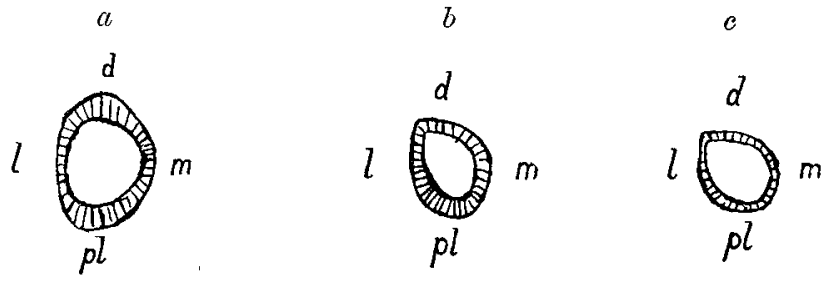

$a$ dorsal, $p l$ plantar, $l$ lateral, $m$ medial.

dick. In der dorsalen Wand verjüngt sich die Compacta allmiihlich von der dicken lateral-dorsalen Ecke nach der medial-dorsalen Ecke hin, um in der medialen Wand nach dem plantaren Rande hin wieder an Stärke zuzunehmen. - Auf dem vierten Schnitt mit fast rundem Lumen, Entfernung $2 \mathrm{~cm}$, ist die Compacta dorsal-lateral, wie auf dem vorigen Schnitt, $2 \mathrm{~mm}$, plantar dagegen $3 \mathrm{~mm}$, in der Mitte der lateralen und der medialen Wand $1 \mathrm{~mm}$ dick. - Weiter distal nimmt die Compacta an den bisherigen dicksten Stellen an Dicke ab, in der medialen Wand dagegen an Dicke zu. Auf dem fünften Schnitt (Fig. 5 b), der ctwa in die Mitte der Knochenlänge fällt, mit annähcrnd elliptischem Lumen, ist dic Compacta noch plantar am dicksten, $2 \mathrm{~mm}$, dorsal $1,5 \mathrm{~mm}$, medial 1,2 mm, lateral nahe der dorsal-lateralen Kante $1 \mathrm{~mm}$ dick. - Auf den nächsten Schnitten nähert sich der Querschnitt dem viereckigen, indem sich die laterale Wand stärker heraus-

1) Die Schnitte lanfen in der proximalen Knochenhälfte parallel zur tarsalen Gelenkflïche, erst in der distalen Knochenbälfte annähernd senkrecht zur dorsalen Fläche. 
wölbt und schließlich aus ihr sich eine laterale und plantare ${ }^{1}$ ) Wand bildet. Die Dicke der Compacta nimmt jetzt fast im ganzen Umfang des Querschnitts ab. Auf dem sechsten Schnitt, in $3,3 \mathrm{~cm}$ Entfernung, ist die Compacta noch immer plantar am dicksten, $1,5 \mathrm{~mm}$, nicht ganz so dick nahe der dorsal-medialen Ecke, im übrigen etwa $1 \mathrm{~mm}$ dick, wobei aber die laterale Wand nahe der dorsalen Kante deutlich diunner ist als die mediale. - Auf dem siebenten Schnitt (Fig. 5 c), 4 cm Entfernung, ist die Compacta in der plantaren Wand noch fast $1 \mathrm{~mm}$ dick. Annähernd ebenso dick ist die dorsale Wand, wesentlich dünner dagegen die laterale und mediale, die laterale am dünnsten: $0,3 \mathrm{~mm}$, die mediale $0,4 \mathrm{~mm}$ dick. - Auf dem achten Schnitt, 4,5 cm Entfernung, im Beginn des Köpfehens, ist nur in der Mitte der dorsalen (in Pronation: medialen) Wand die Compacta noch $0,3 \mathrm{~mm}$ dick, im übrigen hat sie sich bis zu der dünnen Umhüllnngsplatte der Spongiosa des Köpfchens verdïnnt.

Zusammenstellung der Maßeder Compactadicke des frontal durchschnittenen M. V auf deu Schnitten II-VII.

\begin{tabular}{c|c|c|c|c}
\hline Schnitt & dorsal & pluntar & medial & lateral \\
\hline II & 1,0 & - & - & - \\
III & 2,0 & 2,0 & 0,8 & 0,6 \\
IV & 2,0 & 3,0 & 1,0 & 1,0 \\
V & 1,5 & 2,0 & 1,2 & 1,0 \\
VI & 1,2 & 1,5 & 1,1 & 0,9 \\
VII & 1,0 & 1,0 & 0,4 & 0,3
\end{tabular}

Diese Dickenverteilung der Compacta beweist die Richtigkeit unsrer Annahme hinsichtlich der Art und Richtung der Beanspruchung. Am dicksten ist in ganzer Länge des Schaftes die Compacta plantar und dorsal infolge der verhältnismäßig starken Belastung in der Sagittalebene beim Aufsetzen der Fußsohle auf den lateralen Fußrand beim Gehen, plantar dicker als dorsal, da die plantare (konkave) Seite bei Biegung stärker beansprucht wird als die dorsale. Wesentlich geringer ist die Beanspruchung des M. V in der Pronationsstellung des Fußes, in welcher sich der Knochen wach dem medialen Fußrande bin gedreht hat, und die in der Supinationsstellung laterale Fläche mehr dorsalwärts, die bisherige mediale Fläche plantarwärts sieht. In der Pronationsstellung wird das M. $V$ in seiner

1) In Supinationsstellung gedacht; in Pronationsstellung dorsale und laterale Wand. 
Längsrichtung stärker nur beim Zehenstande beansprucht, aber, wie der Augensehein lehrt, wesentlich geringer als beim Gehen. Beim Zehenstande wird die plantare Wand stärker auf Biegung beansprucht als die dorsale, daher ist jene, wie aus der Zusammenstellung hervorgeht, - in dieser ist es die mediale - fast durchweg dicker als die dorsale (in der Zusammenstellung: laterale). Sollte einmal im Zehenstande die in diesem plantare und dorsale Wand ausnahmsweise (häufiges Hocken) besonders stark beansprucht werden, so werden diese Wände auch im Vergleich zu den andern verhältnismäßig dicker sein.

Bemerkenswert mit Bezug auf die Art und Richtung der vorzugsweisen Beanspruchung des M. V ist auch der Bau der Spongiosa, wie wir ihn auf dem Frontalschnitt im distalen Schaftende und im Köpfchen finden. Der Bau der Spongiosa ist hier in der Regel ausgesprochen tubulös, wir finden auf dem Frontalschnitt die rundlichen Quersehnitte der Tubuli, die meist nicht in der Lüngsrichtung des Knochens, sondern den vom Sagittalschnitt her bekannten Zügen entsprechend in verschiedener Richtung schräg verlaufen. Auf dem Sagittalschnitt sieht man gelegentlich im Centrum des distalen Schaftendes Kreuzungen der Tubulizüge sehr deutlich. Auf dem Frontalschnitt sind nun im distalen Schaftende die Tubuliquerschnitte in sagittalen $\left.{ }^{1}\right)$ Reihen geordnet, die durch Scheidewände getrennt sind, welche der lateralen und medialen Knochenwand parallel laufen und somit selbst annähernd sagittal stehen. Diese im distalen Schaftende noch sehr dünnen Scheidewände der Tubulireihen verdicken sich in ihrem Verlauf in das Köpfchen hinein zu stärkeren Platten. Diese Platten stehen im Köpfchen auch im ganzen in der Sagittalebene1), drehen sich aber nach dem distalen Ende des Köpfchens so, daß sie, namentlich medialwärts, etwas mehr in der Richtung plantar-medial-dorsal-lateral stehen und nach dorsal ein wenig konvergieren. Diese Anordnung der Tubuli und die Richtung ihrer Scheidewände im distalen Schaftende und im Köpfehen ist die Folge der Beanspruchung und ein weiterer Beweis, daß das M. V ganz vorwiegend in der Supinationsstellung in der von mir erörterten Weise beansprucht wird. Steht in der Snpinationsstellung, beim Aufsetzen der Fußsoble beim Gehen, die laterale Fläche des M. V tatsächlich annähernd in der Sagittalebene, so müssen die im distalen Schaftende und im Köpfchen befindlichen, die Tubuli-

1) Das M. V stets in Supinationstellung gedacht.

Archiv f. Entwicklungsmechanik. XXIV. 
reiluen trennenden Scheidewände, die zar Verstärkung des Widerstandes dienen, auch annähernd in der Sagittalebene stehen. Die Drehung der ursprïnglich sagittal stehenden Scheidewände nach dem distalen Ende des Köpfehens hin bringt die aus der Supinationsstellung in die Pronationsstellung erfolgende Drebung des M. V in der Struktur zum Ausdruck.

Die Platten sind im Köpfehen des M. V manchmal nur wenig ausgebildet und auf Sagittalschnitten nicht immer deatlich. Sehr ausgesprochen finden wir aber die Durchschnitte der Tubulischeidewände oft im Horizontalschnitt) (Fig. 6). Wie die Figur zeigt, blättern die diese Durchschnitte darstellenden Längsziuge im Köpfchen von den distalen Enden der Schaftcompacta ab.

Fig. 6 .

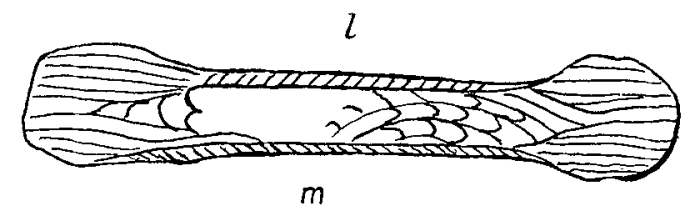

Rech'es Metatarsale $\nabla$, horizontal durclschnitten, schematisch. $l$ lateral, wh medial.

Ein ähnliches Verhalten wie im distalen Knochenende bietet auf dem Horizontalschnitt die Spongiosa im proximalen Knochenende. Von den proximalen Enden der Schaftcompacta blättern proximalwärts Längszü̈ge $a b$, die, zum Teil leicht geschwungen, auf die tarsale Gelenkfläche zu verlaufen (Fig. 6). Sie stellen ebenfalls die Schnitte von Scheidewänden ron Tubulireihen ${ }^{2}$ ) dar, indes haben die Tubuli hier einen wesentlich andern Verlauf als im distalen Knochenende. Sie verlaufen im Zuge des oben beschriebenen Drucksystems in der proximalen Spongiosa (Fig. 1 und 2), also von der Tuberositas her auf die Gelenkfläche fitr das M. IV zu, und sind auf dem Horizontalschnitt annähernd quer getroffen. Ihre Querschnitte bilden longitudinal verlanfende Reihen, die Scheidewände $z$ wischen diesen Reihen stehen rechtwinkelig zur Gelenkfläche für das M. IV. Das Verhältnis der Scheidewände zn dieser Gelenkfläche stellt Fig. 3 dar. Stellenweise, namentlich nach den Compactaenden hin und im Centrum der proximalen Spongiosa, sind die Scheidewände dickere Platten, nach der tarsalen Gelenkfäche zu werden

1) Das M. V stets in Supinationsstellung gedacht.

3) In der Figur nicht eingezeichnet. 
sie dunner und sind weniger deutlich. In der Tuberositas sind anf dem Horizontalschnitt die in Fig. 6 dargestellten Längszüge weniger ausgesprochen, die Tubuli stehen hier nicht mehr in so regelmäßigen Reihen wie nach der Gelenkfläche für das M. IV hin.

Wir sehen also im proximalen und distalen Ende des M. V, in den Abschnitten, mit welchen es, nach dem Aufsetzen des lateralen Fußrandes beim Gehen, auf dem Boden aufruht, die Züge der Biegungskonstruktion durchschnitten von sagittal stehenden, mehr oder minder ausgedehnten Knochenplatten, die wesentlich dazu beitragen, den Widerstand gegen den anf jene Stellen ausgetibten Druck in der Beanspruchungsrichtung zu verstïrken.

Übrigens findet man auf Frontalschnitten des proximalen Knochenendes, daßs sich auch die proximalen Enden der Compacta in Tubuli auflösen, die in der Längsrichtung des Knochens verlaufen und in die proximale Spongiosa eindringen. Diese Tubulizüge sind aber nur deutlich im distalen Abschnitt der proximalen Spongiosa nahe der Markhöhle, weiter proximal ist der Zug der Tubuli im Verlaufe des Drucksystems unbedingt vorherrschend.

Die Markhöhle liegt, wenn die Spongiosa nicht zu stark resorbiert ist, in der proximalen Knochenhälfte und reicht hier in der Regel bis an die Mitte der Knochenlänge heran. Auch bei Präparaten von alten Individuen ist trotz starker Resorption der distalen Spongiosa die Lage der Markhöhle in der proximalen Knochenhälfte durch begrenzende Knochenbälkchen und -Plättchen meist scharf markiert, nur ausnabmsweise reicht in solchen Fällen die Markhöhle in die distale Knochenhälfte hinein.

Bei jüngeren Individuen mit reichlicher Spongiosa ist die Markhöble oft fast rings von Spongiosa umgeben und hat eine, allerdings meist stark durchbrochene Kapsel. Eine solche Kapsel findet sich in dem Präparat der Fig. 1, sie ist auf dieser Figur in ihren Umrissen zu erkennen. In derartigen Präparaten hat die Markhöhle eine annähernd kegelförmige Gestalt mit distaler Spitze und proximaler Basis. Begrenzt wird die Markhöhle durch die am weitesten central von der plantaren und dorsalen Compacta abgehenden Trajectorien, von denen die plantar und dorsal distalwärts verlaufenden sich in Plattenform nach medial und lateral herumkrümmen und den Kegelmantel darstellen, während die distalsten Züge in der proximalen Spongiosa, die von der dorsalen Compacta plantarwärts verlaufen, die Basis des Kegels bilden. Die Basis steht zur dorsalen 
Markhöhlenwand in stumpfem, zur plantaren in spitzem Winkel. Der dorsale stumpfe Basiswinkel ist etwa so groß wie der Winkel, welchen die Gelenkflächen des M. V für das M. IV und das Cuboideum miteinander bilden, die Basis der Markhöhle läuft mit der tarsalen Gelenkfläche annähernd parallel.

Die die Basis der Markhöhlenwand bildenden Spongiosazuige zeichnen sich manchmal durch besondere Stärke aus. Es finden sich hier starke transversal verlaufende Balken, die von gleichfalls starken vertikal stehenden rechtwinkelig gekreuzt werden. An diese kräftigen Balken lehnen sich die uäehstliegenden, von der dorsalen Compacta ausstrahlenden Züge der proximalen Spongiosa an. In einem Präparat von einem alten Individunm mit stark resorbierter distaler Spongiosa bildet die Basis der Markhöhlenwand eine vollstandige starke Platte, welche nach lateral, medial und dorsal bis an die Knochenwand heranreicht, nach plantar von ihr ein wenig entfernt bleibt und durch rechtwinkelig zu der Platte verlaufende, von der plantaren Compacta proximalwärts ausstrablende Bälkchen mit dieser in Verbindung tritt. Diese Platte stellt das der Markhöhle zunächst gelegene der in der proximalen Spongiosa von der dorsalen Compacta nach plantar verlaufenden Trajectorien dar.

Auf der andern Seite findet man in Präparaten mit allgemeiner stärkerer Resorption der Spongiosa die Markhöhlenbasis öfters keineswegs scharf markiert, sondern in Trichterform sich in die hier besonders stark geschwundene Spongiosa hinein erstrecken. Die Wand des Trichters bilden die aus den proximalen Compactaenden sich ablösenden, proximal in der Lüngsrichtung verlaufenden Tubuli, deren dem Trichter zugekehrten Wände mehr oder weniger durchbrochen sind. Von queren, in der Frontalebene stehenden Spongiosazügen fand ich im proximalen Markböhlenende in solehen Präparaten keine Spur.

Auch in derartigen Präparaten mit besonders starker Resorption der Spongiosa fand ich in der distalen Schafthälfte von der plantaren Compacta nach distal abgehende Spongiosazüge, wenn anch nur spärlich, so doch fast stets scharf ansgeprägt, bis an die dorsale Compacta herangehend, von der dorsalen Compacta aber nach distal bis an das Köpfchen heran öfters kein einziges Bälkchen oder Plättchen ausgehend. In solchem Fall wird die Markböhle distal uur durch das ihr zunächst gelegene, von der plantaren Compacta nach distal bis an die dorsale Compacta herangehende Trajectorium begrenzt. 


\section{Metatarsale IV.}

Die Elemente der Biegungskonstruktion des M. V finden sich auch im M. IV mehr oder minder deutlich ausgesprochen. Sie sind am besten zu erkennen auf einem Schnitt, welcher, dem Sagittalschnitt beim M. V entsprechend, also die Dorsalfläche des Schaftes in der Längsrichtung annähernd halbierend, zur plantaren Kante verlauft. Dieser Schnitt steht in der Stellung, in welcher das M. IV, beim Aufsetzen der Fußsohle beim Gehen, aus der SupinationsstelInng des Fußes auf den Boden auftrifft, also in der Supinationsstellung des M. IV, annähernd sagittal, ich will ihn daber, wie den entsprechenden Schnitt beim M. V, als Sagittalschnitt bezeichnen. Mit Bezug auf den Basalteil verlänft der Schnitt etwa durch die Kante zwischen Dorsalfläche und tibialer ${ }^{1}$ ) Gelenkfläche des Basalteils nach der plantaren Ecke seiner fibularen Gelenkfäche. Für den Basalteil ist dieser Schnitt also ein von dorsal-tibial nach plantar-fibular verlaufender Schrïgschnitt. Von der Kante zwischen Dorsalfäche und tibialer Gelenkfläche des Basalteils her entwickelt sich die Dorsalfläche des Schaftes und dreht sich in ihrem Verlauf nach dem Capitulum hin so, daß sie dessen tibiale Fläche wird. Um den Schnitt bei diesem drehenden Verlauf der dorsalen Schafttäche richtig zu orientieren, empfiehlt es sich, ihn, wie beschrieben, sehräg durch don Basalteil, aber eher etwas unterhalb der Kante zwischen seiner Dorsalfläche und tibialen Gelenkfläche zu legen. Auch das Capitulum wird durch einen solchen Schnitt schrig geteilt in einen dorsalen und fibularen und in einen plantaren und tibialen Abschnitt, indes tritt die charakteristische Struktur des Capitulum auf einem in Pronationsstellung des Fußes horizontalen bzw. sagittalen Schnitt besser hervor.

Das Präparat, welches die Fig. 1 wiedergibt, zeigt im M. IV die charakteristischen Elemente der Biegungskonstruktion in dem Abschnitt distal der Markhöhle recht deutlich 2). Auch in der Figur sind sie hier vielfach deutlich zu erkennen. Die scbarf be-

1) Ich ziehe hier die Bezeichnung: stibial-fibular der: smedial-lateral Beim M. V schien mir erstere Richtungsbezeichnung nicht möglich anzrwenden, da sich die dorsale Schafttäche des M. V aus der Gelenkfläche des M. V für das M. IV herans entwickelt, diese Gelenkflïche aber tibial gerichtet ist. Diese tibiale Gelenkfliche mußte der Einheitlichkeit der Darstellung wegen als »dorsals bezeichnet werden.

2) Der Schnitt ist fibularwärts nicht weit genug nach der Planta zu gefillen. 
grenzte Markhöhle liegt wie beim M. V ganz in der proximalen Knochenhälfte. Distal der Markhöhle ist der Schaft bis zum Köpfchen mit Spongiosa ausgefüllt, welche, etwas weniger dicht als beim M. V, infolgedessen noch deutlicher die Trajectorien der Biegungskonstruktion zeigt, welche in ihrem Verlauf denen beim M. V entsprechen. Die diese Trajectorien darstellenden, von der plantaren Compacta herkommenden Bälkchen und Plättchen sind stärker als die von der dorsalen Compacta ausgehenden, also auch hier das primäre System; sie treffen znm Teil auf die dorsale Compacta rechtwinkelig auf. Die von der dorsalen Compacta ausgehenden Trajectorien sind sehr feine Bälkchen, welche die von der plantaren kommenden rechtwinkelig krenzen.

Auch auf dem Röntgenbild, Fig. 2, sind diese Trajectorien hinreichend deutlich zu erkennen, obwohl schwächer als beim M. V. Man erkennt die Kreuzung und sieht, wie die Trajectorien nach der Markhöhle hin stärker gebogen, nach dem Köpfchen hin zunehmend gestreckter verlaufen. Am Schaftende kreuzen sich die von plantar und dorsal kommenden Spongiosazüge mehr spitzwinkelig, und im Köpfchen legen sie sich schließlich annähernd parallel aneinander und laufen in der Knochenlängsrichtung auf die distale Gelenkfläche $\mathrm{zu}$, auf welche sie rechtwinkelig auftreffen, nachdem sie sich zum Teil vorher geteilt haben. Diese Längs z äge im Köpfehen stellen sich in einem dasselbe in seiner Pronationsstellung treffenden Sagittalschnitt als in dieser Stellung sagittal stehende PIatten dar.

In dem Präparat der Fig. 1 und 2 gehen die Längszüge im Köpfchen etwa zu gleichen Teilen von der fibularen und tibialen Compacta aus. So habe ich es in der Regel nicht gefunden. Meist blättern diese Längszüge vorwiegend oder ausschließlich von der stärkeren tibialen Compacta $\left.a b^{1}\right)$. Die von dieser in die fibulare Köpfehenhälfte hineingehenden Längszüge divergieren zum Teil beträchtlich von denen in der tibialen Köpfchenhälfte, teilen sich vielfach und endigen mit einem oft sehr zierlichen Stäbchenwerk in der Druckaufnalımeplatte der Gelenkfläche.

Die proximale Spongiosa ist in dem Präparat der Fig. 1 außerordentlich dicht vou der tarsalen Gelenkfläche bis zur Mark-

1) Nach dem Rüntgenbilde rechts auf Fig. 2 ist scheinbar die fibulare Compacta dicker als die tibiale. Der breite dunkele Schatten am fibularen Schaftrande rührt indes daher, daß hier die Compacta doppelt durchleuchtet worden ist. Der Knochenschnitt war, wie schon erwihnt, auf dieser Seite etwas zu weit dorsalwärts gefallen. 
höhle. In der Nähe der letzteren lassen sich einige von der dorsalen und plantaren Compacta sich ablösende Züge verfolgen, welche etwa nach dem Centrum des Basalteils konvergieren, sich hier zum Teil kreuzen und dann in die äußerst dichte weiter proximale Spongiosa verlaufen. In andern Präparaten mit weniger dichter Spongiosa sieht man anf dem entsprechenden Schnitt nahe der Markhöhle von den proximalen Compactaenden in größerer Zahl mehr oder minder stark geschwungene Trajectorien proximalwärts nach der jedesmal gegenüberliegenden Seite abgehen, welche sich rechtwinkelig kreuzen und nach der tarsalen Gelenkfläche hin sich in Platten verlieren, welche der Dorsalfläche des Basalteils annähernd parallel laufen.

Die Compacta zeigt anf dem Sagittalschnitt für die Biegungskonstruktion ebenso wie im M. V ibre größte Dicke in der Gegend der Markhöhle, verjüngt sich von da aus gleichmäßig nach distal bis zum Köpfehen, nach proximal rasch bis an die tibiale Gelenkfläche und an die tiefe Furche an der fibularen Seite des Basalteils heran.

Genauer werden wir tiber die Lage der eben erwillnten Platten in der proximalen Spongiosa and über die Dicke der Compacta auf den verschiedenen Seiten des Schaftes durch den Frontalschnitt unterrichtet. Ich habe ein Metatarsale IV ron $6,5 \mathrm{~cm}$ Länge durch Frontalschnitte in zehn annähernd gleich dicke Scheiben zerlegt. Außrordentlich wechselnd sind die Bilder auf den Schnitten durch den etwa $2 \mathrm{~cm}$ langen Bereich der proximalen Spongiosa (Basalteil + Anfang des Schaftes), welcher in vier Scheiben zerfällt (Röntgenbilder Fig. 7). Die Platten finden sich nur im Bereich der fibularen und tibialen Gelenkfläche. Sie ziehen in annähernd horizontaler Richtung von einer zur andern Seite ganz hindurch nur, soweit Teile der beiderseitigen Gelenkflächen einander gerade gegenüber liegen, und verlaufen so, daß sie auf beiden Gelenkflächen senkrecht stehen. Soweit einem Abschnitt der einen Gelenkfläche auf der andern Seite nicht ein Abscbnitt der andern Gelenkfläche gegeniiber liegt, finden sich zwar auch horizontale, auf jener Gelenkfläche senkrecht stehende Platten, diese ziehen aber nicht bis zu der der Gelenkfläche gegenüberliegenden Seite durch, sondern hören in größerer oder geringerer Entfernung von der letzteren auf. $\mathrm{Da}$ in der Regel die tibiale Gelenkfläche erheblich weiter distal reicht als die fibulare, so finden sich nach dem Aufhören der letzteren horizontale Züge nur noch tibialwärts; diese erreichen am distalen Ende der tibialen Gelenkfläche die Mitte zwischen tibialer und fibularer Knochenfläche nicht mehr (Schnitt III, distale 
Seite der dritten Scheibe; vgl. Erläraterungen zu Fig. 7). Nahe der tarsalen Gelenkfläche stehen die horizontalen Züge am dichtesten, je weiter distal, desto weitläufiger. Vertikale, die horizontalen senkrecht kreuzenden Züge finden sich nur spärlich. Sie verlaufen, wie aus dem Röntgenbilde Fig. 7 Scheibe II ersichtlich, nahe den seitlichen Gelenkflächen, annähernd parallel mit ibnen and plantarwärts

Fig. 7.

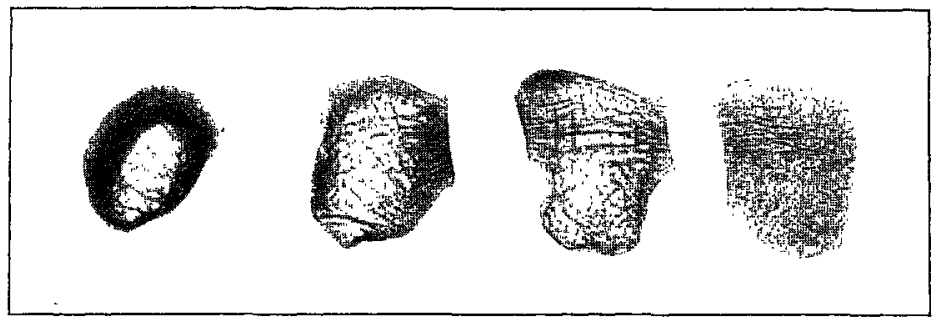

höntgenbilder der ersten vier Scheiben (proximales Ende) eines durch Frontalschnitte zerlegten linken Metatarsale IV, jede Scheibe $4-5 \mathrm{~mm}$ dick. Rechts erste, links rierte Scheibe, bei jedem Bilde links fibularer, rechts tibialer Rand. Die erste Seheibe reicht gerade bis zum proximalen Ende der tibialen Gelenkfläche, diese ist noch nicht mitgetrofen. Die auf der fibularen Gelenkfläche senkrecht stehenden Züge erreichen die tibiale Scheibenflache nicht. - Die zweite Scheibe reicht gerade bis zum distalen Ende der fibularen Gelenkfiche. Es befindet sich also auf beiden Seiten der Scheibe in hrer ganzen Dicke ein Stück der fibularen bzw. tibialen Gelenkfăche, die Gelenkfăchen liegen aber nicht in ihrer gauzen Höhe einander gerade gegenüber. Soweit sie einander gerade gegenüber liegen, ziehen die horizontalen $Z$ üge ron einer zur andern Gelenkfáche durch. - An der dritten Stheibe ist nur noch auf der tibialen Seite ein Stück Gelenkfläche rorhanden und zwar in ganzer Dicke der Scheibe; die Scheibe reicht gerade bis zum distalen Ende der tibialen Gelenkfiache. Die obersten horizontalen Zủge erreichen noch soeben die fibulare Seite an der Stelle, wo die GelenkAāche geride anfgehört hat. Diese Zäge liegen anf der proximalen Seite der Scheibe; die auf der distalen Seite der Scheibe noch vorbandenen, zur tibialen Gelenkfläch $\theta$ senkrecht stehenden Züge erreichen noch nicht die Mitte dieser Scheibenseite. Die nach plantar-tibial kouvergierenden Schrägzüge liegen vorwiegend nach der distalen Scheibenseite hin. Die Markhöhle reicht in die obere Hälfte der Scheibe mit dexn proximalen Ende soeben hinein. - In der vierten Scheibe proximules Ende des Schiftes mit beginnender stärkerer Compacta tibial-dorsal und fibular-plantar. Die Markhöhle erweitert sich von proximal nach aistal vom oberen Ende der Scheibe her und hat am distalen Scheibenrande ihre volle Weite erreicht. Auf der proximalen Scheibenseite finden sich noch die nach plantar-tibial konvergierenden Schragzüge wie in der dritten Scheibe, am distalen Scheibenende nur am obersten und untersten Ende der Ellipse einige Überbräkungen. Einige in Richtung der langen Achse der Ellipse verlaufenden Züge sind zu erkennen. $D_{\ominus r}$ breite Schatten dorsal und fibular rührt von der trichterförmigen Verengerung des Knochenlumens her.

leicht gebogen auf die Stellen zu, wo die Zwischenknochenbänder sich ansetzen, auf der fibularen Seite der Scheibe durch die tiefe Rinne unmittelbar abwärts der Gelenkfläche gekennzeichnet. Diese vertikalen Züge können im Sinne von RasumowsKr ${ }^{1}$ ) als Fortsetzung jener Bänder in den Knochen hinein angesehen werden. Die auf der fibularen Seite verlaufenden vertikalen Ziuge hat $R_{A}$ sumowskx tibri-

1) a. a. 0 . 
gens in seiner Figur im Metatarsale IV nicht gezeichnet. Sie können in Beziehung gebracht werden zu den der Gelenkfläche für das M. IV parallelen Zügen im M. V, welche ich oben beschrieben habe (Fig. 3). Diese Ziige gehen an die Stelle jener Gelenkfläche heran, wo sich das Lig. interosseum ansetzt. Wir würden also Fortsetzungen der Fasern dieses Ligaments in den Knochen hinein sowohl beim M. IV als beim M. V nachweisen können. Dabei ist aber daran festzuhalten, daß die Hauptfunktion der vertikalen Züge beim M. IV, der der Gelenkfläche für das M. IV parallelen Züge beim M. V ist, Stiitzziige zu bilden für das Hauptsystem: dort die horizontalen Platten, hier das Drucksystem im proximalen Ende des M. V. An diese Stiitzziige lehnen sich die ron dem Ligament in den Knochen seindringenden * Fasern an bzw. gehen in sie iiber.

In der Höhe des distalen Endes der fibularen Gelenkfläche des M. IV, also im Beginn der dritten Scheibe, treten schräge Züge auf, welche in der Richtung dorsal-fibular-plantar-tibial verlaufen und, vom dorsalen und fibularen Rande her leicht konvergierend, nach dem abwärts der tibialen Gelenkfäche gelegenen, schräg verlaufenden plantar-tihialen Rande hin zum Teil die ganze Knochendicke zwischen diesen Rändern durchzieben, die horizontalen Züge, soweit solche im Verlaufe der schrägen Zuige liegen, schräg durchschneidend. Je kürzer weiter distal die horizontalen Züge werden, desto mehr treten die schrägen Züge in den Vordergrund. Die am weitesten plantar gelegenen von diesen nach dem plantar-tibialen Rande konvergierenden Zügen verlaufen annähernd horizontal. Solche schrägen, von dorsal-fibular nach plantar-tibial konvergierenden Züge finden sich auch noch im Bereich des proximalen Markhöhlenabschnitts in Scheibe IV (Fig. 7), nach dem distalen Ende dieser Scheibe hin, mit der Ausdehnung der Markhöhle rasch abnehmend, so daf am letzteren Ende nur noch die unteren, annähernd horizontal verlaufenden Zuige vorhanden sind, die hier das plantare Ende des elliptischen Knochenlumens überbrücken. - Gekreuzt werden die schrägen, nach plantar-tibial konvergierenden Züge von einigen längeren oder kürzeren in der Riclttung plantar-fibular nach dorsal-tibial verlaufenden Stützzügen, die gegen das distale Ende der dritten Scheibe stürker hervortreten und in der vierten Scheibe annähernd in der Richtung der langen Achse des elliptischen Knochenquerschnitts verlaufen. Sie stehen hier rechtwinkelig zu den in größerer Zabl das plantare, in geringerer aber auch das dorsale Ende des Knochenlumens überbrückenden Zügen. 
Außerhalb des Bereichs der horizontalen und schrägen Ziige, also namentlich in dem proximalen Abschnitt der unteren Hälfte des Basalteils, ist die Spongiosa rundmaschig, die Rundmaschen zumeist in annähernd vertikalen Reihen geordnet, zwischen welche hinein die die horizontalen Zitge kreuzenden vertikalen sich vielfach verfolgen lassen. In der zweiten Scheibe finden sich innerhalb der Rundmaschen abwärts der horizontalen Züge bereits einige sich kreuzende schräge Züge (Fig. 7). Diese Rundmaschenspongiosa setzt sich aber auch nach distal in die dritte und vierte Scheibe in den Beginn des Schaftes linein fort, rorwiegend in den fibularen und tibialen Randabschnitten dieser Scheiben in die Teile des Schaftes hinein, in denen sich zuerst stärkere Compacta entwickelt, wie das auch aus den Röntgenbildern Fig. 7 ersichtlich ist. Diese Rundmaschen sind Querschnitte ron Tubuli, welche annähernd in der Längsrichtung des Knochens verlaufen und auf der tarsalen Gelenkfläche senkrecht stehen. In diese Tubuli löst sich die Compacta des Schaftes an ihrem proximalen Ende auf, oder umgekehrt: aus ihnen bildet sich die Compacta des Schaftes, indem ihre Lumina sich immer mehr verengern. Tibialwärts lassen sich die Tubuli auch zwischen die horizontalen Zuige hinein nahe der Gelenkfläche verfolgen, also in die Stelle hinein, an welche sich auf dieser Seite der dickste Teil der Compacta anschließt.

Diese Tubuli dienen ohne Zweifel der Druckibertragung in der Längsrichtung des Fußes, von der tarsalen Gelenkfläche her in die Compacta hinein und umgekehrt, wäbrend die horizontalen Platten ganz vorwiegend die Druckübertragung von der Basis des M. V her nach der Basis des M. III oder umgekehrt vermitteln.

Die nach tibial-plantar konvergierenden schrägen Züge bilden nach meinem Dafürhalten eine wirksame Versteifung des Schaftansatzes an den Basalteil, besonders bei der Beanspruchung des M. IV beim Stehen auf den Zehen. In der Pronationsstellung, in welcher sich dieses hierbei befindet, ist die tibiale Schaftfläche des M. IV stark plantarwärts gedreht, und beim Erheben auf die Zehen wird der Basalteil gegen den mit der langen Achse seines elliptischen Querschnitts schräg stehenden Schaft stark aufwärts abgebogen. Dem widerstreben in ausgezeichneter Weise die nach tibialplantar konvergierenden Züge. Dieselben dienen überhaupt zur sicheren Befestigung des mit seinem elliptischen Querschnitt schräg in den melir viereckigen Basalteil eingefügten Schaftes. Der Schaft 
setzt sich nur an den tibialen plantaren Abschnitt des Basalteils an, die fibulare dorsale Ecke des letzteren mit der Gelenkfläche für das M. V dient nur dazn, die Verbindung mit letzterem in zweckmäßiger Weise herzustellen und durch diese Ergänzung des Basalteils dem Schaft des M. IV die richtige Stellung für das Aufsetzen der Fußsohle beim Gehen zu geben, ohne diese Ecke würde dem Fuß die erforderliche Wölbung fehlen. Eine solche ergänzende Ecke am Basalteil finden wir weder beim M. III noch beim M. II; bei diesen bildet der ganze Basalteil die Fortsetzung des proximalen Schaftendes. Die schräge Einfügung des Schaftes des M. IV in den Basalteil bedingte eine Schwäche in der Verbindung zwischen beiden, welche jene Verstrebung durch die konvergierenden schrägen Züge wirksam beseitigt.

Die Compacta beginnt in der vierten Scheibe (Fig. 7) und ist an deren distalem Ende (Fig. 8, Schnitt IV) dorsal-tibial und plantarfibular auffallend stark entwickelt, während dorsal-fibular und besonders plantar-tibial ihre Dicke noch sehr gering ist. Die größte Dicke

Fig. 8.

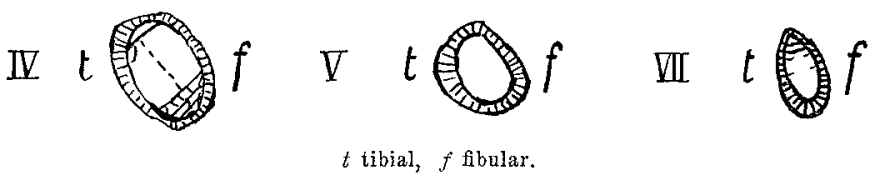

der Compacta auf diesem Schnitt beträgt dorsal-tibial 2, plantar-fibular 1,5 mm, während sie an den diunnsten Stellen dorsal-fibular 0,6 , plantar-tibial $0,4 \mathrm{~mm}$ dick ist. Der Frontalschnitt hat hier etwa die Gestalt einer Ellipse mit dem langen Durchmesser in der Richtung doral-tibial-plantar-fibular. Dieser Durchmesser steht zu der medialen Gelenkfläche in einem Winkel von annähernd $45^{\circ}$. - Weiter distal bleibt die Compacta bis $3,5 \mathrm{~cm}$ (Fig. 8, Schnitt V) plantar-fibular gleich dick wie auf Schnitt IV. In der tibialen Wand liegt auf diesem Schnitt die dickste Stelle etwas abwärts, in der Mitte der Wand; sie beträgt noch $2 \mathrm{~mm}$. Dorsal-fibular und plantar-tibial ist auf Schnitt $V$ die Compacta dicker als auf IV, 1,2 bzw. $1 \mathrm{~mm}$. - Weiter distal nimmt die Dicke der Compacta an den bisherigen dicksten Stellen ab. In $4,1 \mathrm{~cm}$ Entfernung (Schnitt VI) ist sie ringsherum fast gleichmäßig dick, $1 \mathrm{~mm}$, doch tibial Mitte, plantar-fibular und an der dorsalen Kaute noch ein wenig dicker als an den andern Stellen. Auf Schnitt VII (Fig. 8), in $5 \mathrm{~cm}$ Entfernung, unmittelbar vor Beginn des Capitalum, hat sich die Compacta fibular und tibial, namentlich nach der dorsalen scharfen Kante hin, wesentlich verschmälert, wäh- 
rend sie jetzt plantar verhältnismäßig am dicksten, noch $1 \mathrm{~mm}$ dick ist. An der dorsalen Kante beträgt ihre Dicke nur 0,3, fibular und tibial Mitte etwa 0,5 mm. Der Querschnitt des Schaftes hat sich gegen die Mitte der Länge, also bei Schnitt $\mathrm{V}$, dem runden genähert, un gegen das distale Schaftende in eine schmale, annähernd vertikal stehende Ellipse mit dorsaler scharfer Kante überzugehen.

Zusammenstellung der Compactadicke.

\begin{tabular}{c|c|c|c|c}
\hline Sehnitt & $\begin{array}{c}\text { dorsal-tibia } \\
\mathrm{mm}\end{array}$ & $\begin{array}{c}\text { plantar-fibular } \\
\mathrm{mm}\end{array}$ & $\begin{array}{c}\text { dorsal-fibular } \\
\mathrm{mm}\end{array}$ & $\begin{array}{c}\text { plantar-tibial } \\
\mathrm{mm}\end{array}$ \\
\hline IV & $\begin{array}{c}2,0 \\
\text { tibial Mitte } \\
2,0\end{array}$ & 1,5 & 0,6 & 0,4 \\
V & 1,5 & $\begin{array}{c}1,2 \\
\text { dorsal } \\
1,0\end{array}$ & 1,0 \\
VI & 1.0 & $\begin{array}{c}1,0 \\
1,0\end{array}$ \\
VII & 0,5 & $\begin{array}{c}\text { fibular Mitte } \\
0,5\end{array}$ & 0,3 & $\begin{array}{c}\text { plantar } \\
1,0\end{array}$
\end{tabular}

Aus der starken Anhäufung von Compacta am proximalen Schaftende des M. IV dorsal-tibial und plantar-fibular miissen wir den Schluß zichen, daß das M. IV in der Richtung dieser beiden Compactannhïufungen besonders stark beansprucht wird, nond daß, entsprechend der Stellung des M. $V$ beim Aufsetzen der Fußsohle beim Gehen, hierbei auch das M. IV in Supinationsstellung: mit annëhernder Vertikalstellung der langen Achse seines elliptischen Schaftquerschnitts anf don Boden gelangt. Die regelmäßig fortgesetzt stärkere Beanspruchung des M. IV bein Gehen in dieser Stellung bewirkt die auffallend starke Compactaentricklung an diesen Stellen. Wegen der geringeren Beanspruchung des M. IV auf Biegung beim Anfsetzen der Fußsohle beim Gehen ist die Compacta bei diesem Metatarsale weniger dick als beim M. V.

DaB die Compacta dorsal-tibial nnd weiterlin tibial Mitte bis iiber die Mitte der Schaftlänge nach distal hinaus dicker ist als plantar-fibular, wie $i c h$ dies in meinen Präparaten stets gefunden habe, ist vermutlich die Folge der stärkeren Beanspruchung der tibialen Seite beim Steben, auch bei den vorzugsweise beim Stehen beanspruchten M. II und III finden wir rlas gleiche Dickenverhältnis der Compacta. Als Beweis für die stärkere Beanspruchung der tibialen Seite des M. IV beim Stehen kann angesprochen werden, daß die Längsziige (sagittalen Platten) im Köpfehen häufig ausschließlich von der tibialen Compacta, die sich meist nach dem Köpfchen hin 
nur sehr langsam verjüngt und manchmal bis nahe an das Köpfchen heran fast ebenso dick bleibt wie in der Markböhlengegend, sich ablösen, ohne daß die fibulare Compacta zur Bildung jener Züge beiträgt, wie ich das bereits erwähnt habe. Da die sagittalen Platten im Köpfehen im wesentlichen der Druckaufnahme beim Stehen dienen, so ist ibre Ablösung aus der tibialen Compacta beweisend für die besondere Beanspruchung dieser Compacta beim Stehen.

Da das M. IV beim Stehen stärker beansprucht wird als das M. V, so ist auch die Compacta des M. IV am distalen Schaftende plantar verbältnismäßig dicker als beim M. V, dieses in Pronationsstellung gedacht, und zeigt, eben wegen der verhältnismäßig starken Beanspruchung beim Stehen, am distalen Schaftende im Vergleich zu den ỉbrigen Stellen der Wandung plantar die größte Dicke.

Die Folge eben dieser stärkeren Beanspruchung des distalen Schaftendes beim Stehen ist auch der schmale elliptische Querschnitt am distalen Ende des Schaftes des M. IV, während das in wechselnden Ebenen von verschieden großer Neigrung zur Horizontale ziemlich gleichmäßig stark beanspruchte distale Schaftende des M. V einen quadratisch-rundlichen Querschnitt hat ${ }^{1)}$.

Die Markhöhle ist bei diesem frontal durchschnittenen Präparat (Fig. 7,8) sehr ausgedehnt. Sie reicht von ihrem proximalen engen Begian am distalen Ende der dritten Seheibe bis unmittelbar zum Beginn des Capitulum - distales Ende der siebenten Scheibe. Im proximalen Ende der fünten Scheibe finden sich in Fortsetzung der Spongiosa der vierten Scheibe noch einige Überbriickungen durch transversale Balken im oberen und unteren Pol des elliptisehen Lumens, namentlich im unteren, und im distalen Ende der siebenten Scheibe im oberen Pol des elliptischen Lumens die Enden einiger unvollständiger longitudinal gerichteter Tubuli, deren Reihen durch horizontale Zwischenwände getrennt sind, sonst findet sich in der fünften bis siebenten Scheibe keine Spongiosa.

Im Capitnlum sieht man auf der proximalen Seite der achten Scheibe annähernd horizontale Züge, welche, von einer seitlichen Knochenwand zur andern ziehend, die horizontalen Scheidewände zwischen

1) W. GebHaRdT, Über funktionell wichtige Anordnungsweisen der gröberen und feineren Banelemente des Wirbeltierknochens. Arch. f. Entw.-Mech. Bd. XII. 1901. S. 10. "Überwiegt Biegungsbeanspruchung in einer Hauptebene, ohne aber die andern Richtungen auszuschließen, so stellt sich z. B. ein elliptischer Ringquerschnitt als geeignet dar. 
Reihen annähernd longitudinal gerichteter Tubuli darstellen, deren Enden wir in der siebenten Scheibe fanden. Auf der distalen Seite der achten Scheibe, 5,5 cm Entfernung, sieht man mehr unregelmäßige Rundmaschen mit weniger bestimmter Zuganordnung, doch treten auch hier einige horizontale Tubulischeidewände hervor, und nächst den Seitenwänden bemerkt man diesen parallele Längsziige, den Beginn der Abblätterung der sagittalen Platten des Capitulum. Voll entwickelt finden wir diese erst im Gelenkfächenbereich, auf dem nennten Schnitt, $6 \mathrm{~cm}$ Entfernung. Hier sehen wir vertikale Züge, die Schnitte der Platten, von dorsal bis plantar durchziehen. Sie finden sich uber die ganze Fläche des Schnittes bis nahe an die Seitenränder heran, vielfach durch Querzuige untereinander verbunden und gegen die Umbïllungsplatte der Seitenflächen abgestiitzt. Kurz vor den Gelenkflächen teilen sich einige von den vertikalen Zügen, um schließlich auf erstere rechtwinkelig aufzutreffen.

In dieser Zahl und Größe finden sich die sagittalen Platten nicht immer; es hängt das wahrscheinlich ganz von der Art und dem Grade der Beanspruchung ab (viel oder wenig Stehen auf den Zehen!). In andern Präparaten findet man nur ganz im Centrum des Capitulum wenige kleine Plättchen, von deren distalem Rande man im Sagittalschnitt auf die distale Gelenkfäche zu speichenförmig sebr zierliche Bälkchen verlaufen sieht, welche auf der Druckaufnahmeplatte rechtwinkelig stehen.

Von Interesse ist es noch, die Struktur der proximalen Spongiosa auf einem Longitudinalschnitt kennen zu lernen, welcher rechtwinkelig zur Dorsalfläche des Basalteils steht. Auf diesem Schnitt finden sich rom Dorsum bis zur Planta Längszüge, von denen sich diejenigen, welche in den Bereich der seitlichen Gelenkflïchen fallen, also etwa in der dorsalen Hälfte des Schnittes liegen, charakteristisch unterscheiden von den Lüngszügen in der plantaren Hälfte $\left.{ }^{1}\right)$. Die Längszü̈ge im Bereich der seitlichen Gelenkflächen zeichnen sich durch ihre Stärke, ihren geradlinigen Verlauf, annähernd parallel miteinander und mit der dorsalen Knochenfläche, und ibre dichte Lage zueinander aus. Sie gehen zum Teil - die am weitesten dorsalen - unmittelbar vom proximalen Ende der dorsalen Compacta aus, zum Teil - die plantarwärts folgenden - stehen sie distal mit dieser durch, zwar auch im ganzen horizontal, aber nicht so geradlinig verlaufende sehr derbe Züge in Verbindung, die untersten, am

1) Vgl. Röntgenbild Fig. 11 für M. III. 
weitesten plantarwärts gelegenen der geradlinigen Züge lehnen sich auch wohl nach distal an Ziuge an, die nicht von der dorsalen Compacta ausgehen, sondern nach der Markhöhle zu frei endigen, ebenso etwas unregelmäBig horizontal verlaufend wie die weiter dorsal von der Compacta ansgehenden. Proximal gehen die geradlinigen Züge im seitlichen Gelenkflächenbereich an die Druckaufnahmeplatte der tarsalen Gelenkfläche heran, manche, nachdem sie sich kurz vor derselben geteilt haben. Sie treffen auf diese Gelenkfläche unter rechtem Winkel auf. Untereinander stehen die Längszüge mehrfach durch vertikal verlaufende Querzüge in Verbindung. Diese starken geradlinigen Längszüge im Bereich der seitlichen Gelenkflächen sind die Durchschnitte der rechtwinkelig zu diesen Gelenkflächen stehenden horizontalen Platten, die sich zum Teil nach distal anlehnen an die geradlinigen anschließenden unregelmäßigeren Horizontalzüge, die Schnitte der Schrägzïge, welche wir im Frontalschnitt distal von den horizontalen Platten im Bereich der seitlichen Gelenkflächen gefunden haben. Die unregelmäßigen Horizontalzüge weisen sich aneinanderreihende knotige Verdickungen auf, die Durchschnitte einzelner schräg: verlaufender Balken. Diese Züge sind also nicht die Schnitte von Platten, sondern die Schuitte einzelner miteinander verbundener schräg: verlaufender stärkerer Balken.

Plantar von den starken geradlinigen Längszitgen im Bereich der seitlichen Gelenkflächen stehen die Längszüge weniger dicht, verlaufen leicht geschwungen, sind stellenweise unterbrochen und viel zarter als jene. Sie gehen teils - die untersten - von dem proximalen Ende der plantaren Compacta aus, teils stehen sie - die weiter dorsalwärts gelegenen - distal in Verbindung mit derben, unregelmäßigen Horizontalziigen von der Art der vorher bei den geradlinigen Längszügen erwähnten. Auch die zarten geschwungenen Längszüge in der plantaren Hälfte der proximalen Spongiosa lassen sich nach proximal bis an die tarsale Druckaufnahmeplatte heran verfolgen und stehen mit ihren Enden zu ihr rechtwinkelig. Diese Längszïge sind die Längsschnitte der Wandungen der Tubuli, deren Querschnitte anf dem Frontalschnitt abwärts des Bereichs der seitlichen Gelenkflächen sichtbar sind. Auf dem Längsschnitt lassen sich mebrfach die Röhrchen vom proximalen Ende der plantaren Compacta bis an die tarsale Druckaufnahmeplatte heran verfolgen.

Ich habe bei dem in Frontalschnitte zerlegten Präparat (Fig. 7, 8) auf die groBe Ausdehnung der Markhöhle nach distal bis an das Köpfchen heran besonders hingewiesen. Geradezu das andre Extrem 
in der Ausdehnung der Markhöhle nach distal beim Metatarsale IV stellt das Präparat der Fig. 1 dar; bei diesem reicht die Markhöhle nach distal nicht einmal bis zur Mitte der Knochenlänge. Für gewöhnlich erstreckt sich die Markhöhle bis zur Mitte der Knochenlänge oder etwas über dieselbe hinaus nach distal. Es kommt hierbei ganz auf den Grad der Resorption der Schaftspongiosa an.

\section{Metatarsale III.}

Auch im M. III finden sich bei einem stark gewölbten Fuße und reichlicher Spongiosa wie im Präparat der Fig. 1 die Elemente der Biegungskonstruktion des M. V noch dentlich ausgeprägt, wenn auch schwächer als im M. IV, dagegen treten die Besonderheiten der Architektur, welche auf die Beanspruchung des Knochens beim Stehen zurïckzufithren sind, in den Vordergrund.

Auch im M. III wird die Biegungskonstruktion am besten zur Anschauung gebracht auf einem den Basalteil schräg treffenden Schnitt, welcher dem beim M. IV beschriebenen entspricht. Ein solcher durch die dorsale Fläche und plantare Kante des Schaftes verlaufender Schnitt ist in dem Präparat der Fig. 1 gut zur Ausführung gelangt, und diese Figur gibt die für diesen Schnitt charakteristische Struktur und Dicke der Compacta zutreffend wieder.

In Fig. 1 sind die Grenzen der Markhöhle, die in diesem Präparat ganz in der proximalen Knochenhälfte liegt, dentlich zu erkennen, ebenso, namentlich mit der Lupe, die distal der Markhöhle von der beiderseitigen Compacta abgehenden Trajectorien. Die von der plantaren (fibularen) Compacta kommenden sind zum Teil Platten. Sie treffen vielfach annähernd rechtwinkelig anf die dorsale (tibiale) Compacta auf und werden ron sehr zarten, ron dieser ausgeherden Bälkchen rechtwinkelig gekrenzt. Am proximalen Markhöhlenende kann eine Grenzplatte, die von der plantaren (fibularen) Compacta bogenförmig zur dorsalen (tibialen) verläuft und auf diese rechtwinkelig auftrifft, noch als Trajectorium der Biegungskonstruktion angesehen werden, im übrigen finden sich in der proximalen Spongiosa vorwiegend Längszüge, welche fast ausschlieBlich von der beim Stehen besonders beanspruchten tibialen Compacta abgehen und auf die tarsale Gelenkfläche zu verlaufen. Im Köpfchen finden sich von den distalen Compactaenden auf die Gelenkfäche zu verlaufende Längsziige, entsprechend denen im M. IV, diese Längszitge gehen aber im M. III ganz vorwiegend von der tibialen Compacta ab. 
Entsprechend der Beanspruchnng auf Biegung beim Aufsetzen der Faßsohle beim Gehen ist die fibulare Compacta im Bereich der Markhöhle am dicksten, wie dies in Fig. 1 deutlich ist, und verjüngt sich von da nach dem Köpfehen hin schnell, nach proximal nur wenig und hört hier ziemlich breit an der tiefen Furche an der fibularen Seite des Basalteils auf. Auch die tibiale Compacta besitzt in der Markhöhlengegend eine beträchtliche Dicke, diese erhält sich aber noch ein Stück über das distale Markhöhlenende hinaus, wie dies ebenfalls Fig. 1 zeigt. Entsprechend der verhältnismäßig starken Beanspruchung auf Biegung beim Aufsetzen der Fußsohle beim Gehen bei dem stark gewölbten Fuß ist im Präparat der Fig. 1 die fibulare Compacta fast ebenso dick wie die tibiale.

Die Längszüge in der proximalen Spongiosa gehen ganz vorwiegend von der tibialen Compacta ab, im Präparat der Fig. 1, wie schon erwähnt, fast ausschließlich. In diesem Präparat sind es verhältnismäßig dünne Bälkchen, welche sich zum Teil bis an die tarsale Gelenkfläche verfolgen lassen, wie das ans der Figur ersichtlich ist. In andern Präparaten finden sich kräftige, in Pronationsstellung des Fußes annähernd sagittal stehende Platten, von denen die am meisten central gelegenen, also am weitesten distal von der beiderseitigen Compacta abblätternden, vielfuch nicht rechtwinkelig auf die tarsale Gelenkflïche zu laufen, sondern leicht konvergierend nahe distal derselben unter spitzem Winkel zusammentreffen. Gekreuzt werden die Längszüge mehrfach von queren Zügen, die meist rechtwinkelig zu ersteren von einer Seitenwand zur andern laufen. Mit diesen Querzügen können, wie im Präparat der Fig. 1, Längszüge in Verbindung stehen, welche nicht von den proximalen Compactaenden abgehen, sondern central von den Compactalängszügen und parallel mit ihnen nur zwischen den Querzïgen und der tarsalen Gelenkfläche verlaufen.

Die queren Züge stellen sich, soweit sie nicht in den Bereich der seitlichen Gelenkfächen fallen, gewöhnlich als horizontale Bälkchen dar, können aber auch als frontale auftreten, namentlich in Höhe der tiefen Furche an der fibularen Seite des Basalteils, wie im Präparat der Fig. 1. Sie stellen hier gewissermaßen die Fortsetzung des Ligamentum interosseum, welches in dieser Furche inseriert, in den Knochen hinein dar.

Im Bereich der seitlichen Gelenkflächen des Basalteils finden sich, entsprechend M. IV, annähernd horizontale Platten, über deren Lage und Verlanf der gleich eingehend zu beschreibende 
Frontalschnitt genauen Aufschluß gibt. Treffen sagittale, von des Compacta abblätternde Platten mit den horizontalen zusammen, so können wir, namentlich nahe der tarsalen Gelenkfäche, in der proximalen Spongiosa ausgesprochenen tubnlösen Bau finden.

Besonders bemerkenswert sind in der proximalen Spongiosa des M. III sich kreuzende schräge Züge, welche sich anscheinend regelmäßig nahe der Markhöhle zwischen den centralsten von der fibularen und tibialen Compacta abblätternden Längsziigen und zwar

Fig. 9.

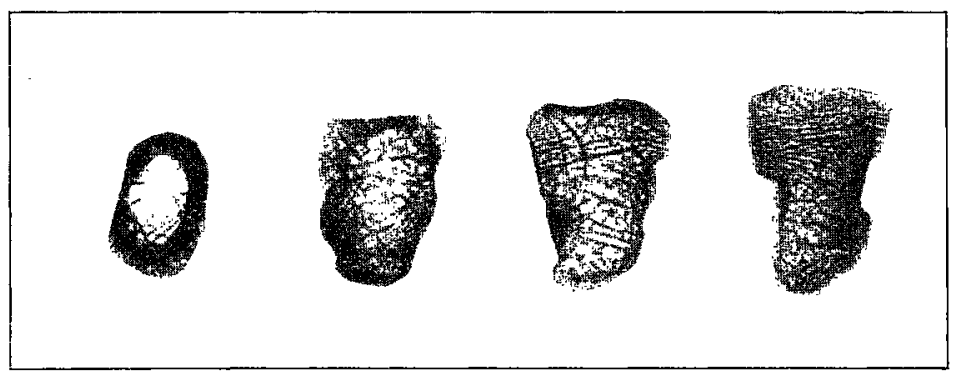

Röntgeubiliter der vior ersten (proximalen) Scheiben eines durch Frontalschnitte zerlegten, 6, $6 \mathrm{~cm}$ la.gen linken Metatarsale III, jede Scheibe $4-5 \mathrm{~mm}$ dick, rechts erste, links vierte Scheibe, bei jeder Suheibe rechts tibial, links fibulur. Anf dem ersten Bilde leicht gebogene horizontale Züge im Bereich der oberen seitlichen Gelenkfäehen, beiderseits rechtwinkelig zu diesen endend. Die auf der unteren tibialen Gelenkflache rechtwinkelig stehenden Züge divergieren gegen den fibularen Rand hin. In der Mitte des Bildes, zwischen diesen oberen und unteren Zugen, schräge Züge, vorwiegend. ron plantar-tibial nach dorsal-fibular. - An der $z$ weiten Seheibe befinden sich nur noch die beiden oberen seitlichen Gelenlffǚchen, zwischen denen horizontale $Z \mathrm{Züg}_{\theta}$ entsprechend denen in der ersten Seheibe. In dern unteren Abschnitt der zweiten Scheibe sich kreuzende schräge Züge, namentlich auf der distalen Seite dieser Scheibe. Die beiden oberen seitlichen Gelenlfiuchen enden am distalen Rande der zweiten Scheibe. - In der Mitte der oberen Hälfte dex dritten Scheibe das proximale Ende der Markhōhle, in ihrer Ungebung Tubuliquerschnitte. In ler unteren Hülfte der dritten Scbeibe sich hreuzende schräge Züge. Vertikale Züge, die im Präparat naho den Seitenwänden besonders auf dex proximalen Seite der Suheibe hervortreten, sind im Runtgenbild zu erkennen, aber nicht sehr deutlich. - In der vierten Scheibe erweitert sich die Markhöhle nach distal und hat auf der disialen Seite dieser Scheibe ihre volle Weite. In der nnteren Hälfte der Scheibe sich kreuzende schräge Züge, vorwiegend im plantaren tibialen Abschnitt.

hier nur plantarwärts finden. Es verlaufen in dieser Gegend stärkere Bälkchen in schräger Richtung von plantar-fibular nach dorsal-tibial, welche von ungekehrt verlaufenden schwächeren rechtwinkelig gekreuzt werden. Diese schrägen Züge sind schon auf dem longitudinalen Schrägschnitt des Basalteils für die Biegungskonstruktion und auf andern Längsschnitten meist recht deutlich zu erkennen, am schönsten auf dem Frontalschnitt. In einem horizontal durchschnittenen Prüparat, in welchem die sagittalen Längszüge (Platten), die der Markhöhle zunächst liegen, etwa $2 \mathrm{~cm}$ von der tarsalen Gelenktläche entfernt sich von der beiderseitigen Compacta ablösen und 
leicht konvergierend nahe dieser Gelenkfläche spitzwinkelig aufeinander treffen, finden sich jene schrägen Züge zwischen den Platten auf eine Strecke von $1,3 \mathrm{~cm}$, von der plantaren Compacta der einen Seite nach der sagittalen Platte der andern Seite hinaufziehend.

Auf dem Frontalschnitt (Fig. 9) sehen wir, daß die in der proximalen Spongiosa den Druck an den seitlichen Gelenkflächen aufnehmenden und übertragenden Platten wie beim M. IV mit ihren Enden rechtwinkelig zu diesen Gelenkflächen stehen. Da die fibulare und obere tibiale Gelenkfläche nicht parallel laufen, sondern plantarwärts konvergieren, so können die die Schnitte der Platten darstellenden Züge nicht geradlinig von einer Fläche zur andern verlaufen. Ihr Verlauf ist in der Regel so, daß sie von der größeren fibularen Gelenkfläche, an welcher der Druck aufgenommen wird, eine große Strecke geradlinig verlaufen, um dann, manchmal crst dicht vor der tibialen Gelenkfläche, nach dieser nmzubiegen (sehr dentlich auf Scheibe II Fig. 9). Soweit die fibulare Gelenkfläche die obere tibiale plantarwärts iiberragt, biegen die auf ersterer rechtwinkelig stehenden Platten meist bald in schräge, plantarwärts verlaufende Züge um (besonders Scheibe I Fig. 9). Die anf der plantaren tibialen Gelenkfläche rechtwinkelig stehenden horizontalen Platten divergieren leicht in der Richtung auf die fibulare Knochenwand. Sie verlaufen in der Regel von dieser Gelenkfläche aus nur eine kurze Strecke geradlinig, dann leicht gebogen auf die fibulare Knochenwand zu, welche sie meist erreichen (Scheibe I Fig. 9).

In der Zone zwischen den beiden tibialen Gelenkflächen treten schräge Züge hervor, welche teils in der Richtung plantar-tibial-dorsal-fibular, etwa rom oberen Rande der plantaren tibialen Gelenkfläche nach dem unteren Rande der fibularen, teils in umgekehrter Richtung verlanfen.

Rechtwinkelig gekreuzt werden die von der fibularen zur tibialen Knochenwand gehenden Ziige von Zuigen, die zwar im ganzen eine vertikale Richtung haben, aber, da jene nicht alle parallel laufen, vielfach geknickt sind. Auf der fibularen Seite lassen sich diese vertikalen Züge bis an die tiefe Furche abwärts von der Gelenkfläche verfolgen, sie laufen auf diese Furche zum Teil leicht bogenförmig zu (Fig. 9 Scheibe II), entsprechen also den auf der tibialen Seite des M. IV beschriebenen vertikalen Zügen und würden die Fortsetzung des Lig. interosseum in den Knochen hinein darstellen (Rasumowsky). Auf der tibialen Seite des M. III finden sich vertikale Züge mit entsprechendem Verlauf, die auf die Gegend zwischen 
den beiden Gelenkflächen zu laufen müßten, nicht. Hier kann man die annähernd horizontal oder leicht schräg auf diese Gegend zu laufenden Züge als Fortsetzung des Zwischenknochenbandes in den Knochen hinein annehmen. Ich will hier gleich hinzufügen, daß ich im M. II Vertikalzuige, wie sie RASUMOWSKx zeichnet1), nicht gefunden habe, nur spärliche schräge Züge auf der fibularen Seite des M. II, welche auf die Gegend zwischen den beiden Gelenkflächen zu ziehen (Fig. 12 Scheibe II) und den Zügen auf der gegenüberliegenden Seite des M. III mithin entsprechen. Auf der tibialen Seite des M. II sowie im M. I können die von Rasumowsky gezeichneten vertikalen Züge schon deshalb nicht vorhanden sein, weil hier das Lig. interosseum fehlt. Ich habe solche Züge in meinen Schnitten auch nicht gefunden.

Distal des distalen Randes der seitlichen Gelenkflächen des M. III treten die sich kreuzenden schrägen Züge in den Vordergrund und nehmen etwa die plantaren zwei Drittel des Frontalschnitts ein. Dorsalwärts dieser schrägen Züge erstreckt sich die Markhöhle bis in die Höhe der distalen Ränder der fibularen and oberen tibialen Gelenkfläche heran. Dieses proximale Markhöhlenende kann seitwärts, dorsal und plantar von einer Kapsel eingeschlossen sein. Im Präparat der Fig. 9 hat der Querschnitt dieser Kapsel annähernd die Form eines gleichseitigen Dreiecks, dessen Spitze dem Dorsum zugekehrt ist, während die ihr gegenüberliegende Seite annähernd horizontal verläuft. Zwischen den seitlichen Dreieckseiten und der Knochenwand liegen die Querschnitte von Tubuli, welche sich aus der Compacta proximalwärts in die Spongiosa hinein erstrecken. Plantarwärts der plantaren Dreieckseite finden sich die schrägen, sich kreuzenden Züge. Sowohl die Kapselwände als auch die Tubuliwandungen sind stark durehbrochen (Fig. 9 Scheibe III).

Die schrägen Zïge finden sich zahlreicher und dichter in der Richtung plantar-fibular-dorsal-tibial als umgekehrt. Seitlich begrenzt werden sie durch annähernd vertikal und geradlinig verlaufende Züge, die Querschnitte der früher erwähnten, im Horizontalsehnitt besonders hervortretenden sagittalen Platten, welche von den proximalen Compactaenden ausgehen. Im Frontalschnitt zeigt es sich, daß diese vertikalen Züge aus der Seitenwand, von ihrem plantaren Ende angefangen bis gegen ihre Mitte hin, sich folgeweise ablösen, in der Richtung dorsalwärts leicht divergieren' und sich in

1) a. a. 0 . 
die das proximale Markhöhlenende umgebenden Tubulischnitte verlieren.

Die Bedeutung dieser sich kreuzenden schrägen Züge ist darin zu suchen, daß sie Verstrebungen darstellen, welche geeignet sind, dem M. III bei der Beanspruchung beim Stehen gerade an dieser Stelle erhöhte Festigkeit zu geben. Es ist anzunehmen, đaß das M. III beim Stehen vorwiegend, in höherem Grade als die andern in Betracht kommenden Metatarsalien, beansprucht wird. Es ist daher den beim Stehen namentlich dann eintretenden Schwankungen, wenn sich der Körper ganz oder vorwiegend auf einen Fuß stützt, besonders ausgesetzt. Bei diesen Schwankungen ist der Teil des proximalen Endes des M. III, welcher unmittelbar distal der seitlichen Gelenkflächen liegt, besonders gefährdet und bedarf einer inneren Stütze durch Spongiosazuige, welche so verlaufen, daß sie geeignet sind, Schädigungen des Knochens durch seitliche Verdrehungen um eine longitudinale Achse starken Widerstand zu leisten. Zu derartigem Widerstand müssen schräge, sich krenzende Balkenzüge, wie die in Rede stehenden, für besonders geeignet gehalten werden. Daß, wie ich das stets gesehen habe, die in der Richtung plantar-fibular-dorsal-tibial verlaufenden Bälkchen stärker, zahlreicher sind und dichter stehen als die in entgegengesetzter Richtung verlanfenden, rïhrt wohl daher, daß die lange Achse des annähernd elliptischen Knochenquerschnitts zwar nahezu vertikal steht, aber doch ein wenig mit ihrem dorsalen Ende nach dem tibialen Fußrande abweicht, daher der plantare tibiale Abschnitt der Knochenellipse, welchen jene stärkeren und zahlreicheren Ziuge überbrücken, einer besonderen Stïtze bedarf.

Eine stärkere Compacta tritt in dem durch zehn Frontalschnitte zerlegten Präparat der Fig. 9 zuerst auf Schnitt III in $1,4 \mathrm{~cm}$ von der tarsalen Gelenkfläche auf. Auf diesem Schnitt (Fig. 9 Scheibe III distal und Scheibe IV proximal) finden sich die plantaren zwei Drittel angefuillt mit den sich kreuzenden schrägen Zügen, im dorsalen Drittel das Lumen des proximalen Markhöhlenendes, umgrenzt von dreieckiger Kapsel, und diese wieder fibular, tibial und dorsal umgeben von Tubuliquerschnitten. In diesem dorsalen Drittel findet sich, die Tubuliquerschnitte umsäumend, ein schmaler Compactastreifen, welcher tibial am dicksten ist und stellenweise $1 \mathrm{~mm}$ erreicht, dorsal und fibular höchstens $0,4 \mathrm{~mm}$. Im Bereich der schrägen Züge ist noch keine Andeutung stärkerer Compacta. - Auf dem nächsten, vierten, Schnitt (Fig. 9 Scheibe IV distal) ist die Compacta in $2 \mathrm{~cm}$ Entfernung 
ringsherum stärker ansgebildet. Der Schnitt hat annähernd die Form einer fibular leicht abgeplatteten Ellipse, deren lange Achse, wie schon erwähnt, annähernd vertikal steht, aber mit ihrem dorsalen Ende ein wenig nach tibial abweicht. Auf diesem Schnitt ist die Compacta. am dicksten in der Mitte der tibialen Wand mit 1,3 mm und im plantar-fibularen Winkel mit 1,2 mm; im übrigen erreicht sie dorsal und plantar fast 1, fibular in der Mitte $0,8 \mathrm{~mm}$. - Auf dem fünften Schnitt, in 2,8 cm Entfernung (Fig. 10a), ist der Knochenquerschnitt etwa halbkreisförmig, die tibiale Seite stark, die fibulare nur sehr wenig gewölbt. Eine dorsale Seite ist nicht mehr ausgesprochen. Die Dicke der Compacta beträgt in der Mitte der tibialen Wand $1,5 \mathrm{~mm}$, im plantaren Winkel 1,2, dorsal 1,0 und in der Mitîe der fibularen Wand $0,8 \mathrm{~mm}$. Spongiosa enthält die fünfte Scheibe nicht. - Weiter distal behält zunächst der Querschnitt seine Form, wird nur kleiner, die Compacta nimmt dagegen an Dickerzu. Diese beträgt auf dem sechsten Schnitt

Fig. 10.

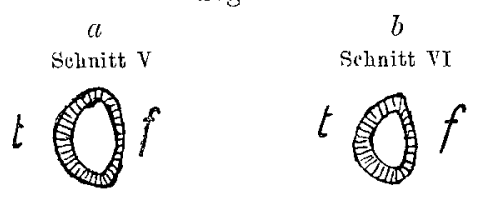

$t$ tibial, $f$ fibular. (Fig. 10b) tibial Mitte fast 2, plantar 1,5 , dorsal 1,4 , fibular $1 \mathrm{~mm}$ in $3,5 \mathrm{~cm}$ Entfernung. - Auf dem siebenten Schnitt in 4,1 cm Entfernung hat die Dicke der Compacta wieder abgenommen und beträgt tibial Mitte und plantar 1,2, dorsal 1,0, fibular $0,8 \mathrm{~mm}$. - Auf dem achten Schnitt $(4,7 \mathrm{~cm}$ Entfernung) ist die Compacta tibial und plantar 1,0, fibular 0,8, dorsal $0,5 \mathrm{~mm}$ dick. Der Querschnitt hat die Form einer schmalen Ellipse, deren langer Durchmesser annähernd vertikal steht, entsprechend der Form des Querschnitts am distalen Schaftende des M. IV. Bis zu diesem Schnitt erstreckt sich nach distal die Markhöhle. In der plantaren Hälfte des distalen Endes der achten Scheibe finden sich die spärlichen Anfänge der distalen Spongiosa, durchbrochene horizontale Ziige. - Auf dem neunten Schnitt (5,2 cm Entfernung), im Beginn des Köpfchens, hat sich wieder eine dorsale und eine plantare Seite ausgebildet, die plantare ist etwas schmaler als die dorsale. Fibular und tibial beträgt die Dicke der Compacta noch $0,2-0,3 \mathrm{~mm}$, plantar und dorsal ist sie nicht mehr meßbar. Die dichte Spongiosa zeigt im wesentlichen horizontale Zuige, mit unregelmäßig stehenden vertikalen Stützverbindungen. - Der zehnte Schnitt in 5,7 cm Entfernung verläuft ganz im Köpfchen. Auf diesem Schnitt finden sich vorwiegend vertikale Züge, entsprechend denen im Köpfehen 
des M. IV. Auf einem Sagittalschnitt des Köpfehens des in Pronation stehenden M. III erscheinen diese Züge als sagittal stehende, mehr oder minder große Platten.

Zusammenstellung der Dicke der Compacta des M. III.

\begin{tabular}{c|c|c|c|c}
\hline Schnitt & dorsal-tibial & dorsal-fibular & dorsal & plantar \\
\hline III & 1,0 & 0,4 & - & - \\
& tibial Mitte & fibular Mitte & & \\
IV & $\mathbf{1 , 3}$ & 0,8 & 1,0 & $\mathbf{1 , 2}$ \\
V & $\mathbf{1 , 5}$ & 0,8 & 1,0 & 1,2 \\
VI & 2,0 & 1,0 & 1,4 & 1,5 \\
VII & 1,2 & 0,8 & 1,0 & 1,2 \\
VIII & 1,0 & 0,8 & 0,5 & 1,0
\end{tabular}

Auch beim M. III zeigen wie beim M. IV die Befunde auf dem Frontalschnitt, daß am proximalen Ende die Compacta dorsal-tibial und plantar-fibular am stärksten ist. Aber dies nur ganz vorübergehend, lorsal-tibial auf dem dritten, plantar-fibular auf dem vierten Schnitt. Schon vom vierten Schnitt an ist infolge der starken Beanspruchung des M. III beim Stehen die tibiale Compacta in der Mitte am dicksten und übertrifft die fibulare Compacta beträchtlich an Dicke. Letzteres ist die Regel im Gegensatz zu dem Präparat der Fig. 1, bei welchem es sich um einen stark gewölbten Fuß handelt. Das M. III der Fig. 9 und 10 ist anscheinend beim Aufsetzen der Fußsolle beim Gehen nur wenig beansprucht worden. Dafür spricht außer dem fast völligen Mangel an Spongiosa in der distalen Schafthälfte die fast gleichmäßige Dicke der fibularen Wand in der ganzen Länge des Schaftes. Infolge stärkerer Beanspruchung beim Stehen ist durchweg die plantare Compacta dicker als die dorsale.

Die Röntgenbilder Fig. 11 der beiden Hälften eines in Pronationsstellung sagittal durchschnittenen rechten Metatarsale III zeigen sehr schön, namentlich bei Lupenbetrachtung, die Ausdehnung der horizontalen Platten im Basalteil in der Längsichtung des Knochens und ihre verschiedene Stärke in den verschiedenen Abschnitten des Basalteils. Der Schnitt ist so gelegt, daß er den Basalteil in der Richtung von der Mitte seiner Dorsalfläche nach dem plantaren Rande halbiert. Im Röntgenbilde der tibialen Hälfte des Knochens, die zwei seitliche Gelenkflächen besitzt, finden sich Längszuige, die Durchschnitte der horizontalen Platten, fast in ganzer Ausdehnung der oberen zwei Drittel des Basalteils, besonders kräftig hervortretend im oberen Drittel und in der Mitte des mittleren Drittels, 
da wo die seitlichen Gelenkflächen ihre größte Ausdehnung in der Lüngsrichtung haben. Im Röntgenbilde der fibularen Hälfte, die nur eine seitliche Gelenkfläche besitzt, finden sich kräftige Längszî̀ge nur im oberen Drittel des Basalteils, abwärts von dem distalen Ende dieser Längszüge unregelmäßige Vertikal- und schräge Züge, welche sich nach distal in den plantaren Schaftabschnitt hinein erstrecken und das proximale Markhöhlenende, welches in den oberen Abschnitt

Fig. 11.
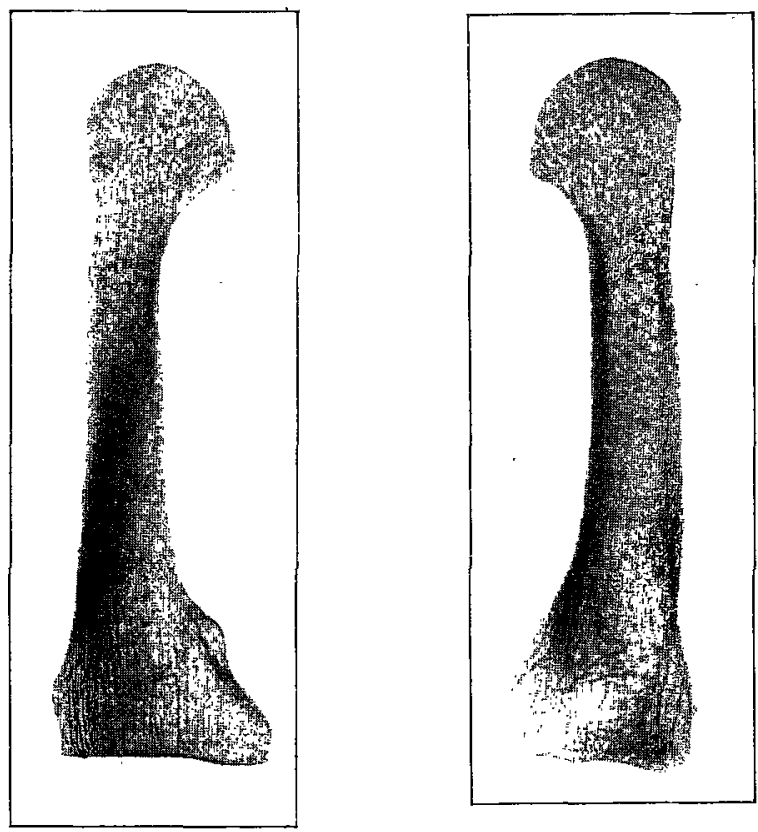

Róntgenbilder der beiden Hälften eines sagittal durchschnittenen rechten Metatarsale III. Der Schnitt halbiert den Basalteil von der Mitte seiner Dorsalfläche zum plantaren Rande. Links tibiale, rechts fibulare Hälfte.

des Basalteils himeinreicht, von unten her begrenzen. Auch in der tibialen Hälfte sind diese unregelmäßigen Vertikal- und Schrägzüge an entsprechender Stelle angedeutet. Die Längsziüge blättern zum Teil von der Compacta ab, zum Teil lehnen sie sich distalwärts an die Vertikal- und Schrägzüge an.

Die Markhöhle liegt im Präparat der Fig. 1, wie erwähnt, ganz in der proximalen Knochenbälfte. In der Regel reicht sie indes mehr oder minder weit in die distale Kuochenhälfte hinein und kann sich, wie im Präparat der Fig. 9, bis an das Köpfchen heran erstrecken. 


\section{Metatarsale II.}

Auch beim M. II finden wir in Präparaten mit reichlicher Spongiosa noch die Trajectorien der Biegungskonstruktion auf einem, dem beim M. IV und III beschriebenen entsprechenden Schnitt. Ein solcher die Dorsalfäche des Schaftes halbierender Schnitt fällt wohl regelmäßig auch in die Dorsalfäche des Basalteils, und je nachdem die Dorsalfläche des Schaftes mehr oder weniger tibial gewandt (gedreht) ist, wird der Schnitt der Mitte der Dorsalfläche des Basalteils mehr oder weniger nahe liegen. Im Präparat der Fig. 1 ist die Dorsalfläche des Schaftes stark tibialwärts gedreht. Der auf der tibialen Seite etwas zu weit plantarwärts liegende Schnitt fällt im Basalteil etwas unterhalb des tibialen Randes der Dorsalfläche.

Im Präparat der Fig. 1 treten die Trajectorien der Biegungskonstruktion in der proximalen Spongiosa mehr hervor als in der distalen. Die distale Schaftspongiosa ist in diesem Präparat nur spärlich vorhanden, doch sehen wir in ihr, auch in der Figur zu erkennen, eine Anzahl schräger von der plantaren (fibularen) Compacta ausgehender Züge, die zum Teil rechtwinkelig gekreuzt werden von Zügen, die von der dorsalen (tibialen) Compacta ausgehen. Alle diese Züge sind sehr zart. Weit schärfer ausgeprägt sind eine Anzahl Trajectorien in der proximalen Spongiosa nahe der Markhöhle. Man sieht sie (auch in der Fig. 1, plantare Hälfte, sehr dentlich, namentlich unter der Lupe) im Bereich der Markhöhle, etwa von der Mitte ihrer Längsausdehnung, abblättern und von der dorsalen (tibialen) Compacta proximalwärts in starkem Bogen zur plantaren (fibularen) Knochenwand verlaufen, auf diese zum Teil rechtwinkelig auftreffend. Rechtwinkelig gekreuzt werden diese Trajectorien von solchen, die von der plantaren (fibularen) Compacta abgehen und auf die dorsale (tibiale) Knochenwand zu verlaufen. Proximal der eben beschriebenen stark gebogenen Züge gehen von der tibialen Compacta Längszüge $a b$, welche auf die tarsale Gelenkfläche zu verlanfen und bis an diese heran zu verfolgen sind. In der Nähe der tarsalen Gelenkfläche finden sich undentliche quere Züge.

So ausgesprochen wie im Präparat der Fig. 1 finden sich die Trajectorien der Biegungskonstruktion in der proximalen Spongiosa nicht hänfig. In andern Präparaten treten an ihrer Stelle mehr schräge, sich kreuzende Züge hervor, entsprechend denen, welche ich beim M. III in der proximalen Spongiosa nahe der Markhöhle beschrieben habe. Auch findet man einzelne, nach Art der Trajectorien 
der Biegungskonstrnktion schön geschwungene Trajectorien in der Richtung der schrägen Züge aus der tibialen Compacta von plantartibial nach dorsal-fibular ziehen, gekreuzt ron Balken, die aus der fibularen Compacta kommen, entgegengesetzt verlaufend. Dann finden wir auch, wie ich das ebenfalls beim M. III beschrieben habe, nicht nur von der tibialen, sondern auch von der fibularen Compacta Längszüge in größerer Zahl ausgehen, welche leicht konvergierend auf die tarsale Gelenkfläche zu verlaufen. Wie im einzelnen Falle die Spongiosa ansgebildet ist, das hängt von der Art der Beanspruchung ab. Wird das M. II beim Stehen stark beansprucht, so werden die Längszüge mit den Schrägzügen nahe der Markhöhle in der proximalen Spongiosa besonders hervortreten.

Die dorsale (tibiale) Compacta ist in dem Präparat der Fig. 1 erheblich dicker als die plantare (fibulare), am dicksten etwas proximal der Mitte des Schaftes, $3 \mathrm{~mm}$, verjüngt sich von da nach dem Köpfchen hin stark, proximalwärts nur wenig. Die plantare (fibulare) Compacta ist fast von einem Schaftende bis zum andern gleichmäßig dick, etwa $1 \mathrm{~mm}$, in der Markhöhlengegend ein wenig dicker als distal derselben, kurz vor dem Köpfehen und vor der tiefen fibularen Rinne am Basalteil verschmälert sie sich. In einem andern Präparat finde ich die fibulare Compacta im Markhöhlenbereich ausgesprochen dicker als in der distalen Schafthälfte und etwa rou der Mitte der Knochenlänge ab sich gleichmäßig und stark nach dem Köpfchen hin verjüngend, wie ich das auch beim M. III gefunden habe. In diesem Präparat findet sich in der distalen Schafthälfte besonders reichliche Spongiosa, im übrigen etwa dasselbe Dickenverhältnis der tibialen zur fibularen Compacta wie im ersten Präparat.

Auf dem den Basalteil halbierenden Sagittalschnitt findet sich in der proximalen Spongiosa ein Bild, welches dem Bilde desselben Abschnitts des M. III entspricht, nur daß die fibulare Hälfte des M. II mit den beiden seitlichen Gelenkflächen der tibialen Hälfte des M. III und umgekehrt die tibiale Hälfte des M. II der fibularen des M. III entspricht. Unter Berücksichtigung dieses stimmt der Befund auf einem solchen Schnitt des Basalteils in beiden Knochen nicht nur hinsichtlich der Verteilung, Stärke und Länge der Längsziùge, sondern auch hinsichtlich der Vertikal- und Schrägzüge annähernd iuberein. Auch beim M. II zieht die Markhöhle oberhalb der plantar gelegenen Schrägzüge noch ein Stück proximalwärts. Ich nehme auf die Röntgenbilder eines sagittal durchschnittenen M. III, Fig. 11, Bezug, denen die von einem entsprechend durchschnittenen M. II fast gleichen. 
Im Köpfehen finden sich im Sagittalschnitt (in Pronations stellung des M. II ausgeführt) sagittal stehende Platten, die auch hinsichtlich ihrer proximalen und distalen Verbindungen denen an gleicher Stelle des M. III und M. IV entsprechen. Auf dem Horizontalschnitt erscheinen diese Platten in Längszügen, die sich ziemlich gleichmäßig von der tibialen und fibularen Compacta ablösen.

Weitere sehr bemerkenswerte Aufschlïsse über die Struktur des M. II ergeben die Befunde auf dem Frontalschnitt. Fig. 12 gibt die Röntgenbilder der ersten (von proximal) vier Scheiben eines $7,5 \mathrm{~cm}$ langen rechten M. II wieder, welches ich durch Frontalschnitte in elf

Fig. 12.

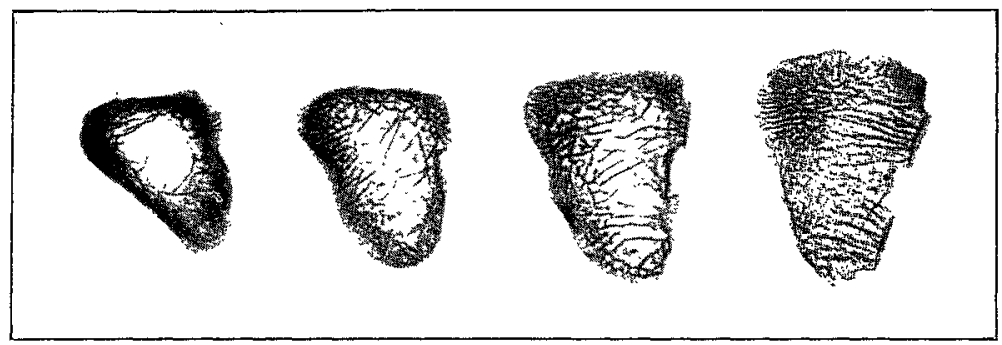

Röntgenbilder der vior ersten (proximalen) Scheiben eines durch Frontalschnitte zerlegten rechten Metatarsale Ir, jede Scheibe $4-5 \mathrm{~mm}$ diek, bei jeder Scheibe rechts fibular, links tibial, die proximalste Scheibe befindet sich rechts. An der ersten Scheibe befinden sich die tibiale nnd die plantare fibulare Gelenkflache ganz und ein Stück der dorsalen fibularen Gelenkfläche: vorwiegend horizontale Züge. An der zweiten Scheibe befindet sich nur noch ein Stück der dorsalen fibularen Gelenkfl̈che: neben horizontalen finden sich nach der distalen Seite der Suheibe hin schräge Zũge, welche nach einem Knochenkern an der tibialen Seite der Scheibe konvergieren. Auf dem Bilde der Jritten Scheibe scbräge Züge entsprechend denen in der zweiten, nach dorsal und fibular gekreuzt von einigen bogenförmigen Zügen. Die Mirkhöhle reicht soeben in den oberen distulen $\Delta \mathrm{b}-$ sehnitt der dritten Scheibe hinein. In der vierten Scheibe deutliche Konturlamelle.

annähernd gleich dicke Stiicke zerlegt habe. Auf dem Röntgenbilde der ersten Scheibe sehen wir zwischen den beiden dorsalen seitlichen Gelenktächen annähernd horizontale Züge leicht gebogen verlaufen, deren Enden zu den Gelenkflächen rechtwinkelig stehen, ähnlich wie wir dies beim M. III und M. IV gesehen haben. Da die beiden Gelenkflächen verschieden hoch stehen, die tibiale weiter dorsalwärts reicht als die fibulare und die fibulare weiter plantarwärts als die tibiale, so erreichen die oberen zur tibialen Gelenkfü̈che rechtwinkelig stehenden und die unteren zur fibularen Gelenkfläche rechtwinkelig stehenden Züge die gegenïberliegende Gelenkfläche nicht, sondern treffen entweder auf die dieser benachbarten Knochenwand auf oder verlieren sich, noch ehe sie diese erreichen, im Ge- 
webe. Die zur tibialen Gelenkfläche rechtwinkelig stehenden Züge stehen weit dichter als die zur dorsalen fibularen Gelenkfläche rechtwinkelig stehenden. Erstere gehen, auch soweit die Gelenkflächen einander gerade gegenüberliegen, nicht sämtlich in die zur dorsalen fibularen Gelenkfläche rechtwinkelig stehenden Züge über, sondern verlieren sich zum Teil in ein dichtes Maschenwerk, welches die dorsale tibiale Ecke ausfüllt. Auch im Bereich der unteren fibularen Gelenkfläche finden wir zu dieser rechtwinkelig stehende annähernd horizontal verlaufende Züge. Diese erreichen nicht alle die gegenüberliegende Knochenwand, sondern verlieren sich zum Teil im Gewebe, bevor sie auf jene auftreffen. Dieses Gewebe nahe dem unteren tibialen Rande besteht, ähnlich wie auf derselben Seite oben, aus ziemlich dichten Rundmaschen. Im Präparat deutlicher als im Röntgenbilde finden wir in der tibialen Hälfte der Scheibe eine Anzahl vertikaler Züge, welche dem tibialen Rande annähernd parallel laufen, zu den horizontalen Ziigen rechtwinkelig stehen und nach oben und unten sich in das Rundmaschengewebe verlieren.

An der zweiten Scheibe findet sich nur noch die dorsale fibulare Gelenkfläche. Auf der proximalen Seite dieser Scheibe sieht man zunächst noch horizontale Züge, die auf der Gelenkflïche rechtwinkelig stehen und zum Teil die gegenuiberliegende Seite erreichen. Auch hier findet sich in der dorsalen tibialen Ecke ein dichtes Maschenwerk, ebenso zunächst nocb in der tibialen Hälfte Längszüge entsprechend denen bei Scheibe I erwähnten. Nach der distalen Seite der zweiten Scheibe hin treten schräge Züge hervor, welche von dorsal und von fibular her, und zwar in zahlreichen Strablen von der ganzen Höhe der fibularen Seite her, konvergieren nach einer nmschriebenen Stelle etwas unterhalb der Mitte der tibialen Seite. An dieser Stelle findet sich eine kleine Verdickung: der Knochenwand (noyau de renforcement [BouRGERY]), die sich auf dem Röntgenbilde (Fig. 12) deutlich kennzeichnet. Gekreuzt werden diese schrägen Züge meist rechtwinkelig durch bogenförmig verlaufende Züge, welche annühernd einen Halbkreis bilden. Der am weitesten peripher gelegene bogenförmige Zug beginnt mit dem einen Ende in der dorsalen tibialen Ecke, verläuft nahe der dorsalen und der fibularen Knochenwand und endet in der plantaren Ecke. Solcher bogenförmigen Züge verlaufen mehrere einander annähernd parallel. Am vollständigsten ist der am weitesten peripher gelegene, nach dem Knochencentrum zu sind sie mehr oder weniger unvollständig. Im Röntgenbilde der zweiten Scheibe (Fig. 12) sind die 
schrägen konvergierenden Ziige dentlich zu erkennen, nicht aber die kreuzenden bogenförmigen. Angedeutet sind letztere auf dem Röntgenbilde der dritten Scheibe, auf dem sich die schrägen Züge auch noch finden. Um die bemerkenswerten bogenförmigen Züge deutlich darzustellen, füge ich eine schematische Zeichnung der distalen Seite der zweiten Scheibe bei (Fig. 13a).

Weiter distal, im Beginn der Markhöhle, auf der distalen Seite der dritten Scheibe, $1,5 \mathrm{~cm}$ Entfernung von der tarsalen Gelenkfläche, schließt sich der peripherste bogenförmige Zug zu einem an$\mathrm{n} \ddot{\mathrm{a} h e r n d}$ vollständigen $\mathrm{Kreis}$, indem er von der dorsalen tibialen Eeke auch an der tibialen Knochenwand herunterläuft bis etwa zu deren Mitte und in der Mitte der fibularen Seite tibialwärts herumbiegt und bis nahe an die Mitte der tibialen Knochenwand herangeht (Fig. $13 b$, die ich beigefügt habe, da auf dem Röntgenbild der dritten Scheibe, Fig. 12, der kreisförmige Zug nicht hinreichend deutlich ist). Zwischen der plantaren Rundung dieses kreisförmigen Zuges, die nur wenig nach abwärts von der Mitte der dorsal-plantaren Knochenhöhe herunterreicht, und

Fig. 13.

a $b$

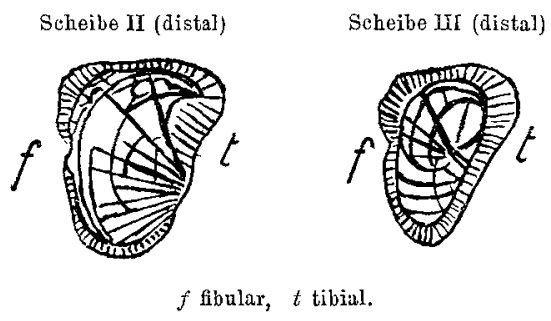
der plantaren Knochenecke finden sich drei Züge, welche leicht bogenförmig parallel zu jener Rundung von der fibularen zur tibialen Knochenseite verlanfen und die Schnitte von Lamellen sind, die sich von distal her plantarwärts ans der Compacta ablösen, um weiter proximal in die untersten annähernd horizontalen der nach tibial konvergierenden Züge überzugehen. Schräge Züge finden sich auf der distalen Seite der dritten Scheibe nur innerhalb des kreisförmigen Zuges, mit der Hauptrichtung dorsal-fibular-plantar-tibial; besonders hervor tritt ein starker Balken, welcher aus der dorsalen fibularen Ecke zur Mitte der tibialen Seite verläuft (Fig. 13 b). Gekrenzt werden diese schrägen Züge von einigen bogenförmigen Zügen, welche im wesentlichen die Richtung dieser Züge auf der distalen Seite der zweiten Scheibe innehalten.

Noch schärfer tritt der kreisförmige Zug innerhalb. der vierten Scheibe von proximal hervor, die bis $2 \mathrm{~cm}$ von der tarsalen Gelenkfläche reicht. Hier findet sich auf beiden Seiten der Scheibe eine geschlossene Konturlamelle mit annähernd kreisförmigem Quer- 
schnitt, welehe der Knochenwand, abgesehen von der plantaren Knochenecke, nahe anliegt. Wie die weiter distalen Frontalschnitte zeigen, löst sich diese Konturlamelle von distal, von der Mitte der Knochenlänge her, ringförmig aus der Compacta ab und verläuft, trichterförmig sich erweiternd, auf die proximale Spongiosa zu. Rings umgeben ist die Konturlamelle von Tubuliquerschnitten, die bereits auf der proximalen Seite der vierten Scheibe einen Kranz zwischen Lamelle and Knochenwand mit einer kleinen Lücke im plantaren Winkel, auf der distalen Seite dieser Scheibe einen vollen Ring bilden. Diese in der Knochenlängsrichtung verlaufenden Tubuli beginnen mit sehr feinem Lumen zusammen mit der Konturlamelle nahe der Knochenmitte, erweitern sich nach proximal und dringen in die proximale Spongiosa ein, in welcher sie sich namentlich, wie wir sahen, in der dorsalen Knochenbälfte und hier wieder in der tibialen dorsalen Ecke zahlreich finden. Auf dem Röntgenbilde der vierten Scheibe sind die Kontarlamelle und die sie umgebenden Tubuliquerschnitte deutlich zu erkennen. Mit der Lupe sieht man in der dorsalen Compacta zahlreiche sehr feine Lumina, die distalen Anfänge weiterer Tubuli, die sich erweiternd ebenfalls aus der Compacta ablösen und nach proximal in die Spongiosa, namentlich in der tibialen dorsalen Knochenecke, eindringen, so daß sich hier weiter proximal eine größere Anhäufang von Tubuliquerschnitten findet.

Die Konturlamelle läßt sich distal verfolgen durch die fünfte Scheibe bis Schnitt V (2,5 cm Entfernung), wo ihre Abblätterung. aus der Compacta in der tibial-dorsalen und in der plantaren Ecke eben begonnen hat, und in ersterer Ecke noch ein Stiick in die secbste Scheibe hinein. Auch auf Schnitt $V$ finden sich zwischen Lamelle und Knochenwand, so weit jene abgeblättert ist, Tubuliquerschnitte.

Diese Konturlamelle habe ich in allen Präparaten mehr oder minder ausgesprochen gefunden, nicht immer so weit distal reichend, auch nicht immer in der ganzen Peripherie sich von der Compacta abhebend. In einigen Präparaten sah ich sie in die distale Schafthälfte sich hinein erstrecken, besonders wenn diese mit reichlicher Spongiosa gefullt war, und eine Verbindung zwischen proximaler und distaler Spongiosa herstellen. Es besteht in dieser Hinsicht eine Ähnlichkeit mit dem Metatarsale I. Auch bei diesem finden sich, wie wir sehen werden, Konturlamellen in der Umgebung der Markhöhle, deren Lage entsprechend in der distalen Knochenhälfte, und auch beim $M$. I habe ich eine Verbindung zwischen distaler und proximaler Spongiosa im Anschluß an eine Konturlamelle festgestellt. Dic 
entsprechenden Feststellungen beim M. II sind ein Beweis für seine Inanspruchnahme als Hilfsstütze bei der Abwicklung des Fußes beim Gehen.

Wie wir gesehen haben, erstreckt sich die Konturlamelle im proximalen Markhöhlenabschnitt bis unmittelbar an die proximale Spongiosa heran und stützt sich hier auf die Schicht der schrägen von dorsal-fibular nach plantar-tibial konvergierenden Züge. Diese bilden ein kräftiges, sehr zweckentsprechendes Widerlager. Der Knochenkern in der tibialen Wand des Basalteils, nach welchem die schrägen Züge konvergieren, liegt ein wenig abwärts der plantaren Rundung des proximalen Endes der Konturlamelle. Da wo dieses bei seinem Aufstoßen auf die proximale Spongiosa eines besonders kräftigen Widerlagers bedarf, in seinom plantaren, sich nicht unmittelbar an die Knochenwand anlehnenden Abschnitt, stößt es auf die hier sehr dicht stehenden schrägen Züge nahe ihrer besonders widerstandsfahigen Vereinigungsstelle in dem Knochenkern auf. Daß als Widerlager für die Konturlamelle schräge, nach tibial konvergierende Ziige dienen, hat seinen Grund in der besonderen Beanspruchung der tibialen Knochenseite bei der Funktion des Metatarsale II als Hilfsstuttze bei der Abwicklung des Fußes. Diese Bealspruchung macht eine möglichst gleichmäßige Verteilung des auf die tibiale Knochenseite einwirkenden Druckes nach der fibularen und dorsalen Seite hin erforderlich, und eine solche Druckverteilung ist durch die von tibial nach dorsal und fibular divergierenden Balken erreicht. Das Zusammentreffen der Balken gerade am Ort des Knochenkerns ist durch die vorher erörterten Umstände bedingt.

Nach Kenntnis der Anordnung der Zitge in der proximalen Spongiosa auf den verschiedenen Frontalschnitten wird uns klar, daß die auf dem Schrägschnitt durch den Basalteil für die Biegungskonstruktion oder auf einem der Dorsalfläche des Basalteils parallelen Schnitt getroffenen Längsziuge, welche von den proximalen Compactaenden gegen die tarsale Gelenkfläche ausstrahlen, namentlich die von der tibialen Compacta her, nicht in ihrem ganzen Verlauf durch die proximale Spongiosa gleich gerichtet sind. Die von der tibialen Compacta ausstrahlenden Längsziuge, als Platten gedacht, wie wir sie tatsächlich vielfach finden, stehen nach der tarsalen Gelenkfläche hin mehr vertikal (sagittal), nach der Markhöble hin konvergieren sie gegen die tibiale Knochenwand. Diese selben schräg stehenden, gegen tibial konvergierenden, gegen fibular divergierenden Platten erscheinen auch auf dem den Basalteil halbierenden Sagittalschnitt 
als Längszüge, an die sich proximal im Bereiche der seitlichen Gelenkflächen die Schnitte der horizontalen Platten anschließen. Auch auf dem Sagittalschnitt sind also die Platten, deren Schnitte als Längszüge erscheinen, im proximalen und distalen Abschnitt der proximalen Spongiosa verschieden gerichtet. Bei genanerer Betrachtung kann man zuweilen auf dem Sagittalschnitt die Grenze zwischen den horizontal and schräg stehenden Platten an einem Absatz erkennen, der sich im Verlaufe der im übrigen geradlinigen Längszüge findet. Die Lage dieses Absatzes entspricht dem distalen Ende der dorsalen fibularen Gelenkfläche, dieses überschreiten die horizontalen Platten nach distal nicht. In der plantaren Knochenhälfte, in welcher die nach tibial konvergierenden Platten annähernd horizontal liegen, ist ein solcher Absatz in der Regel nicht zu erkennen. Hier gehen die zur plantaren fibularen Gelenkfläche rechtwinkelig stehenden Platten in jene unmittelbar über.

Die Befunde anf dem Frontalschnitt bringen uns ferner zu der Überzeugung, daß die Trajectorien der Biegungskonstruktion im Bereiche der Markhöhle in der Konturlamelle verlaufen. Die oben beim Schrägschnitt durch den Basalteil erwähnten, im Bereiche der Markhöhle abblätternden proximal verlaufenden Trajectorien sind Durchschnitte einer Konturlamelle, welche sich auf ihrem Verlauf von distal her gegen das proximale Ende der Markhöhle hin teilt, wie das auch aus Fig. 1 ersichtlich ist. Die Lamellenschnitte verlaufen bis zum proximalen Markhöhlende der Compacta annähernd parallel und biegen erst beim Eintritt in die Spongiosa. nach der entgegengesetzten Knochenwand um. Auf dem Frontalschnitt läßt sich dieses Umbiegen nicht erkennen, auf diesem sehen wir nur am proximalen Markhöhlenende die Konturlamelle sich scharf gegen die schräg verlaufenden Züge absetzen, wir sehen, wie sie sich gewissermaßen auf diese stützt bzw. durch sie gestützt wird. Ohne Zweifel werden die Konturlamellen ganz vorwiegend bei der Funktion des Metatarsale II als Hilfsstütze des M. I bei der Abwicklung des Fußes beim Gehen beansprucht, für diese Funktion sind sie gebildet, nebenbei verlaufen in ihnen aber noch die nur in geringer Zahl vorhandenen und wenig bedeutungsvollen Trajectorien der Biegungskonstruktion von distal her bis zum proximalen Markhöhlenende.

Ich komme jetzt zu den Dickenverhältnissen der Compacta auf dem Frontalschnitt. Abgesehen von dem kleinen Knochenkern in der tibialen Wand des Basalteils (Scheibe II Fig. 12) findet sich Compacta in erheblicherer Stärke zuerst auf Schnitt III, im Beginu 
der Markhöhle. Hier tritt sie gleich in beträchtlicher Dicke von $2 \mathrm{~mm}$ im tibial-dorsalen Winkel auf (Sćheibe III Fig. 12). Auch in der übrigen dorsalen Wand und in der fibularen Wand plantarwärts des tiefen fibularen Einschnitts findet sie sich bereits in einer Dicke von $1 \mathrm{~mm}$. Auf Schnitt IV ist die Compacta im ganzen Umfange des Schnittes stärker entwickelt, im tibial-dorsalen Winkel $3 \mathrm{~mm}$, im fibular-dorsalen Winkel $2 \mathrm{~mm}$, dazwisehen in der Mitte des dorsalen Randes $1 \mathrm{~mm}$ dick, in der fibularen Wand nahe dem plantaren Winkel 1,5, im übrigen, besonders in der tibialen Wand, $1 \mathrm{~mm}$ (Scheibe IV Fig. 12). - Auf Schnitt V tritt die erhebliche Dicke der Compacta im tibial-dorsalen Winkel noch stärker hervor, besonders da auch die Form des Schnittes eine andre geworden ist. Bisher hatte er die Form eines Dreiecks mit abgerundeten Ecken mit kurzer dorsaler und längerer tibialer und fibularer Seite, zunächst im Bereiche der seitlichen Gelenkflächen mehr die eines gleichschenkeligen, weiter distal eines rechtwinkeligen Dreiecks, dessen rechter Winkel dorsal-fibular liegt. Auf Schnitt IV mißt die längere fibulare Kathete 1,4, die kürzere dorsale 1,2 $\mathrm{cm}$. Auf Schnitt $\mathrm{V}$ in $2,6 \mathrm{~cm}$ Entfernung von der tarsalen Gelenkfläche ist die Form zwar auch noch annähernd rechtwinkelig dreieckig, rechter Winkel dorsal-fibular, aber die fibulare Kathete ist jetzt kürzer als die dorsale, $0,9: 1,1 \mathrm{~cm}$, der tibiale Winkel ist spitzer geworden als der plantare, der Knochen ist in seinem Querschnitt nach der Stelle der dicksten Compacta, dem tibialen Winkel, gewissermaßen spitz ausgezogen. In diesem Winkel beträggt die Dicke der Compacta 3,2, dorsal Mitte 1,2, fibular Mitte 2, tibial nahe dem plantaren Winkel $1 \mathrm{~mm}$. Im dorsal-fibularen Winkel ist die Compacta nicht mehr dicker, sondern dünner als in der übrigen fibularen Wand. - Auf Schnitt VI in $4 \mathrm{~cm}$ Entfernung. ist die Form des Querschnitts wiederum anders. Während die fibulare Seite dieselbe Länge behalten hat wie auf Schnitt $V$, hat sich die dorsale Seite weiter verkleinert und ist jetzt ebenso lang wie jene, $9 \mathrm{~mm}$, dabei ist der dorsal-fibulare Winkel ein wenig kleiner als ein Rechter infolge Drehung der dorsalen Knochenfläche tibialwärts. Die Dicke der Compacta hat im tibial-dorsalen Winkel auf Schnitt VI etwas abgenommen, ist hier aber immer noch ganz auffallend, fast $3 \mathrm{~mm}$, im plantaren Winkel $2 \mathrm{~mm}$, fibular Mitte 1,2, im fibular-dorsalen Winkel $1 \mathrm{~mm}$. - Auf Schnitt VII in 4,8 cm Entfernung ist die Form des Querschnitts noch annähernd dieselbe, die fibulare Seite ist noch fast $9 \mathrm{~mm}$, die dorsale $8 \mathrm{~mm}$ lang, nur hat sich die tibialwärts gedrehte dorsale Wand etwas tibial-dorsal vorge- 
wölbt für die Bildung der alsbald aus ihr hervorgehenden dorsalen und tibialen Wand, indem alsdann die bisherige tibiale Wand zur plantaren wird. Die Dicke der Compacta beträgt im tibial-dorsalen Winkel fast 2, im plantaren Winkel 1,2, im fibular-dorsalen Winkel und in der ganzen fibularen Wand kaum $1 \mathrm{~mm}$.

Etwa in der Mitte der achten Scheibe, die bis etwa $5,8 \mathrm{~cm}$ von der tarsalen Gelenkfläche reicht, ist das distale Ende der Markhöhle, auf Schnitt VIII findet sich dichte Spongiosa. Die Form des Querschnitts ist auf diesem Schnitt bereits annähernd viereckig durch Ausbildung einer dorsalen und einer tibialen Wand ans der bisherigen dorsalen, nur ist der tibial-dorsale Winkel noch stärker gerundet. Die Maße auf Schnitt VIII sind: in tibial-fibularer Richtung $8 \mathrm{~mm}$ wie auf Schnitt VII, in dorsal-plantarer Richtung fast $1 \mathrm{~cm}$. Stärkere Compacta findet sich auf Schnitt VIII noch in der tibialen Wand nahe dem tibial-plantaren Winkel, sie ist hier $1,5 \mathrm{~mm}$ dick. In der plantaren Knochenwand ist die Compacta noch fast $1 \mathrm{~mm}$, an den übrigen Seiten noch nicht $1 / 2 \mathrm{~mm}$ dick. In der Spongiosa findet sich auf Schnitt VIII der Knochenwand zunächst, wie am proximalen Schaftende, der Querschnitt einer fast ununterbrochen ringsherum laufenden Konturlamelle, zwischen ihr und der Knochenwand Tubuliquerschnitte, innerhalb der Konturlamelle im wesentlichen horizontale Züge. Eine Ablösung dieser Konturlamelle aus der Compacta von proximal her auf ein irgend größeres Stiick ist nicht nachzuweisen, auf Schnitt VII findet sich noch keine Spur Spongiosa. In einem andern Präparat, in welchem proximale und distale Spongiosa miteinander in Verbindung stehen, finde ich dorsal und tibial eine Lamelle rom proximalen bis zum distalen Markhöhlenende und noch ein Stück in die distale Spongiosa hinein bis nahe an das Capitulum heran verlaufen. Häufig scheint eine derartige Verbindung indes nicht zu sein.

Mit dem Beginn des Köpfchens, Schnitt IX, 6,2 cm Entfernung; findet sich ringsum nur noch die dünne Umhïllungsplatte der Spongiosa. In dieser treten hier im wesentlichen schräge, von dorsal-tibial nach plantar-fibular verlaufende, nach dem plantar-tibialen Winkel leicht konvexe Zuige hervor. Auf Schnitt X, 6,6 cm Entfernung, finden sich dann die bekannten vertikalen Ziuge, die Schnitte der sagittalen Platten, die hier unter sich und mit den seitlichen Knochenwänden durch besonders zahlreiche und kräftige quere Züge verbunden sind. - Bemerkenswert ist die wesentlich kräftigere Entwicklung des Köpfehens beim M. II im Vergleich zun M. III und 
M. IV. Es ist durchschnittlich erheblich breiter als die Köpfchen von M. III and M. IV.

Zusammenstellung der Compactadicke auf dem Frontalschnitt.

\begin{tabular}{c|c|c|c|c|c}
\hline \hline Schnitt & $\begin{array}{c}\text { tibial- } \\
\text { dorsaler } \\
\text { Winkel }\end{array}$ & $\begin{array}{c}\text { dorsal } \theta \\
\text { Wand } \\
\text { Mitte }\end{array}$ & $\begin{array}{c}\text { fibular- } \\
\text { dorsaler } \\
\text { Winkel }\end{array}$ & $\begin{array}{c}\text { plantarer } \\
\text { Winke11) }\end{array}$ & $\begin{array}{c}\text { tibiule } \\
\text { Wand } \\
\text { Mitte }\end{array}$ \\
\hline III & 2,0 & 1,0 & - & 1,0 & - \\
IV & 3,0 & 1,0 & 2,0 & 1,5 & 1,0 \\
V & 3,2 & 1,2 & 1,2 & 2,0 & 1,5 \\
VI & 3,0 & 1,0 & 1,0 & 2,0 & 1,5 \\
VII & 2,0 & 1,0 & 1,0 & 1,2 & 1,3 \\
VIII & 1,52 & 0,5 & 0,5 & 0,5 & $1,03)$
\end{tabular}

1) bzw. fibulare Wand unten. - g) tibiale Wand unten. 3) plantare Wand.

Die Stärke der Compacta in dem vorspringenden tibialen Winkel ist auf allen Frontalschnitten gegeniiber ihrer Stärke an den andern Stellen der Wand so iberwiegend, daB es nicht zweifelhaft ist, daß das Metatarsale II auf der tibialen Seite besonders stark beansprucht wird. Diese Beanspruchung erfolgt bei der Funktion des M. IL als Hilfsstiitze bei der Abwicklung des Fußes beim Gehen. Die demnächst stärkste Compactaentwicklung findet sich in der fibularen Wand nahe dem plantaren Winkel, wie wir dies anch beim M. III und M. IV gefunden haben, als Folge der Beanspruchung des M. II auf Biegung beim Aufsetzen der Frßsohle beim Gehen. Bemerkenswert ist noch eine stärkere Verdickung der Compacta am proximalen Ende des Schaftes im dorsofibularen Winkel, die auf Schnitt IV hervortritt (Fig. 12 Scheibe IV). Diese Verdickung ist bedingt durch die Notwendigkeit einer besonders starken Verbindung des Schaftes mit dem Basalteil an der Dorsalseite, bei der besonders starken Beanspruchung des M. II auf dieser Seite, die bei der Abwicklung des Fußes allerdings rorwiegend am tibialen Rande, aber doch auch am fibularen Rande erfolgt. Proximalwärts löst sich die starke Compacta der Dorsalseite am tibialen und fibularen Rande in deu Basalteil hinein in dicht stehende Tubuli auf, deren Durchschnitte auf Fig. 12 in den Bildern der Scheiben III und IV deutlich sind, die sich aber auch weiter proximal zwischen die horizontalen Zuige im Bereich der seitlichen Gelenkflichen bis zur tarsalen Gelenkfläche hiu erstrecken (dichtes Maschenwerk namentlich in der dorsal-tibialen Ecke der Scheiben I und II). 
Wie schon erwähnt, findet sich eine besonders starke Entwicklung der Compacta am proximalen Schaftende dorsal-tibial und plantar-fibular wie beim M. II so auch beim M. III und M. IV, bei allen drei Metatarsalien ist an diesem Schaftende die Compacta dorsaltibial in der Regel beträchtlich dicker als plantar-fibular: ein Hinweis darauf, daß diese drei Metatarsalien gleichartig beansprucht werdea. DaB aber das M. II ankerdem noch in wesentlich andrer Weise beansprucht wird, dafür spricht, abgeseben von andrem, die besondere Form seines Querschnitts in der proximalen Schafthälfte, welche sich von der Form des Querschnitts des M. III und M. IV in derselben Gegend wesentlich unterscheidet. Wäbrend beim M. III und M. IV am proximalen Schaftende bis gegen die Mitte des Schaftes hin der Querschnitt annähernd die Form einer Ellipse hat, deren lange Achse in ihrer Richtung der Vertikalen mehr oder minder nahe kommt, ist beim M. II die Querschnittsform in dem entsprechenden Knochenabschnitt ausgesprochen rechtwinkelig dreieckig mit dem rechten Winkel dorsal-fibular und einem spitcen Winkel dorsal-tibial, der sich von proximal nach distal beständig verkleinert. Diese Querschnittsform des M. II diurte bedingt sein durch seine Beanspruchung als Hilfsstiitzc bei der Abwicklung des Fußes, eine Funktion, welche auch die starke Anhäufung von Compacta im tibial-dorsalen Winkel zur Folge hat und bewirkt, daß sich die Knocheuwand in dieser Richtung: tibial-dorsal in Form eines Winkels spitz auszieht.

Bemerkenswert ist noch die Übereinstimmung des Querschnitts des M. II in der distalen Schafthälfte mit dem Querschnitt des Schaftes des M. I. Bei beideu ist die dorsale Fläche anfangs gewölbt, und aus ihr entwickelt sich gegen das Capitulum hin eine dorsale und eine tibiale Fläche, während die vorher tibiale Fläche sich, je weiter distal, desto mehr plantarwärts neigt, bis sie schließlich im Köpfehen zur plantaren Fläche geworden ist. Auch der Ansatz des Schaftes an das Köpfehen hat beim M. II einen Querschnitt, welcher Ähnlichkeit hat mit dem des M. I an dieser Stelle, breit, viereckig, wesentlich anders als beim M. III und M. IV. Weitere Hinweise, daß das M. II in ähnlicher Weise beansprucht wird wie das M. I.

Gegenüber der Beanspruchung des M. II als Hilfsstiitze bei der Abwicklung des Fußes macht sich die Beanspruchung beim Stehen in ihrem Einfluß auf die Dicke der Compacta weniger geltend. Sie findet ihren Ausdruck in einer größeren Stärke der Compacta im plantaren Winkel in der Mitte des Schaftes gegenüber der dorsalen 
Compacta (dorsale Wand Mitte) in diesem Knochenabschnitt. Auch weiter distal iberwiegt die plantare Compacta die dorsale, erreicht aber nirgends in ihrer Dicke die tibiale (tibial-dorsaler Winkel), wie dies beim M. III der Fall ist.

Die Markhöhle liegt nur verhältnismäßig selten bei reichlicherer Spongiosa ganz in der proximalen Knochenhälfte wie in Fig. 1. Meist reicht die Markhöhle mebr oder minder weit in die distale Knochenhälfte hinein, öfters bis nahe an das Köpfchen heran. Ihre seitlichen Wandungen werden in der Regel nicht oder teilweise nicht von der Compacta gebildet, sondern von der diese auf eine mehr oder minder große Strecke innen auskleidenden Konturlamelle.

\section{Metatarsale I.}

Das Metatarsale I unterscheidet sich in seiner Struktur fundamental von den übrigen Metatarsalien 1 entsprechend der ganz verschiedenartigen Beanspruchnng; die ich schon eingangs hervorgehoben habe. Ganz auffallend ist bei diesem am stärksten beanspruchten Metatarsale, welches bei der Abwicklung des Fußes beim Gehen die ganze Körperlast zu tragen hat'1), die dünne Schaftcompacta. Sie wird im Präparat der Fig. 1 von der plantaren Compacta des M. V um das Dreifache übertroffen, ist auch häufig dünner als die Compacta von M. II, III, IV an ihren dicksten Stellen. Dagegen wird das M. I bei jüngeren Individuen häufig fast ganz von Spongiosa ausgefüllt, deren Trajectorien zum Teil, ähnlich denen der kurzen Knochen, von der distalen zur proximalen Gelenkfläche durchziehen, ohne in die Compacta überzugehen. Ein weiterer fundamentaler Unterschied zwischen M I und den übrigen Metatarsalien, den ich auch bereits eingangs erwähnt habe, besteht hinsichtlich der Lage der Markhöhle. Sie liegt bei Metatarsalia I mit reichlicher Spongiosa, wie in Fig. 1, in der distalen Knochenhälfte und ist rings von Spongiosa umgeben, nur bei Metatarsalia I mit stärkerer Resorption der Spongiosa reicht die Markhöhle in die proximale Knochenhälfte hinein, und die Wand der Markhöhle wird zum Teil durch die Compacta gebildet.

Die Spongiosa des M. I bietet in verschiedenen Präparaten ein recht verschiedenes Aussehen. Wir finden beim vollentwickelten

1) Abgesehen von einer Übereinstimmung des M. II mit dem M. I in maneher Beziehung infolge der Beanspruchung des M. II als Hilfsstiitze bei der Abwicklung des Fußes. Unmittelbar stiitzt hierbei das M. II nicht. 
Knochen in dem einen Prïparat eine sehr zarte und dichte Spongiosa, welche denselben bis auf die sehr kleine Markhöhle ganz ausfüllt, in einem andern Präparat recht starke statische Elementarteile, in größeren Entfernungen voneinander, dazwischen die mannigfachsten Übergänge. Eins ist aber bei all dem verschiedenen Aussehen der Spongiosa für diesen Knochen charakteristisch, die immer deutliche tubulöse Form der Spongiosa. Und zwar finden wir diese durchans nicht immer am ausgesprochensten bei jiingeren Individuen, sondern manchmal in ganz ausgezeichneter Weise bei alten. Während die Röhrchenwände bei jüngeren Individuen mit sehr dichter zarter Spongiosa oft großenteils stark durchbrochen sind, finden wir sie bei alten Individuen bei meist größerer Weite der Tubuli viel fich recht vollständig.

Um uber den Bau der Spongiosa des M. I Klarheit zu gewinnen, ist der Frontalschnitt besonders geeignet. Erwünscht ist ein Prïparat mit gut erhaltenen Tubuliwänden. Der Spongiosabau gestaltet sich einfacher und seine Beschreibung wird ibersichtlicher bei einen Präparat mit weiterer Markhöhle, deren Wand zum Teil von der Schafteompacta gebildet wird. Ich will daher ein solches Präparat der folgenden Darstellung des Spongiosabanes zugrunde legen.

Das Praparat enthailt bei $6 \mathrm{~cm}$ Länge des ganzen Knochens eine $1,3 \mathrm{~cm}$ lange Markböhle, welche $1,5 \mathrm{~cm}$ rom distalen Knochenende beginnt, also ganz in der distalen Knochenhälfte liegt. Die Markhöhle hat anuähernd die Gestalt eines Kegels mit proximaler Grundflïche und distaler Spitze. Das Präparat ist durch Frontalschnitte in neun anuähernd gleich dieke Scheiben zerlegt, deren Röntgenbilder Fig. 14 wicdergibt. Dic Markluöhlenbasis liegt in der mittelsten, die Spitze der Markhöhle in der zweiten Scheibe von distal. Nahe der Basis der Markhöhle wird die Wand derselben plantarwärts unmittelbar von der Knochenwand (Schaftcompacta) gebildet, dorsal und fibrlar trennt die Markhöhleuwand nur sehr wenig Spongiosa von der Knochenwand. Der Querschuitt der Markhöhle ist daher an ihrer Basis cutsprechend dem Querschnitt des ganzen Knochens annähernd dreicckig. Von der Basis aus verjüngt sich die von einer ausgesprochenen Kapsel umgebene Markhöhle nach distal beständig, während der Querschnitt des ganzen Knochens zunehmend größer wird. Wollen wir einmal annehmen, daß die distale Knochenhälfte in ihren Äußeren ebenfalls annähernd Kegelgestalt habe mit der Basis am Köpfehen, der abgestumpften $S_{1}$ itze in der Mitte der Knochenlänge, so stecken also zwei Kegel, ein kleinerer und ein größerer, mit ibren Spitzen 
und ihren Basen entgegengesetzt gerichtet, ineinander, so, daß die Basis des inneren, kleineren, des Markhöhlenkegels, zugleich die abgestumpfte Spitze des äußeren, größeren, des Knochenwandkegels ist. Der Markhöhlenquerschnitt nähert sich von der Basis nach der Spitze der Markhöhle hin zunächst der Kreisform, die $1 \mathrm{~cm}$ distal der Basis ausgesprochen ist, dann wird er wieder dreieckig, die Drei-

Fig. 14.
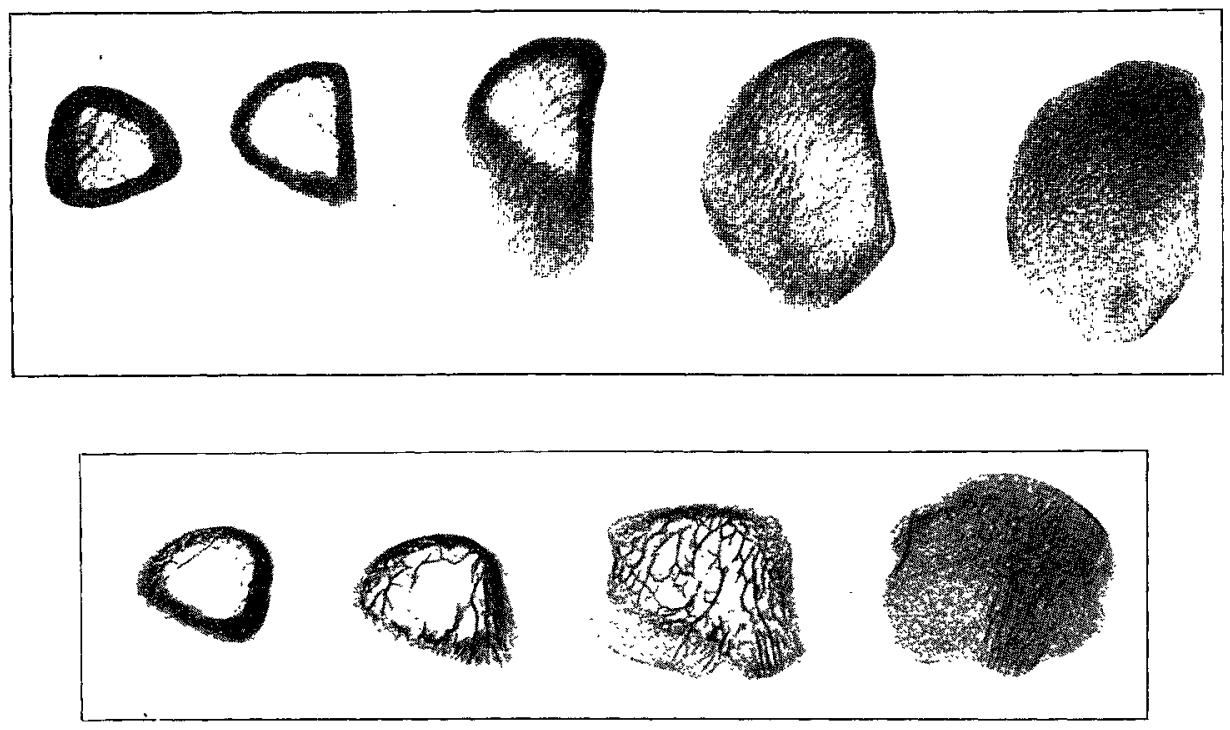

Röntgenuilder der neun Scheiben eines durch Frontalschnitte zerlegten rechten Metatarsale I, rechts oben erste, rechts unten nennte Stheibe von proximal. Bei Scheibe 1-4 und 6-9 rechts fibular, links tibial, bei Seheibe 5 (obere Reihe links, von einem dunkleren $A b z u g e$ ) rechts tibial, links fbular. In Seheibe 5 das Gitterwerk am Boden der Markhóhle. In Scheibe 7 ist die Markhöhlo wesentlich schnaler geworden, fibular, tibial und dorsal von mehr oder minder breiter Spongiosa umgeben. Markhöhlenkapsel, namentlich bei Lupenbetrachtung, deutich. Unmittelbar fibular und tibial der Kapsel stark erweiterte Tubuli. In Scheibe 8 Markhohlenspitze. Vorwiegend Züge mit annähernd vertikaler Richtung, numentlich im fibularen und mittleren Teil der Scheibe, treffen hier rechtwinkelig anf die plantare Gelenkfläche. In der neunten $\mathrm{Scheibe}$ treten neben den vertikalen Zügen ribialdorsal horizontale Züge hervor.

ecksspitze etwa in der Mitte der plantaren Seite, die gegenïberliegende dorsalwärts gewandte Seite gegen früher sehr verschmälert (Scheibe 7 distal).

Betrachten wir, dies vorausgeschickt, die einzelnen Scheiben der Reihe nach genauer, und zwar von der fünften (mittelsten) angefangen distalwärts. Da aus den Röntgenbildern das auf den einzelnen Schnitten Charakteristische nicht immer deutlich zu ersehen ist, habe ich Zeichnungen einiger Schnitte beigefügt. 
Auf der distalen Seite der fünften Scheibe ist die Compacta ringsherum fast durchweg $1 \mathrm{~mm}$ dick, nur an der fibular-plantaren Ecke verdickt sie sich auf fast $2 \mathrm{~mm}$. Auf diesem Schnitt (Fig. 15 Schnitt V, 3,1 cm Entfernung von der tarsalen Gelenkfläche), nahe distal der Markböblenbasis, ist die Compacta plantarwärts ganz dicht, ihr ist auf dieser Seite keine Spongiosa angelagert. Dagegen findet sich an der Innen-(Markhöhlen-) Seite der" dorsalen Compacta ein Kranz dicht stehender, sehr kleiner, rundlicher Lumina, die zum Teil noch ganz in der Compacta liegen, zum Teil mit ihrer Wand über die Innenseite der Compacta hervortreten. Einzelne dieser kleinen Lumina sind nach Resorption ihrer Zwischenwand zu einem etwas größeren länglichen Lumen zusammengeflossen, welches durch eine diunne Lamelle von der Markhöhle getrennt ist. Einige solche feine Lumina finden sich anch im dorsalen Abschnitt der Innenseite der fibularen Compacta.

Während auf diesem Schnitt die Markhöhle noch fast rings von Compacta begrenzt wird, hat sich auf dem nächsten Schnitt distal (Fig. 15 Schnitt VI, 3,8 cm Entfernung) fibular und dorsal als Markhöhlenwand eine Konturlamelle abgeblättert. Zwischen ihr und der Compacta liegen eine Reihe teils rundlicher, teils länglicher Lumina, die Querschnitte von Röhrehen, die zumeist auf dem vorhergehenden Schnitt sehr fein in der Compacta begannen, sich nach distal erweitert habeu und nun auf diesem - sechsten - Schnitt mit vergrößertem Querschnitt, bis zu $1 \mathrm{~mm}$ im Durchmesser, getroffen werden, zum Teil - fibularwärts - sich erst innerhalb der sechsten Scheibe aus der Compacta bildeten. Auch plantarwärts schließen sich einige sehr feine Querschnitte von soeben aus der Compacta gebildeten Röhrchen an, doch finden sie sich hier nur nahe der tibialen und fibular-plantaren Kante, nicht in dem mittleren Abschnitt der plantaren Compacta, der noch ganz dicht ist. Peripher des Kranzes weiterer Rölrchenquerschnitte anf der dorsalen Seite findet sicl am Compactaraude eine zweite Reihe sehr kleiner rundlicher Lumina, entsprechend denen auf dem nächstproximalen Schnitte. Diese kleinen Lumina in der zweiten Reihe sind hier sämtlich fast kreisrund, je zwei benachbarte scharf durch eine Wand voneinander getrennt, nirgends zwei zusammengeflossen.

Auf dem nächstdistalen Schnitt (Fig. 15 Schnitt VII, $4,4 \mathrm{~cm}$ Entfernung) finden wir bereits fibular fünf, tibial vier, dorsal und plantar je zwei Reihen von Röhrchenquerschnitten. Der Schnitt fällt nahe der Markhöhlenspitze, die tibiale Knochenwand hat sich hier 
nahe am Köpfehen aus der sich nach dorsal-tibial herauswölbenden bisherigen dorsalen Wand schon deutlich herausgebildet. Die Scheidewände $z$ wischen den einzelnen Röhrchenreihen sind ziemlich scharf ausgesprochen und laufen den betreffenden Knochenwänden annähernd parallel. Wir haben also um die Markhöhlenkapsel, die central gewissermaßen als erste Lamelle abgeblättert ist, tibial und fibular eine größere, dorsal und plantar eine kleinere Zahl von Lamellen, welche der Knochenwand dieser Seiten parallel laufen. Auf dem Horizontalschnitt überzeugen wir uns davon, daß diese Lamellen teils von der Compacta unmittelbar abblättern, teils durch Teilung einer von der

Fig. 15.

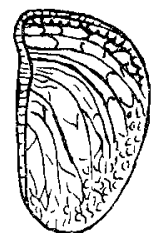

II

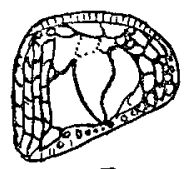

VII
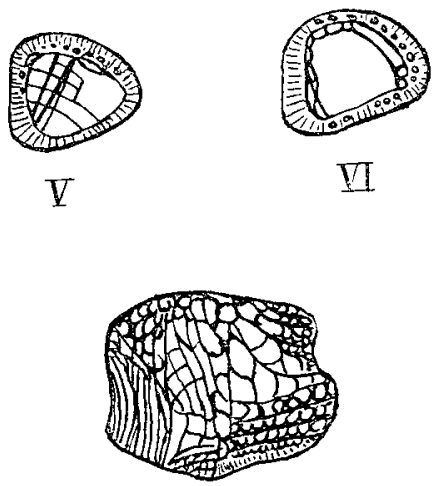

VIII

Compacta abgeblätterten Lamelle entstehen. Durch longitudinal verlaufende, zu den Lamellen annähernd rechtwinkelig stehende Zwischenwände entstehen die Röhrchenreiben zwischen den Lamellen. Die Querschnitte der Röhrchen sind anf Schnitt VII mehr länglich, elliptisch oder etwas eckig. Unmittelbar fibular und tibial der hier beträchtlich verschmälerten Markhöhle, deren Querschnitt (s. o.) annähernd dreieckig mit plantarer Spitze ist, liegen weite Lumina, die Enden der sich nach distal beständig erweiternden ersten Röhrchenreihe, deren proximaler Beginn mit weit kleinerem Querschnitt auf den nächstproximalen beiden Frontalschnitten sichtbar war. Diese zu beiden Seiten der Markhöhle gelegenen weiten Räume, deren Querschnitt unregelmäßig länglich mit dem langen Durchmesser in dorsalplantarer Richtung ist, sind dureh Verschmelzen mehrerer benachbarter Röhrchen entstanden, so daß wir seitlich der tibialen Markhöhlenwand nur einen, seitlich der fibularen zwei solche Räume haben. 
Der horizontale Durchmesser dieser seitlichen weiten Räume beträgt 2-3 mm. Sie reichen bis nahe an die plantare Knochenwand in dieser Breite heran und haben dureh ihre starke Erweiterung die Wände der auf Schnitt VI noch fast kreisförmigen Markhöhle auf der plantaren Seite gewissermaßen zusammengedrängt, so daß die fibulare annähernd vertikal stehende, leicht fibular-konvexe Markhöhlenwand und die tibiale, leicht Z-förmig gebogene, in der Richtung dorsal-tibial--plantar-fibular stehende Markböhlenwand unter sehr spitzem Winkel an der plantaren Knochenwand aufeinander treffen. Die Länge der dorsalen Dreiecksseite des Markhöhlenquerschnitts beträgt $4 \mathrm{~mm}$, sein plantar-dorsaler Durchmesser $6 \mathrm{~mm}$ bei $12 \mathrm{~mm}$ Durchmesser des ganzen Knochens in gleicher Richtnng. Die Durchmesser der Querschnitte der fibular und tibial an die großen Lumina zu beiden Seiten der Markhöhle sich anschließenden Röhrchenreihen sind in fibular-tibialer Richtung wesentlich kleiner als die Durchmesser jener Lumina in derselben Richtnng. Bei den nächst anschließenden Röhrehenreihen beträgt dieser Durchmesser kaum $1 \mathrm{~mm}$, weiter peripher nach der Außenwand des Knochens hin wird er immer kleiner bis zu $1 / 2 \mathrm{~mm}$ und weniger. -- Die Querschnitte der Röhrchen in den beiden dorsalen Röhrchenreihen sind verhältnismäßig größer als die in der zweiten fibularen und tibialen Reihe (von der Markhöhle aus), ibr kleinerer, dorsal-plantarer Durchmesser beträgt etwas iiber $1 \mathrm{~mm}$. Während die Wände dieser Röhrchen in der pcripheren, der Knochenwand anliegenden Röhrchenreile gut erhalten sind, ist die Grenzwand zwischen der centralen dorsalen liöhrehenreihe und der Markhöhle, also die Decke der letzteren, stark durchbrochen, so daß, da gleichzeitig die Trennungswände zwischen den einzelnen Röhrchen dieser centralen Reihe größtenteils geschwunden sind, die Lumina dieser mit der Markhöhle fast verschmelzen. Überhaupt erweist sich die dorsale Markhöhlenwand, sobald sie nach ihrer Abblïtterung von proximal her als solche in die Erscheinung tritt, von Anfang an mehr oder weniger stark durchbrochen, ebenso die nächst angrenzenden Teile der fibularen und tibialen Markhöhlenwand, während der größere plantare Teil der beiden letzteren Wände vollständig solide Platten sind. - Von den beiden plantaren Röbrehenreihen ist nur die periphere vollständig und zeigt fast durchweg sehr kleine Röhrchenquerschnitte, die centrale besteht nur aus einzelnen etwas weiteren Lumina, welche an den plantaren Abschnitt der beiden großen Räume zu den Seiten der Markhöhle angrenzen; sie ist durch die an die plantare Knochenwand lerangehende Spitze des Markhöhlendreiecks 
unterbrochen. - Die Compacta ist auf Schnitt VII schon fast durchweg infolge der starken Lamellenabblätterung sehr diinn, kaum dicker als die Druckaufnahmeplatte des Köpfchens, nur dorsal erreicht sie stellenweise noch knapp $1 \mathrm{~mm}$.

In der achten Scheibe, nahe ihrer distalen Seite, endet die sich immer mehr verengernde Markhöhle, abgeschlossen durch ein Gitter sehr feiner, meist in der Frontalebene liegender, aber in verschiedenen Richtungen verlaufender Bälkchen. In derselben Höhe werden auch die die Markhöhle auf Schnitt VII umgebenden größeren Hohlräume, die sich gegen die Spitze der Markhöhle wieder verengern, durch ein ähnliches Gitterwerk abgeschlossen, und auf Schnitt VII, Fig. 15, $5 \mathrm{~cm}$ Entfernung, finden wir in etwa zwei Drittel der Schnittfläche rom fibularen Rande her Zuige, die annäherud vertikal stehen. Die dem fibularen Rande nahe gelegenen von diesen Zü̈gen lanfen diesem Rande parallel, die nach der Mitte der Schnittfäche und in ihrer tibialen Hälfte gelegenen bilden mit ersteren einen plantarwärts offenen spitzen Winkel. Sämtliche vertikalen Ziige stehen mit ihren plantaren Enden rechtwinkelig zur plantaren Köpfchengelenkfläche, die hier getroffen ist; die nach dem fibularen Rande der Schnittfäche zu gelegenen Züge gehen, zum Teil nach vorausgegangener Teilung, bis unmittelbar an die Gelenkfläche heran, die mehr central gelegenen Züge enden kurz vor derselben. Anf den dorsalen Rand der Schnittfläche treffen die letzteren Züge dagegen unmittelbar auf, während die dem fibularen Rande nabe gelegenen Züge sich dorsalwärts in ein in der fibular-dorsalen Ecke befindliches unregelmäßiges Maschenwerk verlieren. Diese vertikalen Züge sind die Schnitte von Lamellen, welche die Fortsetzung der die Markhöhle fibular und tibial umgebenden Lamellen bilden, fibular sämtlicher Lamellen, welche wir auf Schnitt VII zwisehen Markhöhle und Knochenwand trafen, tibial nur der der Markhöhle zunächst gelegenen. Diese anf Schnitt VII getroffenen Lamellen haben sich zum Teil anf ihrem Zuge distalwärts geteilt, wie uns dies Horizontalschnitte zeigen. Auch auf Schnitt VIII finden wir zwischen einzelnen Lamellen Röhrchenreihen, namentlich im Centrum des Schnitts. Wie auf Schnitt VII stehen die Lamellen nahe der Peripherie des Knochens am dichtesten, nach dem Centrum desselben wird die Entferuung zwischen den einzelnen Lamellen zunehmend größer, indes finden sich im Centrum bei weitem keine so großen Räume wie anf Sehnitt VII, nur einzelne Röhrchenquerschnitte erreichen auf Schnitt VIII noch einen Durchmesser von $2 \mathrm{~mm}$. Wie auf Horizontalschnitten zu ersehen, gehen die sagittalen Lamellen, 
zum Teil nach weiterer Teilung, bis unmittelbar an die Druckaufnahmeplatte des distalen Knochenendes heran. In diesem letzten Knochenabschnitt - neunte Scheibe - stoßen diese Lamellen auch im Centrum des Knochens plantarwärts unmittelbar auf die Druckaufnahmeplatte auf, wie dies aus dem Röntgenbilde der neunten Scheibe (F'ig. 14) zu ersehen ist. - Am dorsalen Rande des Schnittes VIII finden wir nicht mehr wie auf den vorhergehenden Schnitten regelmäßige, dem ganzen Rande entlang und ihm parallel laufende Reihen von Röhrchenquerschnitten, nur im tibial-dorsalen Winkel finden wir eine Anzahl solcher Reihen, geschieden dnrch Lamellen, welehe zur tibialen Knochenwand rechtwinkelig stehen. Diese Lamellen verlaufen fibular-plantar leicht konvex, bedingt durch die Veränderang des Knochenquerschnitts, der auf Schnitt VIII eine Einziehung am tibialen Rande bietet gegenïber der Wölbung auf Schnitt VII. - Nahe dem plantaren Rande wird auf Schnitt VIII die Struktur wesentlich beeinflußt durch die starke Hervorwölbung des Köpfchens plantarwärts über die plantare Fläche des Schaftes, welche auf Schnitt VIII gegeniiber Schnitt VII besonders anffällig ist. Diese Hervorwölbung ist in den tibialen zwei Dritteln der plantaren Seite des Schnittes VIII erfolgt und beträgt gegenüber dem plantaren Rande des Schnittes VII durchschnittlich $0,5 \mathrm{~cm}$. In diesem plantaren $A b-$ schnitt des Schnittes VIII, welcher der Hervorwölbung des Köpfchens entspricht, findeu sich mehrere Reihen von Röhrchenquerschnitten, welche dem plantaren Rande des Schnittes parallel lanfen, am zahlreichsten, vier bis fünf Reihen, nach dem tibialen Raude des Schuittes hin. Diese Röhrehenquerschnitte sind in den einzelnen Reihen etwa gleich grols und erreichen noch nicht $1 \mathrm{~mm}$ im Durelsmesser. Die Richtung der Röhrehen in dem sich plantarwärts hervorwölbenden Köpfchenabschnitt ist durchweg ausgesprochen von proximal-dorsal nach distal-plantar, sie haben sich aus der dünnen plantaren Compacta, die wir noch auf Schnitt VII fanden, in der Richtung der Hervorwölbung des Köpfchens, also nach distal-plantar hin, abgelöst. Diese Schicht plantarer Röhrehenreihen trennt auf Sehnitt VIII noch die centralen sagittalen Lamellen von der plantaren Druckaufnahmeplatte der Gelenkfläche des Köpfchens.

Abgeschlossen wird die Markhöhle proximal durch ein Bälkchengitterwerk (Schnitt V Fig. 15 und Scheibe 5 Fig. 14), welches im wesentlichen in der Frontalebene steht, in der fibularen Hälfte ziemlich dicht ist, nach der tibialen Ecke hin eine Lücke hat. Es besteht aus stärkeren Bälkchen, welche aus der fibularen Knochen- 
wand, namentlich von ihrer plantaren Hälfte, auf die dorsale Knochenwand zu laufen und diese annähernd rechtwinkelig treffen. Diese stärkeren Bälkchen werden von sehr feinen Bälkchen gekreuzt, welche im wesentlichen den fibular-plantaren Winkel überbrücken, von der plantaren zur fibularen Knochenwand verlaufen und zu den stärkeren Bälkchen rechtwinkelig stehen. Der fibularen Knochenwand liegen in der fünften Scheibe rom dorsalen bis zum fibular-plantaren Winkel mehrere in longitudinaler Richtung verlaufende Tubuli an, deren Wandungen nach dem Centrum der Scheibe zu mebrfach durchbrochen sind. Diese Tubuli haben augenscheinlich zur Verbindung der proximalen und distalen Spongiosa gedient. Nach proximal schließt noch jetzt die Spongiosa unmittelbar an das Gitterwerk am Boden der Markhöhle an, auf der distalen Seite der fünften Sclueibe hören indes jene Tubuli mit offenem Lumen auf, im proximalen Ende der sechsten - aächst distalen - Scheibe finden wir von ihnen keine Spur mehr.

Fassen wir das Charakteristische des Spongiosabaues in der distalen Ḧ̈lfte des beschriebenen Präparats zusammen, so ordnen sich um eine kegelförmige Markhöhle, welche umschlossen ist von einer Kapsel, die sich als Konturlamelle von der Compacta abgeblättert hat, mit ibrer Basis bis nahe an die Mitte der Knochenlänge, mit ihrer Spitze bis an den proximalen Beginn des Köpfchens reicht, Züge von Tubuli, die in der Knochenlängsrichtung rerlaufen, proximal nach der Markhöhlenbasis hin mit sehr feinem Lumen beginnen und nach distal sich bis zur Gegend der Markhöhlenspitze trichterförmig erweitern. Die Tubulizüge werden durch Lamellen voneinander getrennt, welche entweder unmittelbar von der Compacta abblättern oder durch weitere Spaltung einer von der Compacta abgelösten Lamelle entstehen. Diese die Tubulizüge trennenden Lamellen sind nicht Konturlamellen, sondern fibular und tibial in größerer Zahl vorbanden als dorsal und plantar. Sie laufen der betreffenden Knochenwand annähernd parallel. In der Gegend der Markhöhlenspitze verengern sich die die Markhöhle fibular und tibial zunächst umgebonden Tubuli, welche sich bis dahin erweitert hatten, wieder, die der Markhöhlenwand auf diesen Seiten zunächst gelegenen Lamellen, welche sich beträchtlich von ihr entfernt hatten, nähern sich ihr wieder. Distal der Markhöhlenspitze, im Köpfchen, verläuft der größere T'eil der vertikal stehenden Lamellen, und zwar sämtliche in der fibularen Knochenbälfte und die nächstgelegenen in der tibialen Knochenhälfte, weiter distal, zum Teil sich erneut spaltend, in meist dicht stehenden Zügen bis an das distalo Knochenende heran. Diese 
vertikal (sagittal) stehenden Lamellen reichen zum Teil, namentlich im mittleren Drittel des Köpfchens, von der Planta bis zum Dorsum. In dem übrigbleibenden tibialen Absehnitt des Köpfehens finden sich Tubuliziuge, die zwar im ganzen auch in der Längsrichtung des Knochens verlaufen, aber durch mehr horizontal verlaufende Scheidewände voneinander getrennt sind.

Aus dieser Struktur in der distalen Hälfte des M. I dürfen wir schließen, daß bei der Abwicklung des Fußes beim Gehen der Druck im Köpfchen aufgenommen wird durch sagittal stehende Platten. Diese blättern ans der Compacta der distalen Schafthälfte fibular- und tibialwärts $a b$ und iibertragen auf diese Weise den Druck zunächst auf jenen Seiten nach proximal. Zugleich wird derselbe aber auch durch Lamellenzüge, welche in der distalen Schafthälfte der dorsalen und plantaren Knochenwand parallel laufen, von den sagittalen Platten im Köpfehen her aufgenommen und so im Schaft auf den ganzen Umfing desselben iibertragen. Die sagittalen Platten finden sich unr etwa iu den fibularen zwei Dritteln des Köpfchens. Hieraus folgt, daB sich bei der Abwicklung des Fußes der Körper auf den fibularen und mittleren Abschnitt des Capitulum m. I stuitzt. Als Seitenstütze dient hierbei das M. II, wie ans dessen Struktur hervorgeht. Da in der Abwicklungsperiode beim Gehen der Gesamtschwerpunkt, welcher wïhrend des Aufstehens der ganzen Fußsohle nahe dem tibialen Fußrande fiel, sich der Gangebene (mittleren durch die Gangrichtung gelegten Vertikalebene) rasch nähert und sie überschreitet, noch bevor die Abwicklung vollendet ist, da noch vor ihrer Vollendung das andre Bein anf den Boden aufgesetzt wird, so neigt sich der Körper, nachdem er sich bei der Abwicklung des Fußes auf dem fibularen und mittleren Abschnitt des Köpfehens aufgerichtet hat, nach der tibialen Seite des Köpfehens hin. Diese Neigung tibialwärts erfordert eine Stütze der sagittalen Platten auf dieser Seite, und diese Stiitze erfolgt zweckmäßig durch die horizontal, leicht bogenförmig rerlaufenden Lamellen im tibialen Köpfchendrittel.

In der proximalen Knochenhälfte bieiet die Spongiosa im wesentlichen ein einheitliches Bild. Die Compacta blättert hier von distal nach proximal in sehr dicht stehende Lamellen auf, welche der dorsalen Knochenwand parallel oder nahezu parallel laufen. Auch hier hat die Spongiosa im ganzen die tubulose Form, doch finden sich deutliche Röhrchenreihen zwischen den Lamellen nur nahe der proximalen Gelenkfläche und weiter distal nahe der dorsalen Knochenwand. Sonst findet man, namentlich nach dem Knochencentrum und 
der Planta hin die Röhrehenzwischenwände innerhalb der Lamellen vielfach durchbrochen, ebenso diese selbst, obwohl die Lamellenzüge dabei immer deutlich bleiben. Überhaupt ist die Spongiosa in der proximalen Knochenhälfte durchweg zarter als in der distalen. Das Lumen der Tubuli übersehreitet $1 \mathrm{~mm}$ im Durchmesser im allgemeinen nicht, nur durch ZusammenflieBen mehrerer Tubuli können Räume mit größerem Durchmesser entstehen. Im übrigen beginnen die Tubuli, da wo die Lamellen von der Compacta abblättern, mit sehr feinem Lumen, entsprechend ihrem Verhalten in der distalen Knochenhälfte.

Zunächst proximal der Markhöhlenbasis ist die Spongiosa etwa in der Ausdehnung von $1 \mathrm{~cm}$ der Knochenlänge noch spärlich, findet sich in derselben Gegend wie in dem Gitterwerk der Markhöhlenbasis stärker ausgesprochen und zeigt dementsprechend einige stär.kere Bälkchen und Plättchen, die, gleich gerichtet jenen an der Markhöhlenbasis, den dorsalen Winkel überbrïckend von der fibularen zur dorsalen Knochenwand verlaufen. Bälkchen- und Plättchenzïge, welche der dorsalen Knochenwand parallel laufen, sind hier noch sehr spärlich und sehr zart. Auf dieser Strecke, $1 \mathrm{~cm}$ proximal der Markhöhlenbasis, ist die Compacta noch deutlich ausgesprochen, wird aber doch dorsal und plantar diinner, während sie sich fibular noch in der Stärke von etwa $1 \mathrm{~mm}$ erhält. Weiter proximal schwindet die Compacta dorsal und plantar mit der raschen Znuahme des Knochenquerschnitts bald völlig bis auf die dünne Umhüllungsplatte, während sich fibular die Compacta länger erhält, namentlich in der dorsalen Hälfte dieser Seite, wo sie in etwa $1,5 \mathrm{~cm}$ von der proximalen Gelenkflüche eine umschriebene Verdickung zeigt (Schñitt II Fig. 15 und Scheibe 2 Fig. 14). Diese hat in der Ausdehnung ron 3 bis $7 \mathrm{~mm}$ von der dorsalen Ecke eine Dicke von $1 \mathrm{~mm}$, während dorsal und plantar dieser Stello die Compacta kaum halb so dick ist. - Von der distalen Seite der dritten Scheibe ab (Schnitt III, 2,1 cm Entfernung von der proximalen Gelenkfläche) wird die Spongiosa reichlicher und zeigt von der dorsalen Wand bis zum plantaren Winkel Züge, welche der dorsalen Wand parallel von der fibalaren zur tibialen Wand ziehen. Diesen hier durchaus vorberrschenden Zügen gegenüber sind rechtwinkelig zu ihnen verlaufende, wie wir sie in den stärkeren Bälkchen an und nahe der Markhöhlenbasis fanden, nur noch spärlich vorhanden, namentlich wie dort in dem dorsalen Winkel. - Weiter proximal (Schnitt II Fig. 15) finden wir zwar nach der dorsalen Wand hin noch Züge, die dieser parallel laufen, im unteren Abschnitt des Schnittes indes ziehen sie jener nicht mehr 
genau parallel, sondern aus dem plantaren Winkel herans auf die beselıriebene Verdickung in der fibularen Knochenwand zu. Diese Richtung behalten die Lamellen bis zum proximalen Knochenende. Sie stehen, je weiter proximal, desto dichter.

Der mittels sagittal stehender Platten im Köpfchen aufgenommene Druck, welcher durch Vermittelung horizontaler Lamellen, welche in der Umgebung der Markhöhle der dorsalen und plantaren

Fig. 16.

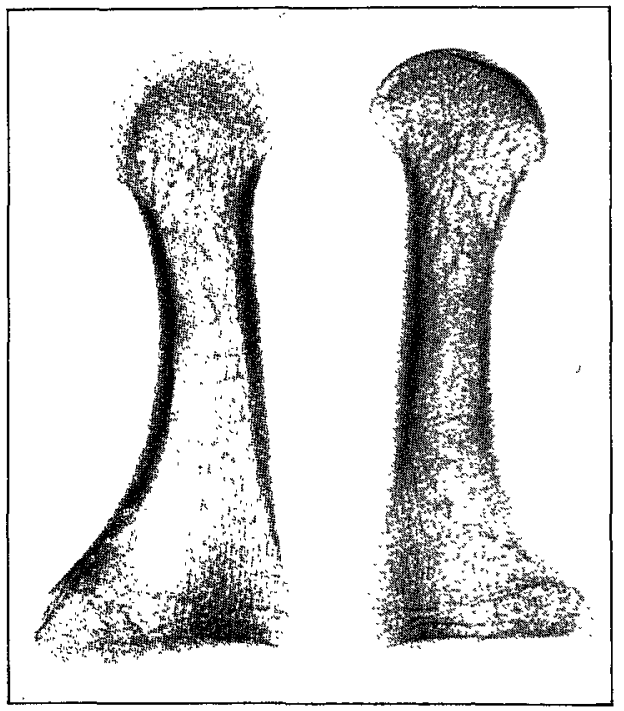

Röntgenbilder der beiden Hälften eines sagittal durchschnittenen rechten Metatarsale I, links fibulare, rechts tibiale Hälfte. Der feine Längsug etwa $1 \mathrm{~mm}$ unterhalb der dorsalen Compacta in der distalen Schafthälfte ist der Schnitt der Verbindungslamelle, namentlich in der fibularen, doeh auch in der tibialen Hälfte deutlich.
Knochenwand parallel làuen, auf den ganzen Knochenumfang iubertragen worden ist, wird also vom proximalen Ende der Markhöhle weiter auf die proximale Gelenkfläche durch Lamellen übertragen, welche im wesentlichen der dorsalen Knochenwand parallel laufen und sich hauptsächlich an die fibulare Knochenwand (Compactaverdickung!) anlehnen. Also auch in der proximalen Knochenhälfte wird das M. I fibularwärts stärker beansprucht als tibialwärts.

Auf Sagittalschnitten finden wir die vorher beschriebenen, der dorsalen Knochenwand parallelen Lamellen als Längs-

züge, welche zum Teil von distal nach proximal von der dorsalen Compacta abblättern nnd an die proximale Gelenkfläche herangehen, zum Teil, weiter plantarwärts, nach dem Knochencentrum zu, von der proximalen Gelenkfäche in gerader Richtung auf die Basis der Markhöhle zu verlaufen und sich hier oder schon früher an Querzïge anlehnen, die in der Frontalebene stehen, wie wir solche auf dem Frontalschnitt an und nahe der Markhöhlenbasis fanden (Röntgenbild Fig. 16, namentlich fibulare Hälfte). Auch in dem plantaren Fortsatz des Basalteils des Knochens finden wir auf Sagittalschnitten Längs- 
züge, die von der plantaren Compacta abblättern und anf die proximale Gelenkfläche zu gehen (Röntgenbilder Fig. 16 und 17, besonders schön Fig. 17). Diese Züge sind auf dem Frontalschnitt nicht dentlich zu erkennen. - Auf Horizontalschnitten sehen wir die Durchschnitte jener Lamellen ebenfalls als Längszitge, welche zum Teil von der tibialen und fibularen Compacta sich ablösend zur proximalen Gelenkfläche ziehen, zum Teil, die centralen Zuige, von letzterer aus die Richtung auf das proximale Markhöhlenende laben und, wie schon für den Sagittalschnitt beschrieben, an diesem Markhöhlenende oder proximal desselben an quere, in der Frontalebene stehende Stiitzelemente sich anlehnen. Die durch den Lamellenverlaufgegebene Beziehung dieser Längszüge zur fibularen Knochenwand bekundet sich auf den Horizontalschnitten dadurch, daß auch die nicht unmittelbar von der Compacta abblätternden centralen Längszüge ihre Richtung distalwärts auf die fibulare Compacta zu nehmen, geschwungen auf diese Fig. 17.

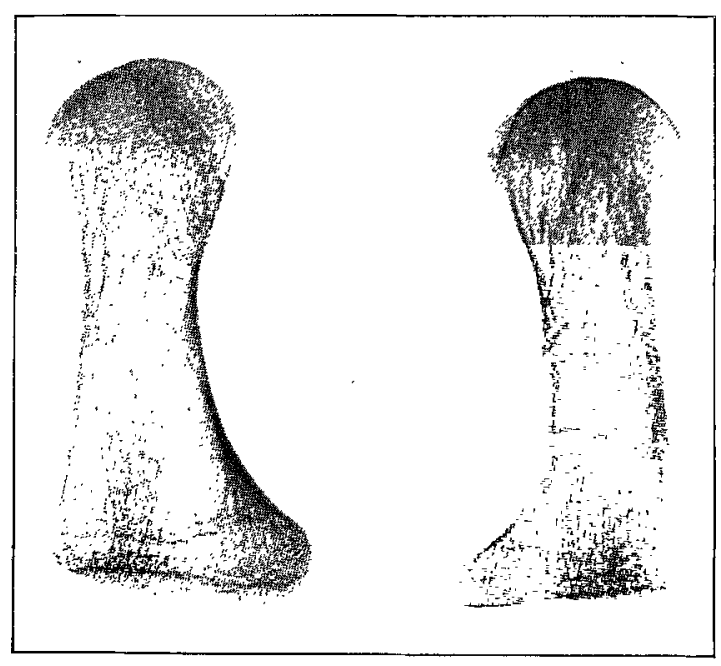

Róntgenbilder der beiden Halften einos sagittal durchschnittenen linken Metatarsale I, links fibulare, rechts tibiale Hälfte. In der fibuluren Hulfte ist namentlich die der dorsalen Compacta zunüchst gelegene Verbindusgslamelle de utlich, weniger ein weiter central gelegene. In der tibialen Fălfte sind melrfacbe Verbiudungen zwisclien distaler no proxima'er Spongiosa angedeutet. zu laufen.

Abgesehen von den erwähnten queren Zügen am Boden der Markhöhle und nalie proximal desselben finden wir in der proximalen Spongiosa auf Sagittal- und Horizontalschnitten anch weiter proximal bis zur Epiphysenlinie hin noch mehrfach mehr oder minder ausgesprocbene quere Stiutzziuge.

Eine derartige Trennung in eine proximale und distale Spongiosa, wie in dem Präparat der Fig. 11 und 15, finden wir nun in der Regel im ausgebildeten M. I nicht, und zwar nicht nur bei jüngeren Individuen, sondern auch bei älteren. Wir finden 
in der Regel eine ausgesprochene Verbindung zwischen den Lamellen in der proximalen und in der distalen Knochenhälfte, namentlich dorsal, in der Weise, daß die nahe der Mitte der Knochenlänge der dorsalen Knochenwand zunächst gelegene Lamelle der proximalen Spongiosa nicht in die Compacta ïbergeht, sondern parallel mit dieser, etwa $1 \mathrm{~mm}$ von ihr entfernt, nach distal verlänft, die Decke der Markhöhle bildet und am distalen Markhöhlenende sich mit der Köpfchenspongiosa verbindet. In einem sehr charakteristischen Präparat (Fig. 16) bildet die Lamelle nicht nur die Decke, sondern auch die tilbiale Wand der Markhöhle, iiberall von der Compacta in gleichmäßiger Entfernung bleibend, der dorsalen Compacta in gleicher Weise parallel laufend and an die fibulare Compacta in gleicher Weise sich ansetzend, wie wir dies oben auf dem Frontalschnitt in der proximalen Spongiosa gesehen haben. In dieser Weise kann dorsal die Verbindung zwischen der proximalen und distalen Spongiosa nicht nur durch eine, sondern durch mehrere Lamellen

Fig. 18.

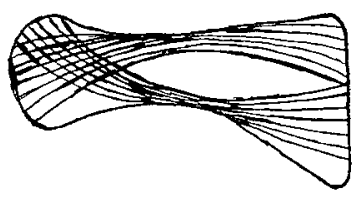
hergestellt sein. So finde ich selbst bei einem alten Individuum mit stark erweiterter Markhöhle, die bis in die proximale Knochenbälfte hineinreicht, zwei verbindende Lamellenziige nahe der dorsalen Compacta (Fig. 17). Öfters ist die dorsale Decklamelle der Markhöhle zwar solide, aber von proximal geht die Spongiosa an sie nicht in Lamellenform heran, sondern in feinen weitmaschig miteinander verbundenen Bälkchen, ein solches Maschenwerk oft in mehreren Lagen übereinander.

Wie die Röntgenbilder der sagittal durchschnittenen Metatarsalia I (Fig. 16, 17) zeigen und auch die Betrachtung der Präparate lehrt, findet eine derartige Trajectorienkreuzung im Köpfchen, wie sie H. MEXER in seiner schematischen Zeichnung (Fig. 18) darstelit ${ }^{1}$, nicht statt. Vereinzelt findet man wohl auf dem Sagittalschnitt die die Markhöhle begrenzenden Platten (Lamellen) an der Markhöhlenspitze zusammentreffen und dann leicht divergierend ihren Zug distal gegen die Gelenkfläche fortsetzen, aber derartig zahlreiche, stark geschwungen und stark divergierend auf die distale Gelenkfläche zu verlaufende Züge, wie sie $H$. Meyer darstellt, habe ich nirgends gefunden.

Während die Verbindungen zwischen proximaler und distaler Spongiosa dorsal und tibial am ausgesprochensten und zahlreichsten 1) a. a. 0 . 
sind, finden sie sich doch auch fibular, indem die an die fibulare Wand nahe dem Markhöhlenboden sich ansetzenden proximalen Lamellen- oder Balkenzüge, die stets zart sind, sich mit stärkeren, nahe der fibularen Wand in der distalen Knochenhälfte verlaufenden sagittalen Lamellen, welche in der Regel ans dieser Wand nach distal abblättern, in Verbindung setzen (Fig. 1). Plantar können die proximale und distale Spongiosa einander sehr nahe kommen, gelegentlich auch einmal miteinander in Verbindung treten, in der Regel wird aber doch an einer wenn auch nur kleinen Stelle nahe der Basis der Markhöhle die Wand der letzteren von der Compacta unmittelbar gebildet.

In ungemein interessanter Weise finde ich die Verbindung zwischen proximaler und distaler Spongiosa tibial-dorsal durch einen Knochenkern $\left.{ }^{1}\right)$ hergestellt in dem Präparat, welches Fig. 1 wiedergibt. Der Knochenkern liegt da, wo nahe dem Beginn des Köpfchens die dorsale Wand des Schaftes sich in eine dorsale und tibiale Wand zu scheiden beginnt, in dem Winkel zwischen diesen beiden Wänden, ist $1,1 \mathrm{~cm}$ lang, durchschnittlich $3 \mathrm{~mm}$ breit und schätzungsweise ebenso hoch (in Richtung plantar-dorsal). Er erstreckt sich in der Längsrichtung des Knochens annähernd parallel mit der tibialen Knochenwand von 3 bis $4,1 \mathrm{~cm}$ dieser Richtung, vom proximalen Ende her gemessen, bei $5,7 \mathrm{~cm}$ ganzer Knochenlänge. Er trägt mit etwa der Hälfte seiner Länge zur Bildung des proximalen Abschnitts der tibialen Markhöhlenwand bei, mit der andern Hälfte ragt er in die proximale Spongiosa hinein, liegt aber noch ganz in der distalen Knochenhälfte $\left.{ }^{2}\right)$. Die Markböble ist in diesem Präparat sehr klein, beginnt proximal $3,5 \mathrm{~cm}$ vom proximalen Knochenende und erstreckt sich von da $0,9 \mathrm{~cm}$ nach distal. Ihre gröBte Breite nahe der Basis beträgt $3,5 \mathrm{~mm}$ bei einer Breite des ganzen Knochens von $1,2 \mathrm{~cm}$ und einer Dicke der Compacta ron etwa $1 \mathrm{~mm}$, fibular etwas größer als tibial, in derselben Gegend. Der Knochenkern steht in seiner proximalen Hälfte nahe seinem proximalen Ende

1) A. StIeda, Über umschriebene Knochenverdichtungen im Bereich der Substantia spongiosa im Röntgenbilde (Beitr. z. klin. Chir. Bd. 45 [1905]. S. 700), fand solche Knochenkerne nicht ganz selten in kurzen Knochen und den Epiphysen der Röhrenknochen, meist von rundlicher, aber auch von ovaler Gestalt, im Fuß anßer im Talus, Calcaneus, Cuboideum, auch in den Epiphysen der Metatarsalien. Über die Beziehungen zum Verlauf der Knochenbïlkchen sagt StuEda nichts, doch dürfte hierauf zu achten sein.

2) Dies in Fig. 1 namentlich in der plantaren Hälfte deutlich. 
auf eine Strecke von 1,5 mm mit der tibialen Compacta in Verbindung. Proximal dieser Verbindung liegt er der tibialen Compacta sehr nahe an, ist nur 2 bis 3 Zehntelmillimeter von ihr entfernt, distal der Verbindung entfernt sich die Compacta von dem Knochenkern, der in gerader Längsrichtung des Knochens liegt, infolge der Zunahme des Breitendurchmessers des Knochens mehr und mehr, so daß am distalen Ende des Knochenkerns die Entfernung zwischen ihm und der Compacta, die hier nur noch die Dicke der dünnen Umhüllungsplatte des Köpfchens hat, $3 \mathrm{~mm}$ beträgt. Iri das sich ein wenig verschmälernde, leicht abgerundete proximale Ende des Knockenkerns treten nun, soweit auf dem Schnitt zu erkennen, fünf Balkenzüge vom proximalen Knochenende her ein und am distalen Ende des Knochenkerns vier Balkenzüge aus, um auf das distale Knochenende zuzugehen. Außer jenen fünf Balkenzügen treten an die fibulare Seite der proximalen Hälfte des Knochenkerns noch zwei weitere Balkenzïge von proximal her heran, so daß also an die in die proximale Spongiosa hineinragende proximale Hälfte des Knochenkerns sieben Balkenzüge herangehen. Diese sind in der dorsalen Hälfte (Fig. 1), besonders mit Lupe, deutlich zu erkennen. Interessant ist nun der große Unterschied in der Dicke der von proximal her an den Knochenkern heran- und der nach distal aus ihm heraustretenden Spongiosaziuge. Von proximal treten sehr zarte Bälkchen an den Kern heran, die distal austretenden Balkenzitge (sagittal stehende Platten) sind etwa vier- bis fünfmal dicker als jene ${ }^{1}$ ), ein Unterschied, der sich in ähnlicher Weise, wenn auch nicht überall so stark, immer zwischen proximaler and distaler Spongiosa findet. Der Knochenkern ist als eine Verstärkung der Verbindungszüge, als ein solides Schaltstück zwischen den Zügen der proximalen und der distalen Spongiosa an dieser Stelle aufufassen.

In diesem Präparat mit dem Knochenkern ist, soweit sich das an dem Horizontalschnitt ersehen läßt, die Markhöhle in der Tat allseitig von Spongiosa umgeben. Auf der fibularen Seite, dem Knochenkern gegenüber, ist. es ebenfalls interessant zu sehen, wie die zarte proximale Spongiosa unter Vermittelung eines dünnen Plättchens an einen derben Balken der distalen Spongiosa herangeht. Dieser derbe Balken reicht proximal bis zur Basis der Markhöhle. Wenn die beschriebene Struktur sich auch der Hauptsache nach in allen Metatarsalia I wiederfindet, so ist sie in Einzelheiten bei

1) In Fig. 1 erscheinen die ron proximal an den Knochenkern herantretenden Balkenziige breiter als sie in Wirklichkeit sind. 
den verschiedenen Individuen doch recht verschieden, wie dies bereits mehrfach hervorgehoben wurde. Namentlich variiert die Zahl der Lamellen, die auf den verschiedenen Seiten in der Umgebung der Markhöhle von der Compacta abblättern, und ihre Entfernung voneinander. Es ist durchaus nicht typisch, daß dorsal und plantar der Markhöhle die Zahl der Lamellen so gering ist, wie im Präparat der Fig. 14, and daß die die Markhöhle seitlich umschließenden Platten plantar fast bis zur Markhöhlenspitze an die Compacta heranreichen. Bei dem Präparat von einem alten Individuum (Fig. 17), dessen erweiterte Markhöhle bis in die proximale Knochenhälfte hineinreicht, dessen Compacta in der Mitte der Knochenlänge plantar nur 1/3 $\mathrm{mm}$ dick ist, blättert, bei einer Markhöhlenlänge von fast $2 \mathrm{~cm}$, plantar $7 \mathrm{~mm}$ distalwärts von der Markhöhlenbasis entfernt eine derbe Lamelle als Markhöhlenkapsel ab und weiter distal zwei weitere, zur letzteren parallel laufende derbe Lamellen, deren erste von der Markhöhlenkapsel ẗ̉ber $1 \mathrm{~mm}$, die zweite von der ersten nicht ganz so weit entfernt ist. In Fig. 17 ist dies namentlich in der tibialen Hälfte dentlich. Anderseits kann dorsal der Markhöhle eine Aufblätterung der Compacta erst nahe der Markhöhlenspitze stattfinden, wie im Präparat der Fig. 16. Hier wird, wie erwähnt, die Markhöhlenkapsel dorsalwärts von einer aus der proximalen Spongiosa herkommenden Lamelle gebildet. Die Compacta hat sich dorsal von proximal her nach der Basis der Markhöhle hin durch das Herantreten von Lamellen beständig verdickt unả bleibt im Verlaufe der Markhöhle bis an ihre Spitze heran, da wo sich die dorsale Knochenwand am Köpfchenansatz stark aufwärts (dorsalwärts) biegt, gleichmäßig stark, erst an letzterer Stelle strahlen starke Balken oder Lamellen in die Spongiosa des Köpfchens hinein.

Fibular und tibial der Markhöhle können nicht nur die Tubuli der der Markhöhlenkapsel zunächst gelegenen Tubulireihen sich distalwärts stark erweitern, konfluieren und größere Räume bilden, sondern auch die Tubuli der weiter peripher gelegenen Reihe, und die von letzteren gebildeten Räume weiter sein als die der Markhöhle benachbarten.

In sehr verschiedener Weise ist auch die Markhöhlenkapsel auf den verschiedenen Seiten durchbrochen. Die dorsale Markhöhlenwand kann von einer fast undurchbrochenen Platte gebildet, dagegen eine Seitenwand auch plantarwärts stark durchbrochen sein. Es ist für die Beschaffenheit der Markhöhlenkapsel ohne Einfluß, ob die proximale Spongiosa wohl erhaltene Tubuli hat, oder ob deren Wan- 
dung mehr oder minder stark durchbrochen ist und ein zartes Bälkchennetz an die Markhöhlenkapsel herangeht. Auch in letzterem Falle kann die Markhöhlenkapsel ebenso wie ihre Nachbarlamellen aus wohlerhaltenen derben Platten bestehen.

Nicht immer ist die proximale Markhöhlengrenze durch ein in der Frontalebene stehendes Bälkchengitterwerk so scharf ausgesprochen wie im Präparat der Fig. 14 und 15. Oft ist dieser »Markhöhlenboden" bis auf spärliche Reste an der Compacta resorbiert, in andern Fällen stehen die die Markhöhle proximal begrenzenden Balkenzüge sehr schrüg zur Frontalebene.

\section{Ergebnisse.}

1) Die Metatarsalia $V$ bis II einerseits und das Metatarsale I anderseits sind hinsichtlich ihrer Struktur roneinander zu trennen entsprechend ihrer voneinander wesentlich rerschiedenen Beanspruchung.

2) Entsprechend der nacheinander stattfindenden Beanspruchung: auf Druck und Zug der Metatarsalia $V$ bis II beim Anfsetzen der Fußsoble beim Gehen finden wir in diesen Metatarsalien Trajectoriensysteme, welche in der Längsrichtung des Knochens verlaufen und anf einem Sagittalschnitt am deutlichsten in die Erscheinung trete!. Bei Ansfiihrung dieses Sagittalschnitts müssen sich die Metatarsalien in der Stellung befinden, in welcher sie beim Aufsetzen der Fußsohle beim Gehen auf den Fußboden auftreffen (Supinationsstellung). Da das M. V bei diesem Aufsetzen der Fußsohle am stärksten und in der Weise beansprucht wird, dab der Knochen an beiden Enden auf den Fußboden aufgesetzt wird, so finden wir diese Trajectoriensysteme im M. V am stärksten ausgesprochen in Gestalt einer oft ausgezeichneten Biegüngskonstruktion. Im. M. IV bis M. II sind diese Trajectoriensysteme weniger ausgesprochen entsprechend ihrer nach dem tibialen Fußrande hin immer geringeren Beanspruchung in dem in Rede stehenden Sinne und besonders im proximalen Knochenende unvollkommen ausgeprägt, da dieses nicht wie beim M. $V$ auf den Boden aufgesetzt und in andrer Weise stärker beansprucht wird.

3) In der Struktur der proximalen Enden der Metatarsalia V bis II kommt die Druckübertragung von einem Basalteil zum andern in bestimmter Weise zum Ausdruck. Der Basalteil des M. $V$ wird beim Aufsetzen des Fußes beim Gehen und beim einbei- 
nigen Stehen in ähnlicher Weise beansprucht wie der Calcaneus beim Aufsetzen des Fußes und beim Stehen, und dementsprechénd finden wir in jenem eine Struktur ähnlich der im Calcaneus: ein von der Planta her kommendes, auf die Gelenkfläche mit dem M IV bzw. dem Talus zu verlaufendes und zu diesen Gelenkflächen rechtwinkelig stehendes Drucksystem, gekreuzt von einem vorwiegend in der Längsrichtung der Knochen verlaufenden Zugsystem, dessen Trajectorien zu denen des Drucksystems rechtwinkelig stehen. Innerhalb des Basalteils'der Metatarsalia IV bis II findet diese Druckuibertragung durch Platten statt, welche der Dorsalfläche des Basalteils annähernd parallel laufen, aber rechtwinkelig zu dẹn seitlichen Gelenkflächen stehen. Diese Platten finden sich nur im Bereich dieser Gelenkflüchen und ïberragen sie nach distal nicht.

4) Die Druckübertragung beim Stehen, also in Pronationsstellung der Metatarsalien, in der Richtnng vom Köpfehen zur tarsalen Gelenkfläche und umgekehrt, erfolgt bei den M. IV bis II durch im wesentlichen sagittal stehende Platten, welche sich im Köpfehen und im Basalteil finden und von den distalen und proximalen Enden der Compacta abblättern. Entsprechend der vorwiegenden Beanspruchung dieser Metatarsalien auf der tibialen Seite beim zweibeinigen Stehen blättern die Platten vorwiegend, manchmal ausschließlich von der tibialen Compacta ab. In der Struktur des M. V kommt eine derartige Druckübertragung beim Stehen infolge seiner der Hauptsache nach andersartigen Beanspruchung nach meinen Feststellungen nicht in irgend auffallender Weise zum Ausdruck. Allerdings finden sich auch beim M. V im Capitulum und im Basalteil Platten mit ähnlicher Richtung wie jene beim M. IV bis II. Die Platten im M. V stehen aber im Gegensatz zu letzteren in Supinationsstellung des M. V sagittal und dienen zur Verstärkung des Widerstandes beim Aufsetzen der Fußsolle auf den fibularen FuBrand beim Gehen.

5) Da wo im Basalteil der M. IV bis II die zu den seitlichen Gelenkflächen rechtwinkelig stehenden Platten mit den sagittalen Platten zusammentreffen, findet sich oft eine ausgesprochen tubulöse Struktur. Die Tubuli verlaufen in der Längstichtung der Knochen, reichen einerseits nach proximal bis zur tarsalen Gelenkfläche und setzen sich anderseits nach distal zwischen den sagittalen Platten in die proximalen Compactaenden hinein fort. Die Tubuli finden sich im dorsalen Abschnitt des Basalteils auch außerhalb des Bereichs der sagittalen Platten, namentlich dicht unterhalb der Dorsalfläche des Knochens, auch hier sich ans den proximalen Enden der Compacta 
ablösend und zur tarsalen Gelenkfläche ziehend, zu welcher sie rechtwinkelig stehen. Manchmal treten im Bereich der sagittalen Platten die Tubulireihen in den Vordergrund, während jene weniger dentlich sind, so besonders im M. IV. Auch diese Tubuli bilden ein wesentliches Element für die Druckübertragung in der Längsrichtung des Knochens and dienen vermutlich besonders der zweckmäßigen Druckverteilung von der Compacta her in proximaler Richtung beim Springen.

6) Für die besondere Beanspruchung des M. III beim Stehen sprechen schräge, sich kreuzende Züge im plantaren Abschnitt des Basalteils nahe dem Beginn der Markhöhle. Weniger ausgesprochen sind diese Zijge und finden sich nicht regelmäßig an gleicher Stelle im M. II. Im M. IV habe ich sie nicht gèfunden. Es darf hieraus gefolgert werden, daß beim gewöhnlichen zweibeinigen Stehen von den Metatarsalien vorwiegend das M. III, weniger das M. II beansprucht wird. Das M. IV wird wahrscheinlich nur beim Stehen auf den Zehen, nicht beim gewöhnlichen Stehen beansprncht.

7) Das Metatarsale I hat eine von den übrigen Metatarsalien erheblich abweichende Struktur, und diese ist wieder in der distalen Hälfte von der in der proximalen Hälfte völlig verschieden. In der distalen Schafthälfte lagern sich um eine von einer Kapsel umschlossene konische Markhöhle mit distaler Spitze nach dorsal und plantar, tibial und fibular eine mehr oder minder große, in der Regel nach den verschiedenen Richtungen hin verschieden große Zabl von Tubulireihen, deren Tubuli in der Knochenlängsrichtung verlaufen und sich von proximal nach distal, zum Teil beträehtlich, erweitern. Diese Tubulireihen werden voneinander getrennt durch Lamellen, welche zumeist von proximal nach distal aus der Compacta abblättern und nach distal leicht divergieren. Die fibularen und die central gelegenen tibialen Lamellen, einschließlich der fibularen und tibialen Wand der Markhöhle, verlaufen über die Markhöhlenspitze hinaus im Köpfchen bis zum distalen Knochenende, zum Teil unter mehrfacher Spaltung, als sagittal stehende Platten. Solche Platten finden sich nur etwa in den fibularen zwei Dritteln des Köpfchens. Vermittels dieser sagittal stehenden Platten wird bei der Abwicklung des Fußes beim Gehen der Druck im Köpfehen aufgenommen. Die von H. v. Meyer beschriebenen Krenzungen stark divergierender Züge sind für die Struktur des Capitulum m. I nicht charakteristisch und finden sich in der von ihm dargestellten Weise nicht. Die Kapsel 
der Markhöhle blättert in vielen Fällen, namentlich bei stark entwickelter Spongiosa (jüngeren Individuen), nicht von der Compacta ab, sondern steht mit ihrem proximalen Ende mit der Spongiosa der proximalen Schafthälfte in Verbindung, zum Teil geht eine Lamelle dieser Spongiosa unmittelbar in die Kapsel der Markböhle über. Eine derartige Verbindung kann auch zwischen der proximalen Spongiosa und den der Markhöhlenkapsel benachbarten Lamellen stattfinden, welche in diesem Falle nicht aus der Compacta abblättern. Bei spärlicher entwickelter Spongiosa, namentlich bei älteren Individuen, blättert die Markhöhlenkapsel in der Gegend der Mitte der Knochenlänge als Konturlamelle aus der Compacta ab. - Die proximale Schafthälfte ist bei reichlich entwickelter Spongiosa vollständig mit Spongiosa angefüllt, deren Züge fast in ganzer Länge der Schafthälfte der dorsalen und tibialen Wand annähernd parallel laufen und an den dorsalen Abschnitt der fibularen Wand herangehen. Auch die Spongiosa der proximalen Schafthälfte zeigt im allgemeinen einen ausgesprochen tubulösen Bau, die Tubuli gleichfalls der Längsrichtung des Knochens gleich gerichtet, nur ist diese Spongiosa viel zarter als die in der distalen Schafthälfte, die Wandungen der Tubuli sind häufig stark durchbrochen, während die Lamellen und Platten in der distalen Schafthälfte auffallend dicker und seltener durchbrochen sind. Diese dicken distalen und dünnen proximalen statischen Elementarteile grenzen sich scharf gegeneinander ab in der Gegend des proximalen Endes der Markhöhle. Diese tubulöse und lamellöse Struktur des Metatarsale I, äe zum Teil unmittelbare Verbindung der Elemente der Spongiosa der distalen und proximalen Schafthälfte, die sehr reichliche Spongiosa, die die proximale Knochenhälfte in der Regel ganz ausfuillt und in der distalen oft nur für eine sehr kleine Markhöhle Raum läßt, machen das M. I besonders geeignet, dem durch Vermittlung der sagittalen Platten im Köpfchen bei der Abwicklung des Fußes aufgenommenen sehr starken Druck standzuhalten. Durch diese Struktur steht das M. I einem kurzen Knochen nahe, zumal seine Compacta in der Regel im Vergleich zur Compacta der übrigen Metatarsalien dünn ist. Das Metatarsale I fügt sich gewissermaßen den Tarsalien am tibialen Fußrande als weiterer kurzer Knochen an, um in Verbindung mit ihnen bei der Abwicklung des Fußes die Last des Körpers zu tragen.

8) Die vorwiegende Beanspruchung des Metatarsale I in seinem fibularen Abschnitt, welche aus der Struktur des M. I hervorgeht, läßt erwarten, daß das Metatarsale II bei der Abwicklung des 
FuBes beim Gehen mitbeansprucht wird. Eine derartige Beanspruchung kommt in der Tat in der Architektur des M. II zum Ausdruck, namentlich in der auffallend starken Entwicklung der Compacta auf der tibialen Seite des M. II, der Form seines Querschnitts, welche, in der proximalen Hälfte rechtwinkelig dreieckig mit von proximal nach distal zunehmend spitzer werdenden tibialem Winkel, in der distalen Hälfte dem Querschnitt des M. I ähnelt, und dem Vorhandensein einer oder mehrerer die Markhöhle umgebenden Konturlamellen auch bei dem M. Ir. Dies spricht dafür, daß das M. II regelmäßig, mehr oder minder stark, als Hilfsstütze bei der Abwicklung des Fußes beim Gehen gebrancht wird.

9) Im Gegensatz zum Metatarsale I liegt in den Metatarsalia $\mathrm{V}-\mathrm{II}$ bei reichlicher Spongiosa die Markhöhle in der proximalen Schafthälfte und ist, namentlich im M. V und M. IV, durch die sie nächst begrenzenden Balkenzüge scharf abgegrenzt, von annähernd kegelförmiger Gestalt, mit proximaler Basis. Im M. V kann die Markhöhle ring's von Spongiosa umgeben sein. Ist die Spongiosa stärker resorbiert, also namentlich bei alten Individuen, so reicht bei den M. V-II, namentlich bei den M. III und M. II, die Markhöhle in die distale Schafthälfte hinein, manchmal sogar bis nahe an das Capitulum heran. Bei dem M. I kann bei stärkerer Resorption der Spongiosa die Markhöhle bis in die proximale Schafthälfte himeinreichen.

10) In der distalen Schafthälfte nimmt die Spongiosa in den Metatarsalia V--II rom M. V nach dem M. II hin in der Regel an Menge $a b$, entsprechend der rom M. V nach dem M. II hin immer geringeren Beanspruchung auf Biegung beim Aufsetzen der Fußsohle beim Gehen. Manchmal findet man indes im M. II, vermutlich infolge seiner besonders starken Beanspruchung als Hilfsstiitze beim Gehen, die sich durch auffallend starke tibiale Compacta und besonders starke sagittale Platten im Köpfehen dokumentiert, besonders reichliche Spongiosa in der distalen Schafthälfte, wesentlich reichlicher als bei dem M. III und M. IV.

11) Von den Metatarsalien besitzt die stärkste Compacta bei gut gewölbten Füßen nach meinen Feststellungen stets das M. V, und zwar plantarwärts (in Supinationsstellung) in der Markhöhlengegend. Etwas dünner, aber immerhin noch . sehr kräftig, ist die Compacta beim M. V dorsal in der Markhöhlengegend, auf den andern Knochenseiten ist sie wesentlich dünner. Dies Verhalten der Compacta des M. V entspricht der regelmäßigen Beanspruchung des M. V 
auf Biegung in der Sagittalebene beim Aufsetzen des Fußes beim Gehen. Bei den Metatarsalia IV-II ist die Compacta am proximalen Schaftende plantar-fibular und dorsal-tibial am dicksten, aber dorsal-tibial, sowie auch weiter distal auf der tibialen Seite, in der Regel dicker als plantar-fibular infolge der starken Beanspruchung. dieser Metatarsalien beim Stehen. Am stärksten ist von den Metatarsalia IV-II die Compacta in der Regel bei dem M. II infolge seiner Beanspruchung als Hilfsstitze bei der Abwicklnng, doch kommen hierron, je nach der verschieden starken Beanspruchung der einzelnen Metatarsalien bei den verschiedenen Beanspruchungsgelegenheiten, Ausnahmen vor. Die Compacta des M. I ist auf den verschiedenen Seiten in der Regel ziemlich gleich dick, fibularwärts überwiegt ihre Dicke die der andern Seiten meist etwas. Die Dicke der Compacta des M. I ist aber meist geringer als die Dicke der Compacta der M. IV-II anf den Seiten, auf welchen sie bei diesen Metatarsalien am stärksten entwickelt ist.

12) Die Angaben Pfitzaners 1) ïber das gegenseitige Stärkeverhältnis der Metatarsalien können im allgemeinen als zutreffend angesehen werden. Ob das $M . V$ bei normal gebautem $F u ß$ jemals schwächer ist als das M. IV, wie dies Pfrrznen ${ }^{1}$ ) in zwölf Fällen gefunden hat, erscheint mir zweifelhaft. Es darf diesbeziiglich nicht nach dem äußeren Umfange, sondern nur nach der inneren Struktur, der Dicke der Compacta und der Entwicklung der Spongiosa geurteilt werden. Die Stärke des M. IV, M. III und M. II variiert je nach dem Grade der Beanspruchung dieser Metatarsalien bei den verschiedenen Arten der Beanspruchung, und gewiß auch je nach dem Bau des Fußes, seiner stärkeren oder schwächeren Wölbung, die an und für sich eine verschieden starke Beanspruchung jener Metatarsalien bedingt. Als nicht zutreffend muß ich die Änßerung Pfirzners bezeichnen, daß der derzeitige Entwicklungsgang auf eine bestimmte Reihenfolge: I, V, IV, II, III hinzuarbeiten scheint, und daß, nachdem zuerst die tibialen Randstrahlen einen weiteren Ausbau erfahren

1) a. a. 0. (s. Eingang der Arbeit) S. 302, 303, 304.

2) Bei Plattfuß, auch nnansgebildetem, ist eine s Schwäche* des M. V gegeniiber dem M. IV verständlich, da hier, infolge des andersartigen Aufsetzens der Fußsohle beim Gehen, das M. V sehr viel weniger und andersartig belastet wird als bei dem normalen Fuß. Nach meinen Untersuchungen ist die Compacta des M. $V$ beim Plattfuß viel dünner als beim normalen Fuß und dinner als die Compacta des M. I des Plattfußes, auch ist der Schaft des M. V des Plattfußes in der Regel frei von Spongiosa. 
baben, nunmehr auch eine Verstärkung der fibularen Randstrahlen eingeleitet und im Werke sei, daß der fünfte Strabl in progressiver Entwicklung begriffen sei. Die Verstärkung des M. V ist die naturnotwendige Folge des aufrechten Ganges des Menschen, welcher beim Aufsetzen der Fußsohle beim Gehen eine verbältnismäßig starke Belastung des zuerst auf den Boden auftreffenden M. V. bedingt, auf dessen beiden auf den Boden aufgesetzten Enden eine ausgiebige Pronationsdrehung des Fußes stattfindet, während deren Umfang nach dem M. II hin immer geringer wird. Für ein derartiges Aufsetzen der Fußsohle beim Gehen und die sichere Pronationsdrehung des Fußes war auch die Ausbildung der Tuberositas m. V1) erforderlich. Diese durch den aufrechten Gang bedingte Verstärkung ${ }^{2}$ ) des M. V und des ihm benachbarten M. IV ist ohne Zweifel als abgeschlossen anzusehen, sie entspricht der beim Menschen gegebenen funktionellen Beanspruchung. Daß der Entwicklungsgang darauf hinarbeite, daß das M. IV schließlich stets stärker sei als II und III, halte ich für unwahrscheinlich, da das M. II stets als Hilfsstuitze des M. I bei der Abwicklung des Fußes verhältnismäßig stark beansprucht werden muß und je nach der Stärke dieser Inanspruchnahme M. IV an Stärke iibertreffen, ihm gleich oder auch von geringerer Stärke sein kann. Daß das M. III in der Regel das schwächste Metatarsale ist, folgt daraus, daß es beim Aufsetzen der Fußsohle schwächer als IV und bei der Abwicklung des Fußes gar nicht beansprucht wird. Unrichtig ist jedenfalls die Angabe Pfitzners, daß die »Verstärkung der Randstrahlen « weniger in einem Kräftigerwerden als in einem Voluminöserwerden zu bestehen scheine ${ }^{3}$ ). Dem widerspricht für das M. $V$ der Befund auf dem Sagittalsehnitt mit seiner auffallend starken

1) Pritziner, a. a. 0. S. 302.

2) Auch hinsichtlich der Stärke und der Form der Grundphalanx der fünften Zehe: in der größeren Hälfte der Fälle stärker als Grundphalanx IV, stärkere Entwicklung der fibularen Seite der Basis, schrägovaler Querschnitt des Mittelschaftes, Abschrägung der distalen Gelenkflüehe (PFITzNen, a. a. 0. S. 285 a. 304) ist anzunehmen, daß diese Stärke und Form die Folge der besonderen Beanspruchung beim Aufsetzen der Fußsohle beim Gehen ist. Auch die Verschmelzungstendenz der Mittel- und Endphalanx bei der fünften Zehe dürfte die Folge dieser Beanspruchung sein. Für die fünfte Zehe ist beim Aufsetzen der Fußsohle beim Gehen eine getrennte Mittel- und Endphalanx nicht erforderlich, und beim Stehen wird die fünfte Zehe sehr wenig beansprucht. Für die vierte bis zweite Zehe, namentlich für die dritte und zweite, ist im Gegenteil eine dreigliederige Zehe von Vorteil, indem sie beim Stehen ein feineres Lagegefühl vermittelt.

3) Pfimzner, a. a. 0. S. 305. 
Compacta, aber auch für das M. I die sehr reichliche und in der distalen Hälfte sehr kräftige Spongiosa, die hier besonders dicke statische Elementarteile aufweist ${ }^{1}$ ).

13) Der Querschnitt des Schaftes zeigt bei den einzelnen Metatarsalien je nach der verschiedenen Art ihrer Beanspruchung wesentliche Unterschiede. Bei dem M. IV und dem M. III kommt er einer Ellipse nahe, deren langer Durchmesser - in Pronationsstellung des Fußes - bei dem M. III ron der Vertikalen nur wenig, bei dem M. IV stärker abweicht, deren kurzer Durchmesser nach dem Köpfchen hin, im Verhältnis zum langen Durchmesser, sich beträchtlich verkleinert. In der distalen Schafthälfte ist die Ellipse fibularwärts abgeplattet, bei dem M. III stärker als bei dem M. IV, so daß sich bei dem M. III der Querschnitt hier stellenweise einem Halbkreise nähert. Bei dem M. V kommt der Schaftquerschnitt nach dem proximalen Ende hin einem Dreieck mit plantarwärts ausgezogener Spitze nahe, in der Mitte ist er rundlich, nach dem Capitulum wird er mehr viereckiv. Bei dem M. II ist der Schaftquersehnitt, wie schon erwähnt, in der proximalen Hälfte ausgesprochen rechtwinkelig dreieckig, rechter Winkel fibularwärts, lange Katbete zuerst fibular-, dann dorsalwärts; in der distalen Schafthälfte geht der Querschnitt in einen mehr gleichschenkelig dreieckigen und unter zunehmender Vorwölbung der dorsalen Fläche allmählich in deu viereckigen über, der nahe dem Köpfchen ausgesprochen ist. Am distalen Schaftende ist der Querschnitt bei dem M. II in der Regel wesentlich breiter als bei dem M. III und M. IV. Das M. I hat in der proximalen Hälfte seines kurzen Schaftes einen ausgesprochen dreieckigen Querschnitt, der nach dem Köpfchen hin allmählich in einen mehr viereckigen übergeht.

14) Die Struktur der einzelnen Metatarsalien kann bei verschiedenen Individuen sehr verschieden sein, wie dies auch für andre Knochen himreichend bekannt ist. Wir finden bald mehr solide, bald mehr durchlöcherte Platten, bald statt der Platten Gitter; bald Röhrchen mit sehr vollständigen, bald mit stark durchbrochenen Wandungen, bald dickere, weiter voneinander entfernte, bald sehr zarte, dïnne, dicht stehende statische Elementarteile. Infolge stärkerer oder schwächerer Resorption kann die Menge der Spongiosa ver-

1) Pritzanes ist leider nicht zum richtigen Verständnis der Architektur der Fnßknochen gelangt, er behauptet sogar die außerordentliche Minderwertigkeit des Knochenbanes beim menschlichen Fußskelet (a. a. 0. S. 300). 
schieden groß sein. Außerdem kanu je nach Art und Stärke der Beanspruchung der einzelnen Metatarsalien bei den verschiedenen Individuen ihre Struktur verschieden sein. Infolge dieser Umstände haben gleichartige Schnitte gleichnamiger Metatarsalien bei verschiedenen Individuen oft ein recht verschiedenes Ausselion.

Dem Direktor des anatomischen Instituts, Herrn Geheimrat Professor Dr. MERKel, sage ich besten Dank für die Überlassung des erforderlichen Materials, Herrn Privatdozent Dr. Heidericu fuir die freundliche Ausfüihrung der Röntgenaufnahmen. 